\title{
Schwann cell differentiation in \\ Charcot-Marie-Tooth disease 1 A (CMT1A)
}

\author{
Dissertation \\ for the award of the degree \\ "Doctor of Philosophy (PhD)/Dr. rer. nat." \\ Faculty of Biology \\ of the Georg-August-Universität Göttingen
}

within the doctoral program Neurosciences (Msc/PhD)

at the Göttingen Graduate School for Neurosciences, Biophysics, and

Molecular Biosciences (GGNB)

submitted by

Tamer Abdelaal

from Dakahliya (Egypt)

Göttingen 2018 


\section{Thesis Committee}

Prof. Dr. Michael Sereda.

Molecular and Translational Neurology group, Neurogenetics Department, Max Planck Institute for Experimental Medicine, Göttingen

Prof. Dr. Wolfgang Brück

Institute of Neuropathology, University Medical Center Göttingen

Prof. Dr. Alexander Flügel

Institute of Neuroimmunology, UMG Institute for Multiple Sclerosis Research (IMSF)

Members of the Examination Board

$1^{\text {st }}$ Referee: Prof. Dr. Ralf Heinrich

Dept. Cellular Neurobiology, Schwann-Schleiden Research Centre

$2^{\text {nd }}$ Referee: Prof. Dr. Tiago Fleming Outeiro

Dept. of Neurodegeneration, University Medical Center Göttingen,

$3^{\text {rd }}$ referee: Prof. Dr. Walter Paulus

Dept. of Clinical Neurophysiology, University Medical Center Göttingen

\section{Further members of the Examination Board}

\section{Prof. Dr. Klaus-Armin Nave}

Dept. of Neurogenetics, Max Planck Institute for Experimental Medicine

Prof. Dr. Nils Brose

Dept. of Molecular Neurobiology, Max Planck Institute for Experimental Medicine Dr. Manuela Schmidt

Somatosensory Signaling Group, Max Planck Institute for Experimental Medicine

Date of oral examination: 


\section{Declaration}

I hereby declare that I prepared the Ph.D. thesis "Schwann cell differentiation in CharcotMarie-Tooth disease 1 A (CMT1A)" on my own and with no other sources and aids than quoted. I would like to gratefully acknowledge collaborations with Prof. Stefan Bonn (DZNE, Göttingen) for RNA-seq analysis and Prof. Britta Brügger for mass spectrometric analysis of myelin lipids as also indicated in the text.

Tamer Abdelaal

Göttingen, 31. March 2018 


\section{DEDICATED}

TO

\section{MY PARENTS, MY WIFE, MY SON and HUMANITY}




\section{Acknowledgements}

I wish to express deep sense of gratitude to my project supervisors Prof. Michael Sereda, Dr.

Ruth Stassart and Dr. Robert Fledrich for giving me an opportunity to work on such an interesting and challenging project. I'm greatly indebted to them for introducing me to the whole new world of molecular and translational neurosciences, providing me with great support. It was a nice experience to work with them and to learn both scientific and non-scientific skills needed to survive in science. I'm grateful to Prof. Klaus Armin Nave for giving me the chance to join the Neurogenetics department and enjoy the amazing research environment and facilities. I would like also to thank all the members of Remyelination and Nerve remyelination and Translational and Molecular Neurology groups for the continuous support and help throughout my PhD time. I would like to thank all the lab members for their help and support during my PhD time. Many thanks are due to our collaborators Prof. Stefan Bonn and Prof. Britta Brügger for their help with the RNAseq and lipidomics analysis. I also would like to thank my thesis committee members Prof Wolfgang Brück and Prof. Alexander Flügel for their support and helpful advices during my PhD time. I would like to give special thanks to Michaela for making my life easier by taking care of any bureaucratic hurdles. It was great to have an excellent team of Neuroscience graduate program coordinators, Prof. Michael Hörner, Sandra Drube for their administrative support and making this program a great success. Finally, I would like to thank my family, parents, brothers and my wife for the continuous help and support which without it I wouldn't have reached that step. 


\section{Table of Content:}

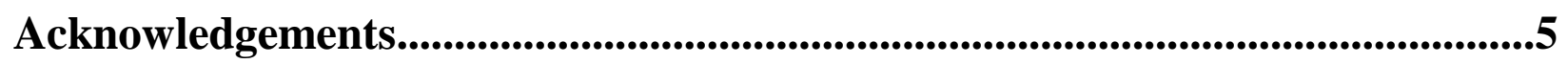

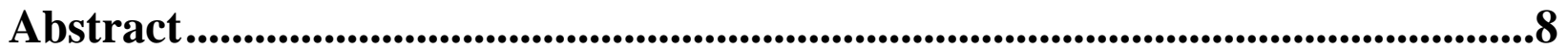

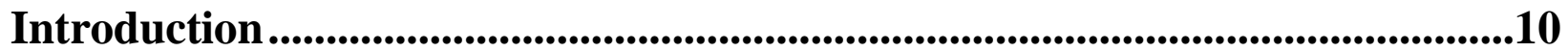

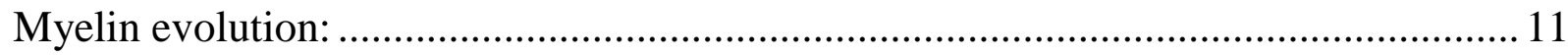

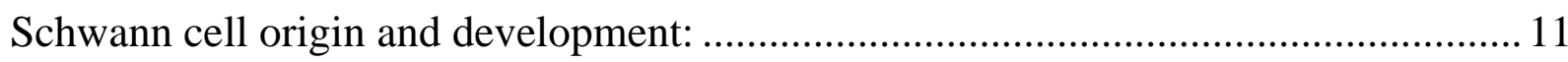

Regulation of Schwann cell differentiation and myelination by axonal NRG1: ........... 13

The role of axonal Neuregulin-1in Schwann cell development: ................................... 14

Schwann cell positive transcriptional regulation: ........................................................ 15

Schwann cell negative transcriptional regulation: ....................................................... 16

Post-transcriptional regulation of peripheral nervous system myelination process: ..... 17

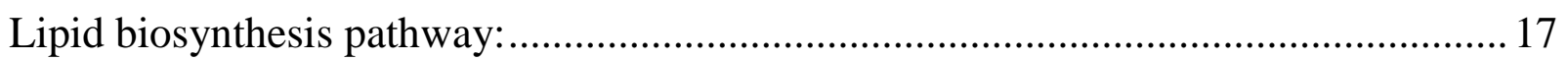

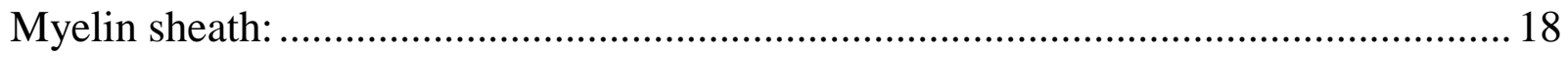

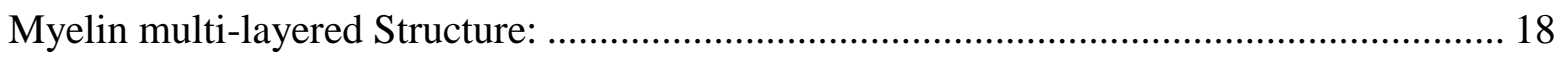

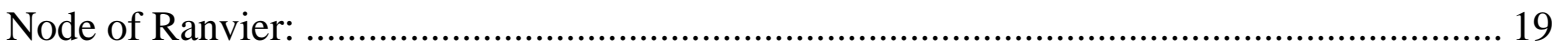

Paranodal regions and Schmidt- Lantermann clefts: …………………………………....... 20

The characteristic composition of myelin sheath:........................................................... 21

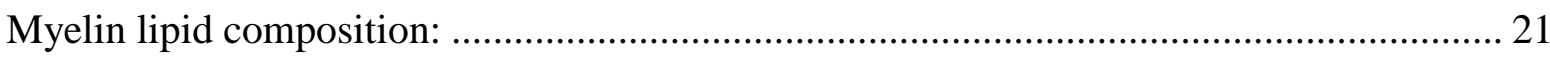

Effect of Lipids biochemical properties on myelin membrane function: ............................. 21

Lipids are essential for myelin assembly, proper backing and insulation: ............................. 22

Myelin lipids role in myelin proteins sorting and localization:........................................... 22

Myelin lipids regulate myelinating glial cell differentiation: .............................................. 22

Myelin specific proteins: ............................................................................................. 23

Protein Zero (P0)/ Myelin Protein Zero (MPZ): ......................................................................2

Myelin Basic Protein (MBP): ............................................................................................. 24

Peripheral myelin protein-22 (PMP22):…………………………………………………...2

Charcot-Marie-Tooth (CMT) disease ......................................................................... 27

Materials and Methods ..................................................................................................................29

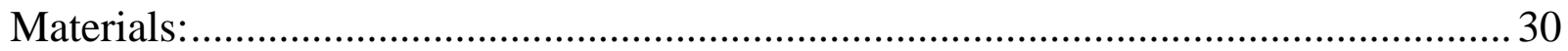




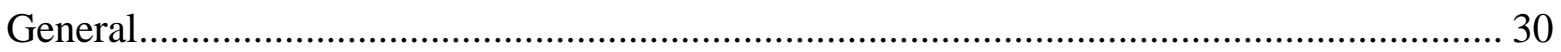

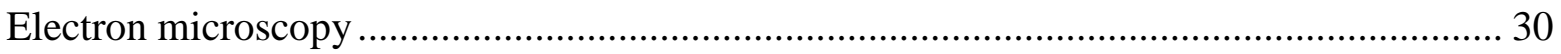

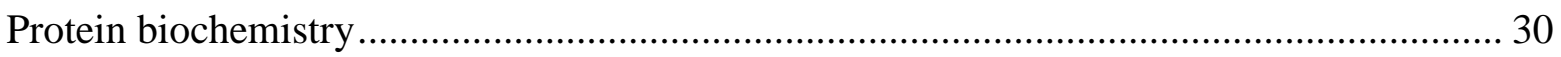

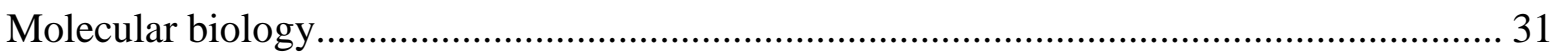

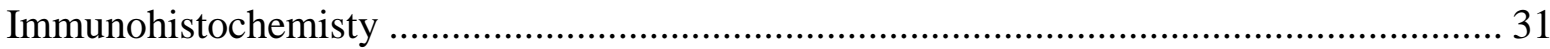

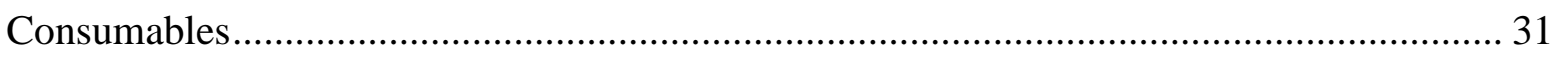

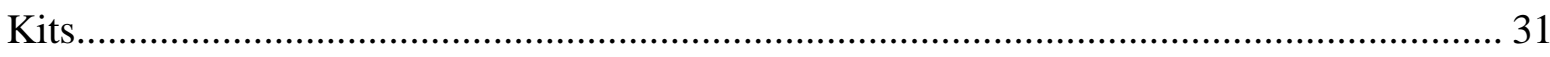

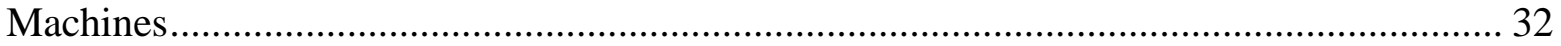

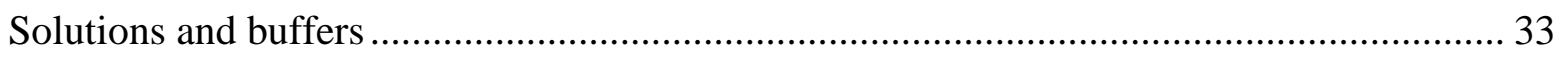

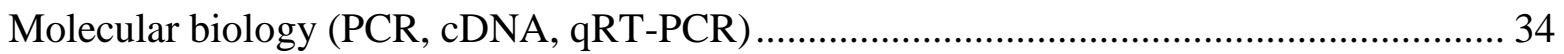

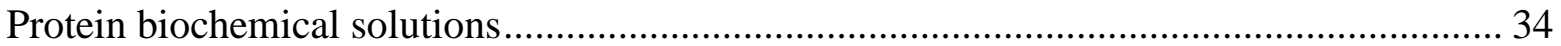

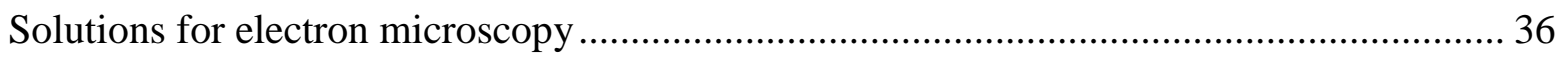

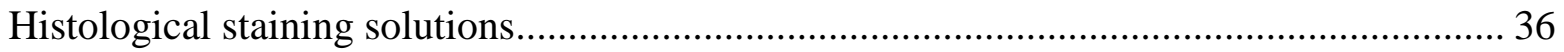

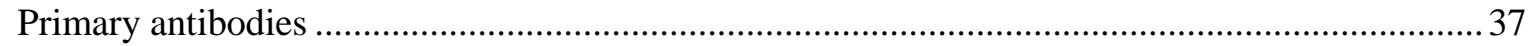

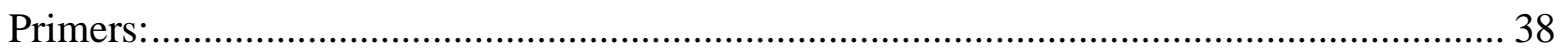

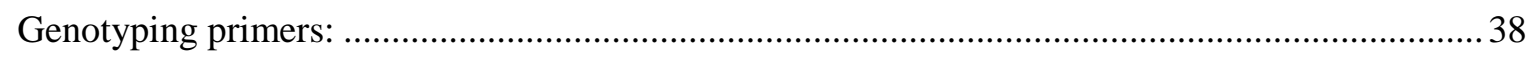

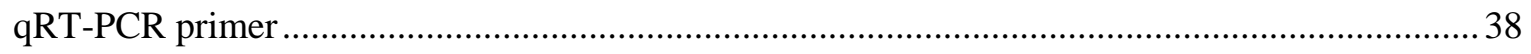

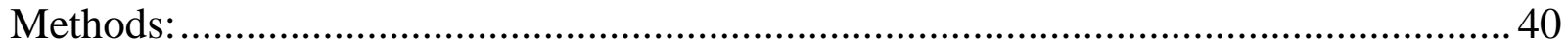

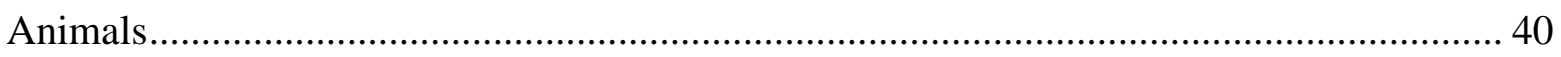

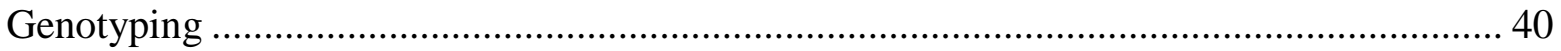

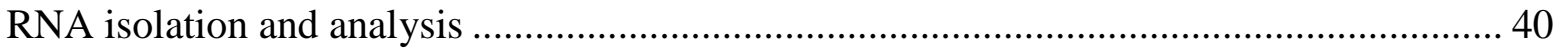

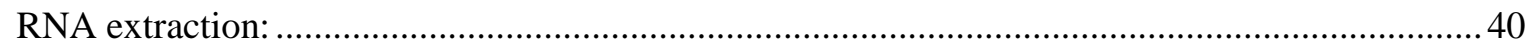

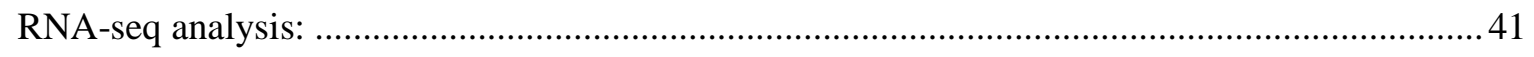

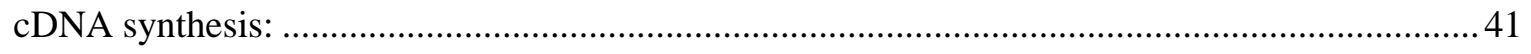

Quantitative real time polymerase chain reaction (qRT-PCR): ..................................................42

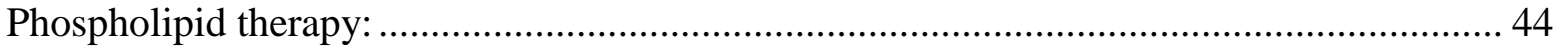

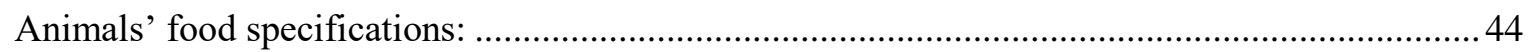

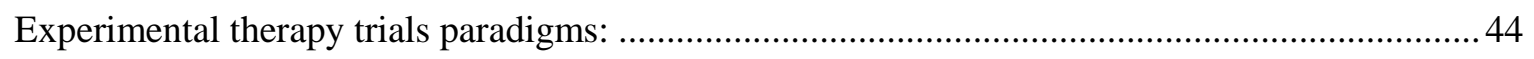

Exogenous PC incorporation into myelin sheath: .............................................................. 44

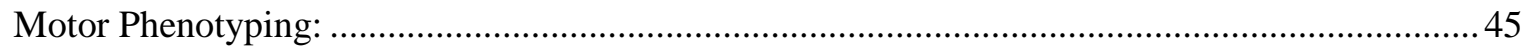

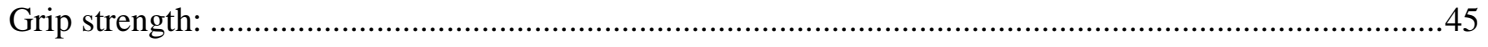

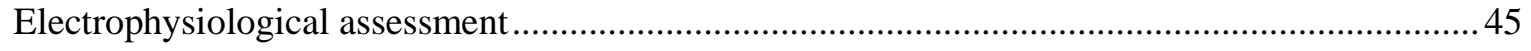




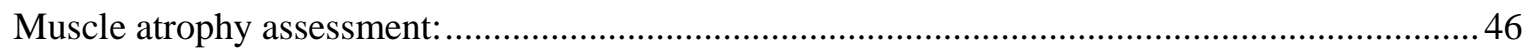

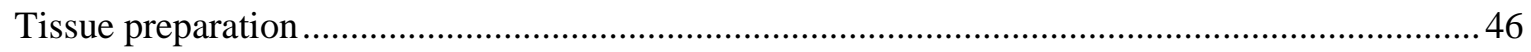

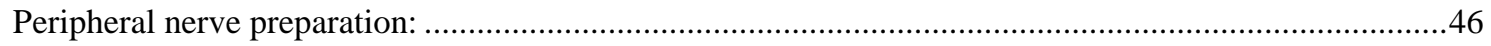

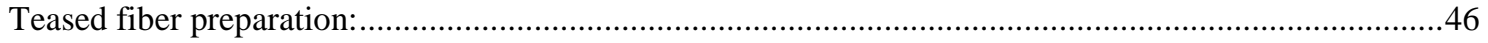

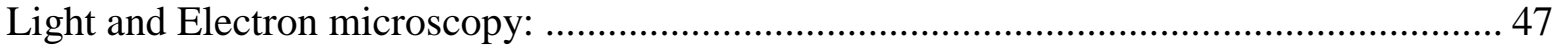

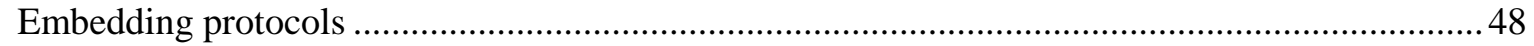

Table 4: Conventional embedding of tissue in Epoxy resin protocol: ........................................ 48

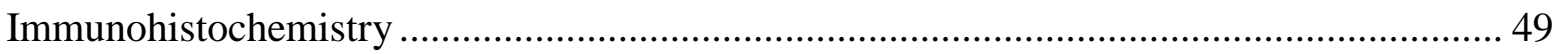

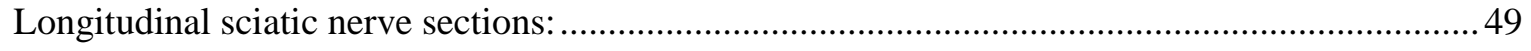

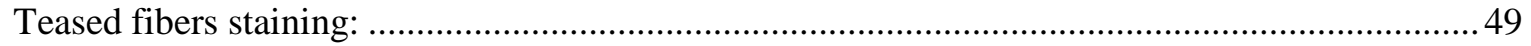

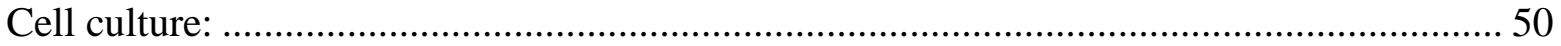

Impact of Pmp22 overexpression on PNS myelination: ..........................................................50

Impact of exogenously supplied phosphatidylcholine (PC) on myelination in vitro:.....................50

Checking PC incorporated into the myelin sheath in vitro: .....................................................50

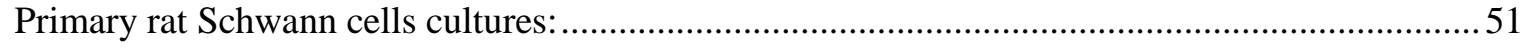

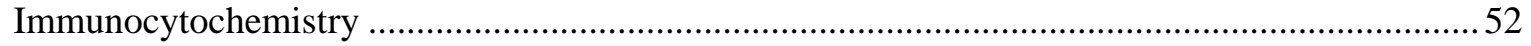

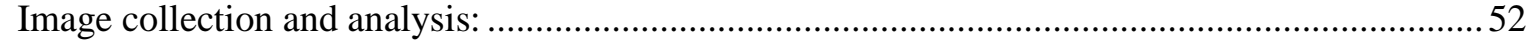

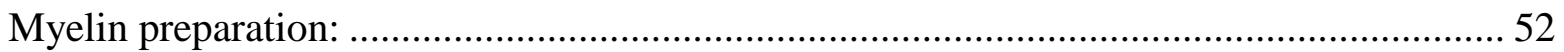

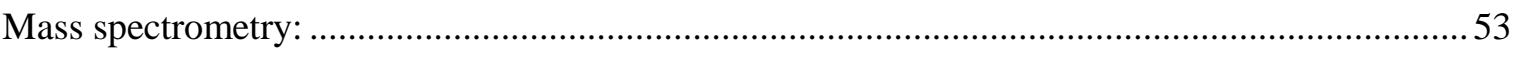

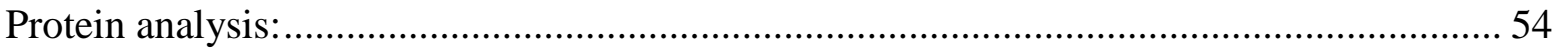

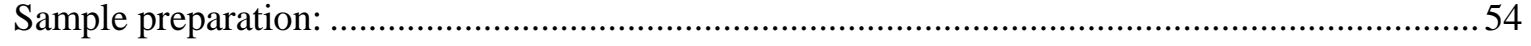

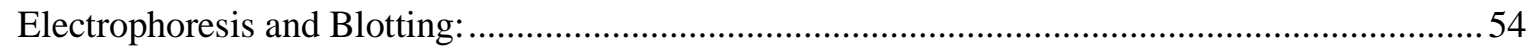

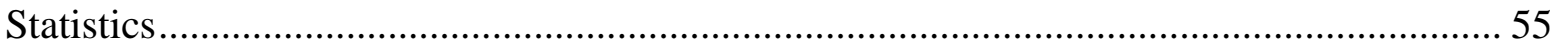

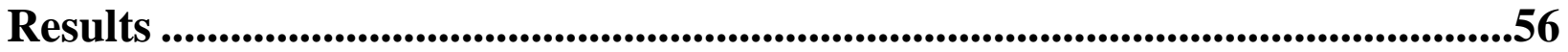

Impact of Pmp22 overexpression on CMT1A Schwann cell developmental

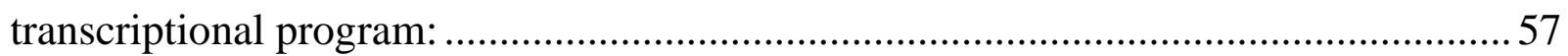

Pmp22 -overexpression leads to remarkable transcriptional dysregulation in CMT Schwann

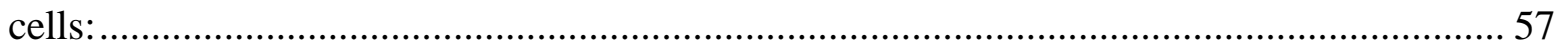

Endogenous Schwann cell-NRG1 is continuously upregulated in Pmp22 tg Schwann cells:

Sc-Nrg1_I ablation in CMT1A mice could reduce hypermyelination of small to mid caliber axons in peripheral nerves: 
Sc-Nrg1_I ablation in CMT1A mice didn't rescue the reduced number of myelinated axons per peripheral nerve:

Impact of Pmp22 overexpression on lipid biosynthesis in CMT1A Schwann cell: ...... 62

Significant reduction of major lipid classes in CMT1A peripheral nerves' myelin: 62

In depth analysis of omics data revealed that phospholipids could be the most suitable lipid class for supplementation: 64

Improvement of myelination through exogenous lipid supplementation: ..................66

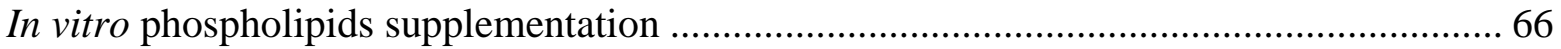

Phospholipid supplementation could significantly improve myelination efficiency in in vitro: ....66

Exogenous phospholipids are incorporated into myelin membrane directly in vitro and in vivo:..67

In vivo phospholipids supplementation 70

Early short term (P2-P21) lecithin therapy treatment could improve myelination in CMT1A rat models' peripheral nerves: .70

Cessation of the lecithin treatment leads to lose of the beneficial effect: . .71

Long term (P2-P112) lecithin therapy treatment could remarkably rescue some of disease histological features in CMT1A rat models:

Lecithin long term supplementation rescues the number of myelinated axons in peripheral nerves of CMT1A rodents:

Lecithin long term supplementation rescue the mild widening of myelin sheath lamellae in peripheral nerves of CMT1A rodents:

Lecithin treatment couldn't rescue the disturbed myelin morphology in CMT1A rat model: . .75

Impact of dietary phospholipids supplementation on myelin lipid as well as protein composition: 78

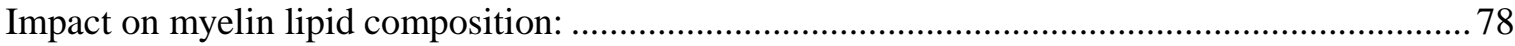

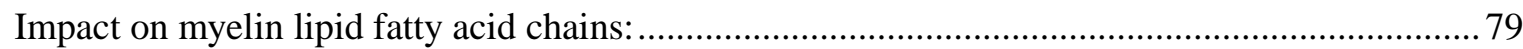

Impact on myelin lipid biosynthesis genes transcription: ......................................... 79

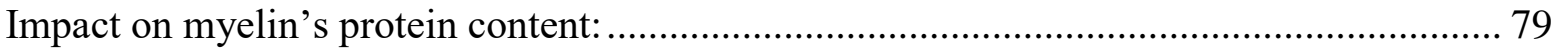

Impact of dietary long term phospholipids supplementation on Schwann cell differentiation:

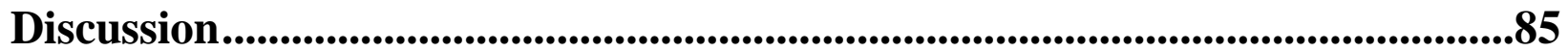

Bibliography ......................................................................................................................................91

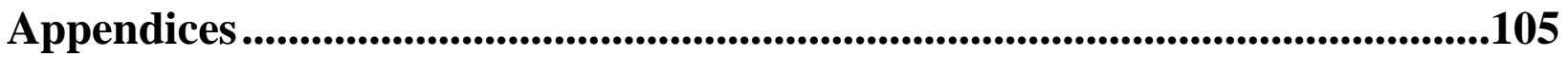




\section{List of Figures:}

Figure 1:The Schwann cell developmental lineage and repair response................................. 12

Figure 2:Schematic structures of major NRG1 isoforms in the nervous system................... 14

Figure 3:Axonal NRG1 controls various aspects of Schwann cell differentiation and myelin sheath thickness.. 15

Figure 4: A diagram depicting some of the ultrastructural features of CNS myelin. ........... 19

Figure 5: Various growth and Schwann cell process are disturbed in CMT Schwann cells especially lipid metabolism related processes: 59

Figure 6:Nrg1-I transcription is induced in sciatic nerves of CMT1A rodent models......... 60

Figure 7: Glial Nrg1-I induces hypermyelination of small to mid-caliber axons and its

deletion ameliorates the pathological hypermyelination in PMP22 tg mice: 61

Figure 8:Glial Nrg1-I knockout doesn't improve the number of myelinated axons in PMP22 tg mice: (A). 62

Figure 9: Disturbed lipid biosynthesis is leading to disturbed myelin lipids stoichiometry as well as lipid to protein ratio: 63

Figure 10:Gene Ontology (GO) gene sets for the major myelin lipid classes......................... 65

Figure 11: Choline pathway is downregulated in CMT1A Schwann cell: 66

Figure 12:Pmp22-tg (CMT1A) Schwann cell Phosphatidylcholine supplementation improves myelination in vitro:

Figure 13:Phosphatidylcholine (PC) is incorporated in the myelin internodes in vitro and in vivo: 69

Figure 14:Early short term phospholipid therapy ameliorates CMT neuropathy symptoms:

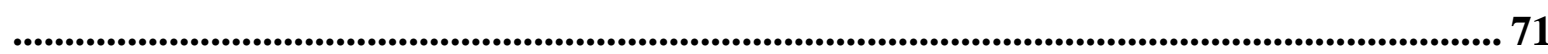

Figure 15: Late effect of early short term lecithin treatment: .................................................... 72

Figure 16:Improved motor phenotype and electrophysiological aspects due to long term phospholipid therapy are coinciding with improved number of myelinated axons per

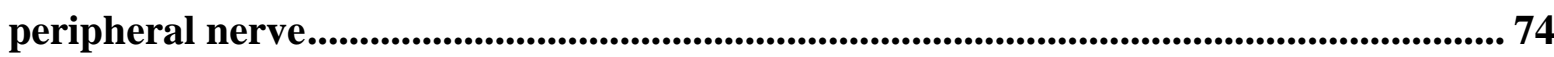

Figure 17:Long term phospholipid therapy improves myelin lamellae periodicity in CMT1A rats: 
Figure 18:long term phospholipid therapy had no impact on myelin morphology:

Figure 19:Dietary phospholipid improved myelin's lipid/protein ratio in CMT1A rat model:

Figure 20:Dietary phospholipids treatments couldn't induce lipid biosynthesis genes transcription:

Figure 21:Dietary phospholipid couldn't rescue myelin's protein content in CMT1A rat model:

Figure 22:Dietary phospholipids supplementation couldn't rescue the perturbed CMT1A Schwann cell differentiation: 


\section{List of Tables:}

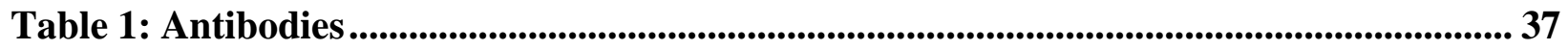

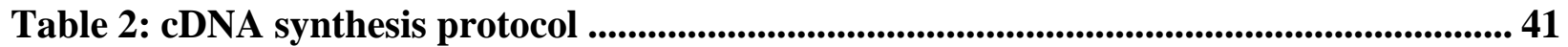

Table 3: Pipetting scheme and program for qRT-PCR (per reaction):................................ 43

Table 4: Conventional embedding of tissue in epoxy resin protocol: .................................... 48 
Abstract

Abstract 


\begin{abstract}
Charcot-Marie-Tooth disease is the most common inherited neuropathy and a duplication of the peripheral myelin protein 22 gene (PMP22) causes the most frequent sub-form Charcot-MarieTooth 1A (CMT1A). In contrary to the notion that CMT1A manifests in the second decade of life, moderate walking disability and electrophysiological abnormalities are usually already present during childhood. The early onset and developmental nature of the disease is also supported by findings derived from a Pmp22 transgenic rat model for CMT1A (CMT rat), which displays a reduced number of myelinated fibers per peripheral nerve already early postnatally and never reaches a wildtype level throughout development. RNA transcription analysis has revealed that there is a striking continuous upregulation of Schwan cell neuregulin 1 type I (NRG1_I) which we could show that it is contributing to the reported hypermyelination of small caliber axons in CMT1A rodent models. On the other hand, CMT rat Schwann cells show a strongly impaired lipid biogenesis required for myelination as assessed by RNA expression and lipid profiling of peripheral nerve transcriptomes and myelin composition, respectively. Importantly, Pmp22 overexpressing Schwann cell also reflects an impaired myelination competence in vitro, when co-cultured with dorsal root ganglia neurons. A remarkable improvement of Schwann cell myelination upon supplementation with phosphatidylcholine in vitro has led to the hypothesis that exogenous supplementation with lipids in vivo may improve disease progression. Indeed, we observed improved disease progression on the histological, electrophysiological and behavioral levels in CMT rats which were fed with a chow enriched in lecithin from P2 to adulthood. Moreover, disease amelioration is also visible after late long term (P21-P112) and early short term treatment (P2 to P21), but the effect is fading after treatment cessation. Therefore, continuously supplying patients with exogenous lipids may be considered as a promising therapeutic approach for CMT1A disease.
\end{abstract}


Introduction

\section{Introduction}




\section{Myelin evolution:}

A big step in evolution is the nervous system development with its subdivion into two major divisions; central (CNS) and peripheral nervous system (PNS). While CNS is the higher control center, PNS is connecting CNS to peripheral organs ${ }^{1,2}$. The rapid transmission of electrically encoded information is an indispensable requirement for nervous system functioning. Such critical function is carried out through highly specialized cells called neurons. In CNS and PNS, neurons commonly are extending over long distances enabling signal transmission between distant central areas and its peripheral effectors. Therefore, the more big and complex an organism is, the more rapid transmission of neural signals becomes necessary as it facilitates coordination and processing of complex neuraly encoded information ${ }^{3}$. Fast conduction of neural signals was achieved evolutionally by two approaches: 1) increasing axonal diameter as in the case of Squad axons, 2) axonal insulation in order to enhance membrane resistance and reduce membrane capacitance. Vertebrates and some invertebrates have adopted the second approach through developing a multilayered structure surrounding the axons called myelin ${ }^{4,5}$.

Although its major functions are similar in CNS and PNS, myelin is produced by two distinct glial cells in each subtype. In CNS, myelin is produced by oligodendrocytes in which more than one segment on the same axon or several axons can be myelinated by the same oligodendrocyte. On the other hand, Schwann cells are myelinating PNS axons in a one to one fashion as one Schwann cell can myelinate a single segment on an individual axon.

\section{$\underline{\text { Schwann cell origin and development: }}$}

In PNS, neural crest-derived Schwann cell (SC) precursors migrate into the periphery in tight association with elongating peripheral axons ${ }^{6-8}$. Further in development, Schwann cell precursor cells evolve into immature Schwann cells which wrap a group of axons ${ }^{9}$. Later, immature Schwann cells send their processes to invade the axonal bundles in order to select and decide to myelinate axons, or not, according to their caliber in a process called radial sorting. In this process, axons bigger than or equal to $1 \mu \mathrm{m}$ will be myelinated after becoming associated with a single Schwann cell in a one to one fashion. In turn, each Schwann cell will produce a single 
myelin segment, termed internode, along an individual axon and leaving unmyelinated small regions in between which are called nodes of Ranvier. On the other hand smaller axons $(<1 \mu \mathrm{m})$ bundles surrounded by Schwann cell cytoplasm instead of getting myelinated they become segregated from each other through ending up in separate pockets in the same Schwann cell forming a unique PNS myelin structure called Remak Bundle ${ }^{10-14}$ (Fig. 1).

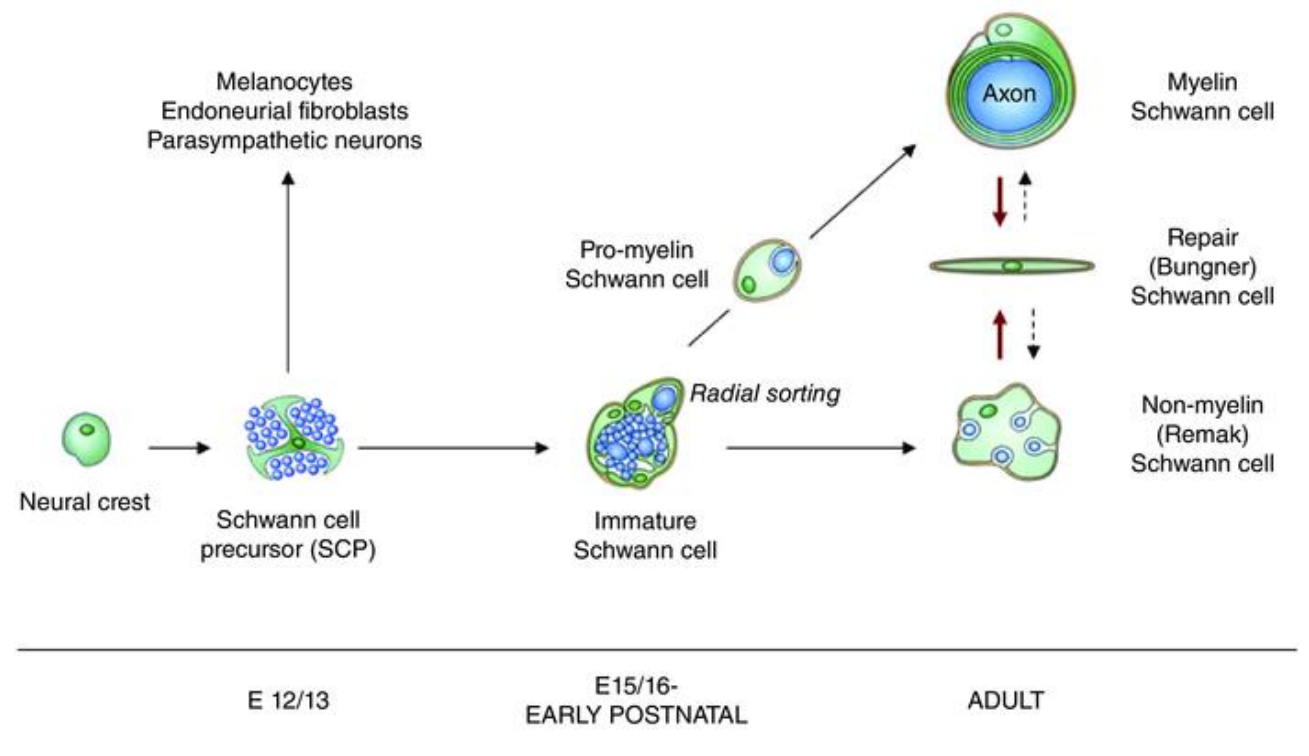

Figure 1:The Schwann cell developmental lineage and repair response. The diagram shows the main developmental cell types, repair (Bungner) Schwann cell and steps of Schwann cell development. Solid arrows indicate developmental steps. Red arrows indicate Schwann cell injury associated transformation into repair cell. Dashed arrows indicate post-repair response. E stands for embryonic time points in mouse development. (Adapted from K. R. Jessen and R. Mirsky (2016).

The radial sorting process is one of the phenomenon exhibiting clearly the neuron-glia cell interactions which indeed act in both directions. Although axonal sorting and later myelination of axons is carried out by immature Schwann cells, the development of Schwann cell depends on the axons' caliber. Such Schwann cell development is mediated by axonal neuregulin-1 type III (NRG1-III), a transmembrane protein which controls almost all aspects of Schwann cell biology including proliferation, migration and differentiation ${ }^{15}$. Sorting of an axon results in pushing immature Schwann cells further in the differentiation lineage and lead to the formation of a promyelinating SC-axon unit. Such association is a requirement for myelin sheath-production programs $_{\text {activation }}{ }^{16}$ via mounting a myelin-specific gene expression program in promyelinating Schwann cells ${ }^{17}$. In contrary, immature Schwann cells wrapping small caliber 
axons $(<1 \mu \mathrm{m})$ and not involved in radial sorting becomes non-myelinating Schwann cells interchangeably called Remak cells which eventually engulf small caliber axons in individual pockets as mentioned before (Fig 1) ${ }^{18,19}$.

\section{$\underline{\text { Regulation of Schwann cell differentiation and myelination by axonal NRG1: }}$}

Axonal NRG1 (NRG1_III) is controlling Schwann cell differentiation and myelination through three major signaling axes. The first is mediated by NRG1_III dependent activation (phosphorylation) of erythroblastic leukemia viral oncogene homolog-2/3 (ErbB2/ErbB3) receptor on Schwann cells ${ }^{15}$. This activation leads to activation of PI3K/PIP3/AKT signaling which is a major axis of Schwann cell development and myelination. In this axis, phosphorylated PI3K catalyze the conversion of PIP3 from PIP2 which in turn phosphorylate AKT; a major positive regulator of Schwann cell differentiation and myelination ${ }^{20}$. Another branch of this axis is the DLg1/PTEN/AKT which is activated by continuous ErbB2/ErbB3-NRG1_III dependent activation. As PTEN reduces AKT activity, it has been shown to be a possible myelination termination signal. Therefore the interplay between NRG1, DLg1-PTEN complex and AKT is controlling the peripheral nervous system myelination ${ }^{21}$. Of note, AKT promotes myelination via cholesterol biosynthesis mediated by sterol regulatory element-binding proteins (SREBPs) ${ }^{22,23}$.

The second axis is the MEK pathway. Yy1 phosphorylation of MEK is important for Krox20 induction, Schwann cell differentiation and myelination ${ }^{24}$. Moreover Erk1/2 ablation from Schwann cell has stopped myelination indicating that it is required for myelination ${ }^{25,26}$. In addition, ablation of tyrosine phosphatase SHP2 (Ptpn11; protein tyrosine phosphatase nonreceptor type-11) in Schwann cell has led to reduced Erk1/2 phosphorylation. This is indicating that MEK/Erk signaling is part of NRG1/SHP2-regulated myelination axis ${ }^{27}$.

The third is mediated by Schwann cell stimulation with NRG1 which leads to an increased level of intracellular calcium mediated by PLC-g (phospholipase C-g). This in turn leads to nuclear translocation of NFATc4 and complex formation with Sox 10 which lead to Krox 20 and P0 genes $\operatorname{activation}^{28}$. 


\section{The role of axonal Neuregulin-1in Schwann cell development:}

Neuregulin-1 signaling is important for neural crest cells differentiation and consecutive Schwann cells development ${ }^{29,30}$. In addition, absence of NRG1 or it receptors ErbB2 or ErbB3 leads to absence of Schwann cell precursors (SCPs) in the nerve trunk ${ }^{31,32}$. Indeed, it has been shown that NRG1 is crucial for SCPs survival ${ }^{9,33}$. Unlike the two other isoforms which contain immunoglobulin domain and can be resealed from the membrane after cleavage by metalloproteases, NRG1_III is a transmembrane protein and act in a juxtcrine manner (Fig.2) 30,34. Interestingly, Schwann cell proliferation, migration, differentiation and eventually myelination process are controlled by axonal NRG1 (NRG_III) ${ }^{35}$.

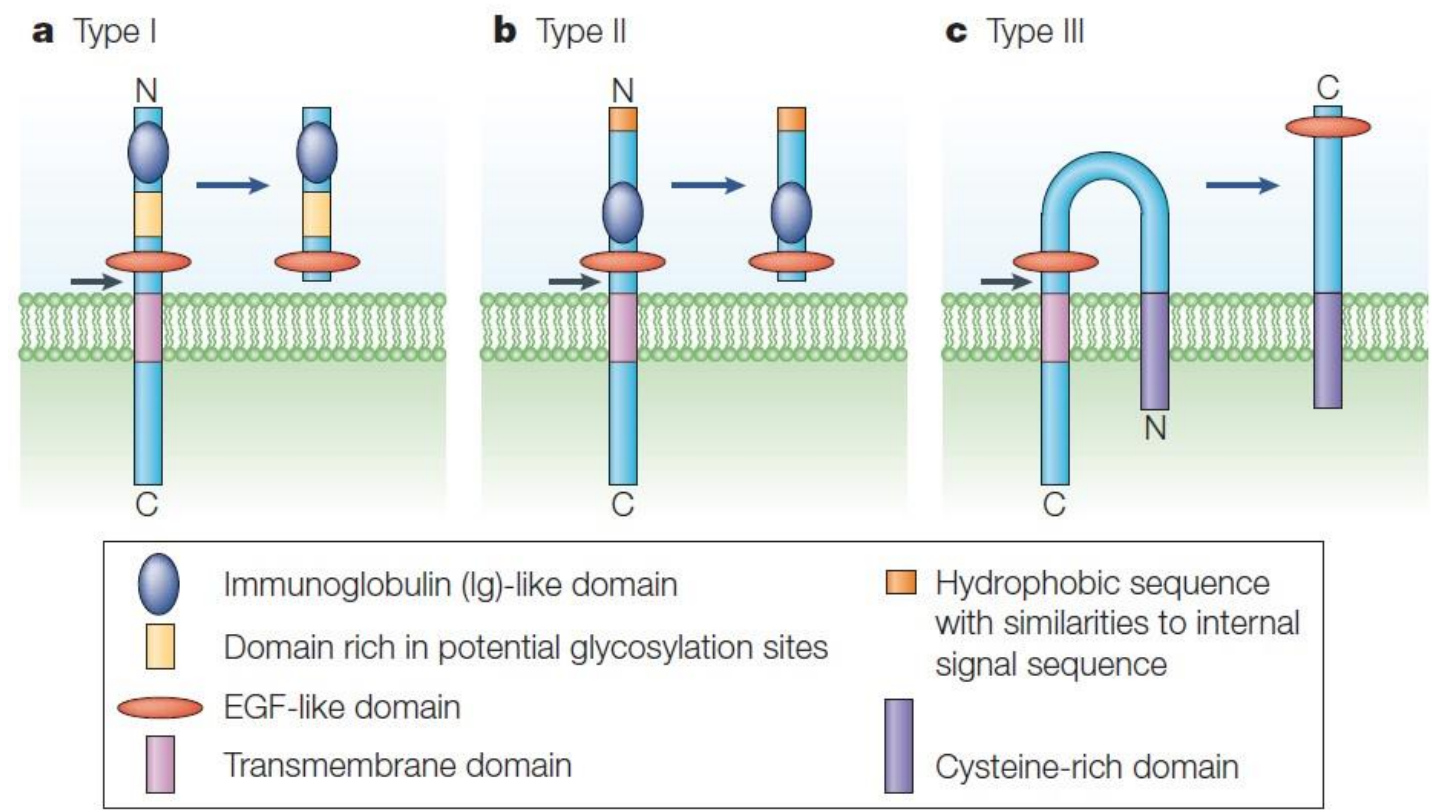

Figure 2:Schematic structures of major NRG1 isoforms in the nervous system. Unlike type III isoform, has two transmembrane domains, other isoforms (I\&II) have only one transmembrane domain. Proteolytic cleavage in the juxta-membrane area releases the epidermal growth factor (EGF) domain containing part of both I\&II isoforms while III remain anchored to the membrane. Adaptaed from Jessen \& Mirsky 2005.

More evidence emphasizing the importance of axonal NRG1_III in controlling Schwann cell myelination were concluded from its ablation as well as overexpression in vivo. Haploinsufficiency of axonal NRG1 has led to reduction in myelin sheath thickness (hypomyelination). On the other hand, overexpression of axonal NRG1 had resulted in an increase in myelin sheath thickness (hypermyelination). In addition, lack of axonal NRG1 has 
resulted in axonal ensheathment defect ${ }^{20}$. Moreover, NRG1_III has been shown to control migration of Schwann cells in the developing nerves to facilitate developmental myelination ${ }^{36}$.

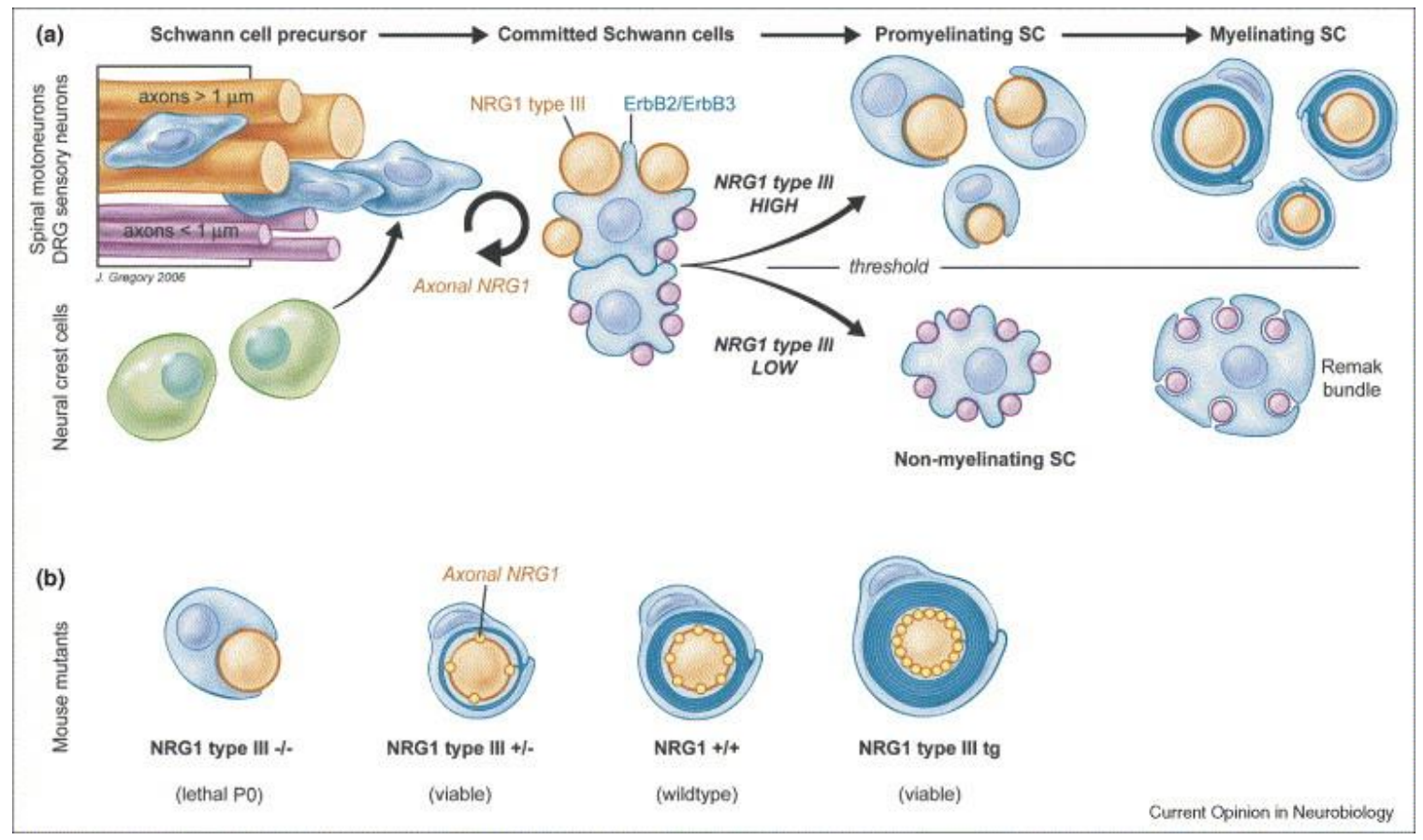

Figure 3:Axonal NRG1 controls various aspects of Schwann cell differentiation and myelin sheath thickness. (a) Neural crest precursor cells (green) fate during development is directed by the extent of NRG1 stimulation received from the associated axons (yellow and purple). Precursor cells subjected to high NRG1 stimulation of ErbB2/3 receptors are differentiating into myelinating Schwann cells while other are forming Remak cell which surround a group of small caliber axons forming a Remak bundle. (b) Axonal NRG1 level of expression on the axonal membrane controls myelin sheath thickness. The scheme in $b$ is showing a gradual in increase in myelin sheath thickness proportional to the leve of NRG1 on the axonal membrane in a mouse model in vivo. Of not, complete loss of axonal NRG1 leads to postnatal death. Adapted from Nave \& Salzer 2006.

Taken together, these observations show that axonal NRG1 is important for Schwann cell lineage survival, migration, proliferation, differentiation, axonal ensheathment as well as myelin sheath thickness in peripheral nervous system (Fig.3) ${ }^{30,35}$.

\section{Transcriptional and molecular control of Schwann cell development:}

A consequence of axonal sorting is the one to one association of sorted axons with Schwann cells. Such association initiates a myelin specific transcriptional program which strictly controls Schwann cell differentiation and myelination combining positive as well as negative regulators ${ }^{37}$.

\section{Schwann cell positive transcriptional regulation:}

Early growth response-2 factor (Egr2 known also as Krox20) plays a central role in controlling Schwann cell myelination as it activates myelination support genes and represses inhibitor of 
myelination in order to support myelination further ${ }^{38}$. A major Schwann cells positive transcription regulator is SRY-related HMGbox- 10 (Sox10) which is central to Schwann cell myelination. Sox10 activates octamer-binding transcription factor-6 (Oct6) which eventually induces the expression of Krox $20^{39}$. Another activator of Krox20 is the nuclear factor of activated T-cells, cytoplasmic, calcineurin-dependent-4 (NFATc4) in association with Sox $10^{28}$. In addition to Krox20 gene activation, NFATc4 activates $M P Z$ gene which encodes myelin protein zero; the most abundant myelin protein which is indispensable for myelin sheath compaction and stability ${ }^{28}$.

In agreement with its role in Schwann cell lineage development, NRG1_III activates the nuclear factor of $\mathrm{k}$ light polypeptide gene enhancer in $\mathrm{B}$ cells transcription factor $(\mathrm{NF}-\mathrm{kB})$ which has been shown to promote myelination via Sox10 gene activation. It is noteworthy that NF-kB activity is epigenetically regulated by histone deacetylases HDAC1 and HDAC2 ${ }^{40}$. Further studies have shown that Sox 10 and Krox20 are also regulated by HDAC1 and HDAC2 which indeed highlight another level of the myelination process regulation ${ }^{41}$.

\section{Schwann cell negative transcriptional regulation:}

Besides activation of positive myelination transcriptional regulators, suppression of the negative regulators must be assured during myelination. NGFI-A/Egr-binding (NAB) corepressors with Krox20 has been shown to associate with the promotors of various myelination inhibitors, including inhibitor of DNA binding-2 (Id2), inhibitor of DNA binding-4 (Id4), and (Ras associated with diabetes) (Rad). Such association leads to the suppression of these myelination inhibitor genes during myelination ${ }^{42,43}$. Another major inhibitor of myelination is the transcription factor AP-1 component c-Jun (referred to as c-Jun). Therefore, this transcription factor is inactivated during myelination process and only activated post injury to promote Schwann dedifferentiation ${ }^{44,45}$.

In addition to NAB and c-Jun, a demyelination inducing transcription factor is the active transcriptional regulator Notch intracellular domain (NICD). It exerts its function by inducing demyelination post injury after being activated through proteolytic release ${ }^{46}$. Such negative 
myelination transcription factors are important for inducing Schwann cell dedifferentiation and demyelination after injury. These two process have been shown to be important for the repair process via helping axonal regrowth and myelinating Schwann cell transdifferentiation to support nerve repair in case of acute nerve injury. Moreover, in case of chronic injuries as in demyelinating neuropathies these negative regulators are inappropriately activated and hampering myelination ${ }^{38}$.

\section{Post-transcriptional regulation of peripheral nervous system myelination process:}

Another level of Schwann cell myelination control is mediated by micro RNAs. The posttranscriptional regulation of Schwann cell myelination was concluded from Schwann cell specific deletion of Dicer in vivo. In turn, this has resulted in differentiation arrest due to disturbance of the regulatory miRNA network ${ }^{47,48}$. On the cellular level, Schwann cell Dicer specific deletion has led to impairment in radial sorting as well as increased Schwann cell proliferation and apoptosis ${ }^{48}$. Moreover, Dicer deletion has led to impaired axonal integrity which indicates a disturbed Schwann cell-axon interaction ${ }^{47}$. On the molecular level, Dicer deletion has led to an increase in myelination inhibitors and decrease in myelin positive regulators ${ }^{47,48}$. In line, miRNAs-138 has been shown to suppress the expression of wellestablished Schwann cell myelination inhibitors including c-Jun, Sox2 and CyclinD1 in vitro ${ }^{49}$. Taken together, these findings indicate that micro RNAs promote myelination positive regulators effect through suppression of the inhibitors which eventually support myelination.

\section{Lipid biosynthesis pathway:}

A consequence of NRG1 dependent-AKT activation is cholesterol biosynthesis which is mediated by sterol regulatory element-binding proteins (SREBPs) ${ }^{50}$. Activation of SREBPs is regulated by SREBP cleavage-activating protein (SCAP) which it is activated in response to cholesterol abundance in endoplasmic reticulum ER ${ }^{50}$. Since cholesterol biosynthesis is crucial for myelination, SCAP deletion results in absence of SREBP-mediated gene expression involved in cholesterol and fatty acid synthesis and leads to impaired myelin synthesis. In addition, cholesterol biosynthesis absence has led to hypomyelination and myelin decompaction most likely due to a P0 export defect from ER ${ }^{51}$. Moreover, Schwann cell Pmp22 overexpression in 
Charcot Marie Tooth disease (CMT1A) leads to reduction in lipid biosynthesis genes expression and eventually leading reduced cholesterol biosynthesis ${ }^{52}$. Moreover, disturbed lipid homeostasis has detrimental consequences on myelination as accumulation of phosphatidic acid (PA), due to a Lpin 1 gene deficiency, abnormally activates MEK-Erk pathway and lead to demyelination and aberrant Schwann cell proliferation after myelination initiation ${ }^{53}$.

Due to the huge required amount of lipids for myelin formation, the myelinating glial cells have the ability to synthesize most of the lipids themselves ${ }^{54,55}$. Furthermore, they are able to build up myelin even if endogenous lipid synthesis has been shut down but in very low levels ${ }^{50}$. In turn this has led to the conclusion that the myelinating cells can assimilate and use lipids from the extracellular environment. Supporting observations for this conclusion were derived from transcription analysis in rodents which has showed that the levels of expression of lipoprotein receptors in oligodendrocytes ${ }^{56}$ as well as low density lipoprotein receptor (LDLR) gene in the PNS were elevated during myelination ${ }^{57}$ and LDLR gene was found not to be required for PNS remyelination $^{58}$

\section{Myelin sheath:}

\section{Myelin multi-layered Structure:}

Biophysical investigations of nervous system structures with parallel axons such as the sciatic nerve in the PNS and optic tract in the CNS revealed that the myelin sheath is characterized by having both a lipid dependent and a protein-dependent birefringence ${ }^{59}$. This is in line with the fact that myelin sheath is composed of alternating protein and lipid repeating unit which have variable spacing distances according to species and tissue type. The spacing distances of the electron density plot, depicting the repeat units, presented in figure 4 shows that one repeat unit

is composed of one bimolecular layer of lipid (about $50 \AA$ ) and two protein layers (about $15 \AA$ each). Also, the diagram shows that a two fused repeating units has twice the value of the one repeat unit ${ }^{60}$.

More information about the nature of the detailed structure of myelin was revealed from electron microscopy where transverse sections of axons showed myelin as a series of alternating dark and less dark lines (protein layers) separated by unstained zones (the lipid hydrocarbon chains). 
According to electron microscopy micrographs of the myelin sheath, it is characterized by asymmetry on protein layers staining. The underlying reason for this asymmetry is the presence of less dark, intraperiod lines representing the closely apposed outer protein layers of the original cell membrane because the membranes are not actually fused. Moreover, the dark, major period line is generated by the fused, inner protein layers of the cell membrane. Interestingly, comparison of PNS and CNS myelin electron micrographs revealed that there a constant average difference in periodicity; $119 \AA$ average repeat distance in PNS myelin and $107 \AA$ in CNS myelin 59 .

\section{Node of Ranvier:}

The wrapping of the axons with a precisely arranged and integrated multi-layerd myelin sheath is indispensible for its function. The myelin sheath high resistance and reduction of the axonal membrane resistance due to axon insulation by the myelin sheath ${ }^{61}$, leads to faster conduction velocity. This can be perceived upon comparison of the mechanisms of signal conduction mechanisms and speed in both myelinated and unmyelinated axons.

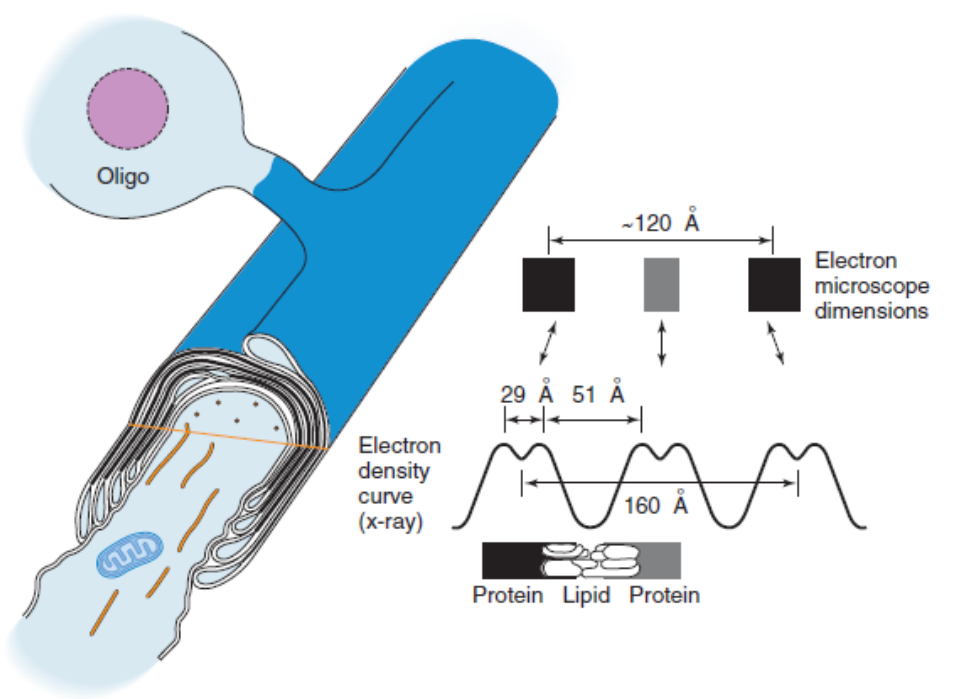

Figure 4: A diagram depicting some of the ultrastructural features of CNS myelin. The cutaway view of myelin and axon shows the nodal and the paranodal regions. A cross section at the intermodal region shows the inner and outer mesaxons and their relationship to the inner cytoplasmic wedges and the outer loop of cytoplasm. The right part of the graph shows a rough representation of myelin repeating units' dimensions and appearance as derived from electron micrographs. Next to that, the dimensions derived from electron density curve of CNS myelin resulted from X-ray diffraction analysis of freshly ioslated nerves. The corresponding components of the peaks and troughs of the curve are drawn below. (Adapted from Norton, W. T.The myelin sheath. In E. S. Goldensohn and S. H. Appel (eds), Scientific Approaches to Clinical Neurology. Philadelphia: Lea \& Febiger, 1977, pp. 259-298 ${ }^{159}$.) 
When the fibers are unmyelinated, the conduction of a neural signal is propagated through local circuits of ion current which flow through the respective channels into the active regions of the axonal membrane, in and out the membranes. The formation of such circuits leads to depolarization of the next membrane region to continue such process along the axonal membrane.

In contrast, myelinated axons are covered with myelin with only regularly spaced regions, called nodes of Ranvier, which are not covered with myelin. The nodes of Ranvier are characterized by high density of $\mathrm{Na}^{+}$channels and spatially separated from voltage-dependent $\mathrm{K}^{+}$channels ${ }^{62}$. Upon membrane excitation, the generated local circuits cannot flow through the myelin the sheath due its high resistance and flow inside the fibers and depolarizes the membrane at the next node. Due the low capacitance of the myelin sheath, little energy is required to depolarize the internodal region which leads to an increase in the speed of local circuit spreading. Such spreading and speeding up leads propagation of the neural impulse which is called saltatory conduction. This speeding up of the depolarization wave is highly rapid than in myelinated axons. To ensure such high conduction velocity and use energy efficiently, nodes must be properly spaced. Moreover, restriction of ions flow to the nodal area leads to a reduction in the overall sodium in flux inside the fibers and eventually the nerve (Fig.4).

\section{Paranodal regions and Schmidt- Lantermann clefts:}

A common feature of the paranodal regions and the Schimdt-Lantermann clefts is that they are cytoplasm filled connected with the Schwann cell cytoplasm, uncompacted regions and found in each layer of the myelin sheath. A specific feature of the paranodal regions is their position at the edges of the myelin sheath. As myelin is separated from the axons by periaxonal space, the lateral loops together with axolemma form membrane complexes which are called transverse bands in order to seal the myelin to the axolemma. In contrast to lateral loops, SchmidtLantermann incisions are in the middle regions of the myelin sheath rather than at the edges ${ }^{63}$. 


\section{The characteristic composition of myelin sheath:}

A high lipid-to-protein ratio is a unique characteristic of the myelin sheath that distinguishes it from other membranes. Lipids in myelin membranes, accounts for approximately $70 \%$ of myelin membrane dry weight shown in myelin biochemical purification via sucrose gradient centrifugation $^{64}$. Myelin membrane has characteristic myelin-specific proteins which I will describe some of them and their contribution to the building up and function of the myelin Sheath.

\section{Myelin lipid composition:}

Although, myelin membrane has no myelin-specific lipids, it has a characteristic lipid composition. The myelin membrane contains a high level of cholesterol of at least $26 \%$ by weight $^{64,65}$ and is enriched in galactolipids ( $31 \%$ vs. $7 \%$ for liver cell plasma membranes). In addition monogalactosylsphingolipidscerebroside and sulfatide , account for $14 \%-26 \%$ and $2 \%-$ $7 \%$ of myelin lipids respectively. Myelin is also characterized by high levels of saturated longchain fatty acids. Plasmalogens (etherlipids) is one of the enriched lipid classes in myelin which comprises $70 \%$ of the total phosphatidylethanolamine in white matter while it contributes to only $5 \%$ in liver ${ }^{66,67}$.

\section{Effect of Lipids biochemical properties on myelin membrane function:}

Intriguingly, the function of the myelin membrane is affected by the biochemical properties of the incorporated lipids ${ }^{68}$. For instance, cholesterol, the most important regulators of lipid organization in the membrane, plays a critical role in establishing the proper membrane fluidity and ion permeability. These properties are critical for the insulating function of the myelin membrane ${ }^{69}$. The membrane fluidity is decreased due to the increased ordering of fatty acids tails. This is mediated by alignment of the cholesterol rigid body alongside the fatty acid tails leading to reduction of polar molecules permeability ${ }^{70-73}$. Moreover, increased fatty acids tails ordering slows down membrane proteins diffusion and decreases membrane pending capacity $^{70,71,74,75}$. The tight binding of some proteins to cholesterol indicate that it is involved myelin protein translocation ${ }^{76}$. 


\section{Lipids are essential for myelin assembly, proper backing and insulation:}

In addition to their structural role, myelin enriched lipids contributes to the appropriate myelin membrane assembly, the proper backing and the insulating property of myelin membrane ${ }^{68}$. Myelin membrane proper backing is achieved by synchronized protein lipid interaction and the importance of such cooperation has been derived from mutation studies ${ }^{77}$. The perturbed endogenous Schwann cell lipid metabolism in SCAP conditional knockout mice is accompanied by myelin backing ultrastructural defects due to increase in the unsaturation level of fatty acids in myelin ${ }^{50}$. The insulating properties of myelin membrane is mediated by the electric insulation the outer layer by glycolipids which is composed of thick and ordered layers of long saturated fatty acids which is further sealed by another layer of cholesterol ${ }^{50}$.

\section{Myelin lipids role in myelin proteins sorting and localization:}

In addition to their structural and biophysical membrane properties role, myelin lipid are essential for myelin protein trafficking and myelin assembly ${ }^{55,78}$. In the CNS, a proof of principle of such role came from certain PLP mutations which resulted in perturbed cholesterol and PLPlipid rafts interaction, a cause of dysmyelination in spastic paraplegia ${ }^{79}$. In the PNS, a partial mislocalization of myelin protein P0 due to disturbed Schwann cell cholesterol biosynthesis resulted in noncompaction of the myelin membrane and hypomyelination ${ }^{55}$. Furthermore, in cell culture experiments, defects due to disturbed myelin protein P0 mislocalization could be restored by cholesterol or lipoprotein supplementation. In turn this is highlighting the essentiality of myelin protein P0 cholesterol recognition motif for the correct trafficking from endoplasmic reticulum to the newly synthesized myelin sheath ${ }^{50,55}$.

\section{Myelin lipids regulate myelinating glial cell differentiation:}

In the CNS, galactosphingolipids were suggested to be regulators of oligodendrocytes differentiation. This regulation is thought to be carried out via two pathways. Galactosphingolipids can play a direct role in cell adhesion necessary for correct timing of

oligodendrocyte (OL) differentiation or via disturbing oligodendrocyt's differentiation indirectly through affecting plasma membrane signaling proteins ${ }^{80}$. In the PNS, phosphatidic acid (PA) was shown to activate Schwann cell de-differentiation via activation of the MEK-Erk pathway. This 
is line with the observed demyelination in Lpin1 mutant mice which was shown to be mediated by an increase of PA levels ${ }^{53}$ due to the absence of Lpin1 activity.

\section{Myelin specific proteins:}

In contrast to usual myelin lipid composition, myelin sheath is characterized by a specific set of proteins. Although there are some proteins shared by the CNS and PNS myelin, some are specific for CNS or PNS. The PNS is characterized by a set of proteins including myelin protein zero (MPZ), myelin basic protein (MBP), P2 protein, Connexin32 and peripheral myelin protein22 (PMP22).

\section{Protein Zero (P0)/ Myelin Protein Zero (MPZ):}

MPZ is a transmembrane, with only one transmembrane domain and is $30 \mathrm{kDa}$, glycoprotein with an immunoglobulin like domain. Since it is the most abundant protein in the myelin sheath it accounts for approximately $50 \%$ of the proteins in PNS myelin ${ }^{81}$. Rat MPZ has a single extracellular Ig-like domain consisting of 124 amino acids form two domains, the first is a hydrophobic transmembrane domain consisting of 26 amino acids and the second is an intracellular domain consisting of 69 amino acids ${ }^{82,83}$. Moreover, MPZ is post-translationally modified via glycosylation with many heterogeneous glycans. In addition, phosphorylation and acylation if MPZ were previously described ${ }^{59}$.

In contrast to CNS, PNS myelin is characterized by greater separation of extracellular surfaces in myelin due to the relatively large, glycosylated, extracellular Ig-like domain of MPZ. By comparing the overall protein composition, in the PNS MPZ is the most abundant protein and PLP is the major protein in CNS. Although MPZ and PLP are different with respect to amino acid sequence, post-translational modifications and membrane topology, they play similar roles in myelin structure formation ${ }^{67}$. In addition to its crucial role in myelin compaction, MPZ has been shown to play a role in cell-cell interactions. This is due to tetrameric homophilic binding of MPZ extracellular domains indicating that P0 stabilizes the intraperiod line of PNS myelin by similar hemophilic binding ${ }^{84,85}$.

Mutation studies revealed that different mutations in the $M P Z$ gene cause dominant demyelinating, dominant axonal, and intermediate forms of inherited neuropathies. According to 
the observed phenotypes, MPZ Mutations could be clustered in two major groups ${ }^{86}$. The first group of mutations is characterized by severe phenotypes, affects myelination during development, cause early onset neuropathy and affects mainly myelin compaction. This phenotype is a result of blocking of the mutated MPZ transport to the plasma membrane or myelin membrane disruption by dominant-negative interactions between the mutated and wildtype MPZ protein ${ }^{86,87}$. The second group of mutations is mainly axonal phenotypes causing a late-onset neuropathy. The underlying patho-mechanisms of such mutations are not clear, it is suggested to be mediated by disruption of mutant MPZ expressing Schwann cell-neuron interactions leading to axonal degeneration and $\operatorname{loss}{ }^{86}$.

\section{Myelin Basic Protein (MBP):}

A remarkable interest in MBP was developed previously because it was first myelin antigen used to induce experimental autoimmune encephalomyelitis (EAE) after its injections in animals ${ }^{88}$. In PNS myelin, MBP has a variable percentage of the total myelin protein while in CNS it ls approximately $30 \%{ }^{89}$. Although it is a minor protein in the myelin sheath, the MBP gene has seven exons in the full length gene. Phylogenetic analysis has shown that MBP gene is conserved in many species and alternatively spliced to produce various isoforms ${ }^{90-92}$. It has been found that isoforms abundance was changing with age as the $14 \mathrm{KDa}$ and $17 \mathrm{KDa} \mathrm{MBP}$ and was abundantly found in mature rodent tissues while the $18.5 \mathrm{kDa}$ isoform was abundant in CNS.

It is noteworthy that since MBP is translated locally and therefore MBP mRNA is localized in the myelin processes. In turn the translated MBP get incorporated with the membrane directly after its synthesis ${ }^{93}$. Interestingly, the PNS shiverer mutant mouse has normal myelin, with respect to amount and compaction, in absence of MBP ${ }^{94}$. This inessentiality of MBP to PNS myelination can be explained by the presence of P0 cytoplasmic domain which can stabilize the major dense line of PNS myelin alone. The involvement of MBP in PNS myelin compaction was revealed from the $\mathrm{P} 0-\mathrm{MBP}$-double deficient animals, as they have shown more sever compaction defect phenotype, in PNS myelin, than that of P0-null mice ${ }^{83}$. 


\section{Peripheral myelin protein-22 (PMP22):}

PMP22 is, a small hydrophobic protein with four transmembrane domains $(22 \mathrm{kDa})$, two of them are extracellular loops and only one of them is glycosylated ${ }^{95}$. Although ubiquitously expressed, PMP22 comprise 2-5\% of myelin protein content in Schwann cells and is characterized by its tendency to oligomerize ${ }^{96,97}$. In addition to its structural role in myelinating Schwann cells, PMP22 has divers functions in various cell types: 1) It promotes cell spreading, cell migration, and apoptosis ${ }^{98,99}$. It is also a component of the developing blood-nerve and blood-brain barriers at intercellular junctions ${ }^{96,100}$. It plays a crucial role in proper myelination and myelin maintenance and its absence leads to delayed onset of myelination ${ }^{101}$. 3) At later stages, mice develop a focal hypermyelinating structures, tomacula, which eventually degenerate with at latter age and lead to demyelination ${ }^{102}$.

Disturbance of PMP22 expression leads to different neuropathies as the type of the disease vary according to the gene dosage. For example, the hereditary neuropathy with liability to pressure palsies (HNPP) is caused by PMP22 haploinsufficiency ${ }^{103}$. This is a recurrent neuropathy that is characterized by minor trauma of the peripheral nerves and tomacula formation ${ }^{104}$. On the other hand, duplication of the region containing the PMP22 gene on chromosome 17p11 leads to the development of Charcot-Marie-Tooth disease 1A (CMT1A) which is the most common form of inherited demyelinating neuropathy ${ }^{105}$. Furthermore, PMP22 was established as the disease causing gene by many transgenic experiments ${ }^{106-108}$.

More importantly, PMP22 over-expression may overwhelm the rapid degradation of, short-life, newly synthesized PMP22 ${ }^{109}$ through the ubiquitin-proteasome pathway before reaching the Schwann-cell plasma membrane ${ }^{110,111}$. The observed accumulation of intracellular vacuolar structures due to PMP22 overexpression in vitro, indicated a failure of proteasomal degredation process $^{112,113}$. Another consequence of PMP22 overexpression is the formation of microtubule (MT)-dependent ubiquitinated PMP22 aggregates called aggresomes ${ }^{111}$. This eventually leads to autophagy activation which help degrading of these aggresomes ${ }^{111}$.

Another disease mechanism mediated by PMP22 over-expression is inducing the formation of actin/ phosphatidylinositol (4,5)-bisphosphate (PI-4,5-P2)-positive vacuoles ${ }^{113}$. This results in 
trapping of membrane proteins by altering ADP ribosylation factor-6 (Arf6)-regulated endosomal- plasma membrane recycling. Taken together, PMP22 overexpression leads to disturbed intracellular degradation of membrane components which in turn may lead to aberrant turnover of other proteins or membrane lipids ${ }^{113}$ which may be a link for a pathomechanism. . The function of low overexpression (as in CMT1A) is, however, still unknown and under investigation (pers. communication M, Sereda).

Interestingly, other myelin related diseases are caused by PMP22 missense mutations. Most of these mutations affect hydrophobic domains of the protein and lead to the development of more severe phenotypes compared with PMP22 overexpression which are known as Dejerine-Sottas syndrome ${ }^{105}$. In the course of this disease, the mutant protein is retained in the endoplasmic reticulum (ER) and fail to reach the cell surface ${ }^{114,115}$. Such retention of the mutant PMP22 may prevent a proportion of wild-type PMP22 can from transport to the cell membrane by a dominant negative mechanism, as the mutant and wildtype PMP22 can make can form homo- and heterodimers and multimers ${ }^{96,116}$. Other studies showed that such transport blocking mechanism is not dominant for all proteins, but it was reported that mutated PMP22 proteins exert a deleterious effect in the absence of wildtype PMP $22^{103}$. The toxic gain of function of mutant PMP22 could be explained by several mechanisms. The first proposed mechanism is based on interaction between PMP22 and P0 which might affect the intracellular trafficking of both proteins. This suggested mechanism was undermined due to the limited interaction of the two proteins $^{117}$. The second suggested mechanism is the general defect in protein biosynthesis via deleterious sequestrateion of calnexin, an ER-resident chaperon, due to its interaction with mutated, ER-retained PMP22 ${ }^{118}$. The third suggested mechanism is via activation of the unfolded protein response in ER. This response is triggered by accumulation of mutant PMP22 as suggested for the retained proteolipid protein (PLP) mutants ${ }^{119}$ but experimental evidence for this mechanism is lacking.

Further insights of the pathomechanisms of PMP22 missense mutations, which next to an altered PMP22 gene dosage also triggers neuropathy, have been revealed form analysis of animal models ${ }^{120,121}$. In mutant Schwann cells, the endosomal-lysosomal pathway ${ }^{109}$ and ubiquitination 111 are upregulated. Furthermore, PMP22- containing aggresomes ${ }^{96,111}$ and myelin-like figures 
${ }^{118}$, representing autophagic vacuoles ${ }^{122}$ are present in mutant Schwann cells. The impaired proteasome activity and accumulated ubiquitinated substrates, in PMP22 mutant animals, indicate that aggresome formation is harmful by failure to remove toxic misfolded PMP $22^{121}$.

\section{Charcot-Marie-Tooth (CMT) disease}

Charcot-Marie-Tooth (CMT) disease is a heterogeneous group of motor and sensory neuropathies which constitute the most common inherited PNS disorders with a prevalence of up to 1 in $2500^{123,124}$. It is a slowly progressive disease and results in axonal loss and thereby leads to distally pronounced muscle atrophy accompanied with weakness. At later stages, patients suffer from sensory impairments and walking disabilities, occasionally leading to wheel chair boundness $^{125-128}$.

The nerve conduction velocity (NCV) value is implemented in the discrimination of demyelinating CMT type 1 (CMT1), the most common CMT form with strongly reduced NCV $(38 \mathrm{~m} / \mathrm{s})$ from the axonal CMT type $2(\mathrm{CMT} 2)$ with normal or slightly reduced $\mathrm{NCV}^{129}$.

Due to disease heterogeneity, several Schwann cell gene mutations can cause CMT1 disease ${ }^{130}$. CMT1A (PMP22 duplication, ${ }^{131,132}$, CMT1B (P0 mutations, ${ }^{133}$, CMTX (CX43 mutations, ${ }^{134}$ and a less common subtype caused by point mutations in early growth response gene $2\left(E G R 2,{ }^{135}\right)$ are the major subtypes of CMT1. This genetic classification of disease subtypes, which results in similar clinical phenotypes, was found to be insufficient. Therefore, the recent classification relies on combining the genetic basis and the characteristic clinical symptoms for a more reliable classification system $^{136}$.

Since studying such inherited neuropathies is difficult in to be conducted in humans, availability of disease animal models is essential. Therefore the accumulated knowledge, derived from CMT animal models during the last two decades, has improved the understanding of the disease greatly. A model of choice for mild CMT1A disease subtype is the human PMP22 YAC transgenic mouse line (C61 het line) which harbor four transgene copies and has up to 2-fold PMP22 mRNA overexpression ${ }^{137}$. It recapitulates the most common CMT1A phenotypes including demyelination, concentric layers of multiple promyelinating Schwann cells around 
naked axons (onion bulbs) and secondary axonal loss ${ }^{136}$. However, a Pmp22 transgenic rat model (the CMT1A rat) best mirrors human pathology and clinical features of CMT1A patients ${ }^{108}$. The low level of Pmp22 gene overexpression leas to slowly progressive neuropathy with impaired motor functions and reduced nerve conduction velocity $(\mathrm{NCV})^{108}$. Furthermore, time line histological evaluation of disease hallmarks in peripheral nerves has revealed that it remarkably resembles the human situation with respect to reduction in myelinated axons numbers, hypomyeliantion of large caliber axons, hypermyelination of small caliber axons as well as onion bulb development ${ }^{138}$.

Therefore, throughout this thesis work I have studied the CMT1A disease progression using combined omics approach in order to define some of the critical players involved in disease progression. Furthermore, by taking the advantage of the availability of various rodent models, I have aimed to exploit the defined disturbed myelin related processes for designing and conducting experimental therapy trials in order to ameliorate CMT1A disease progression. 
Materials and Methods

\section{Materials and Methods}




\section{Materials:}

\section{Chemicals and consumables}

Except otherwise stated all chemicals and consumables are purchased from Sigma-Aldrich, Merck, Serva, Falcon, Eppendorf and Invitrogen.

\section{General}

BSA

Ketamine, $10 \%$

Low fat milk powder

\section{Electron microscopy}

Azur II

Eukit

Formvar

Glutardialdehyde

Glycid ether 100

Lead citrate

Methylnadic anhydride

Methylene blue

Osmium tetraoxide

Propylene oxide

Polyvinylpyrrolidone (PVP filler)

2,4,6-Tris(dimethylaminomethyl)phenol

Uranyl acetate
BioMol

CP-Pharma

Frema
Merck

Kindler / Science Services

Plano

Electron Microscopy Science (EMS)

Serva

Merck

Serva

Merck

Science Services

Serva

Sigma-Aldrich

Science Services

SPI-Chem

\section{$\underline{\text { Protein biochemistry }}$}

Acrylamide

Ammonium persulfate (APS)

Bromphenol blue

cOmplete Mini (Protease inhibitors)

Formaldehyde 37\%

Glycine

2-Mercaptoethanol

PhosStop (Phosphatase inhibitors)

Prestained Page Ruler Plus

SDS (Dodecylsulfate sodium salt)

TEMED

Trizma Base
Serva

BioRad

Sigma

Roche

Merck

Sigma

Fluka

Roche

Fermentas

Serva

Serva

Sigma 


\section{$\underline{\text { Molecular biology }}$}

Agarose

AppliChem

GelRed

GenRuler 100 bp DNA ladder

Biotrend

Fermentas

GoTaq polymerase

Promega

Power SybrGreen

Applied Biosystems

Trizol Reagent

Superscript III-reverse Transcriptase

Invitrogen

Invitrogen

\section{$\underline{\text { Immunohistochemisty }}$}

Aqua Polymount

Goat serum

Haematoxylin (hemalum solution)

Horse serum

Paraformaldehyde, pure
Polysciences

Gibco

Merck

Gibco

Serva

\section{Consumables}

Copper grids (100Mesh, Guitarr, Slot) Coverslips

Histobond slides

PVDF Western Blotting membranes

Superfrost Plus slides
Gilder Grids

Thermo Scientific Menzel-Gläser

Marienfeld

Roche

Thermo Scientific Menzel-Gläser

\section{$\underline{\text { Kits }}$}

Agilent RNA 6000 Nano Kit

DC Protein Assay Kit

Genomic DNA-Isolation Kit

GoTaq DNA polymerase

RNeasy Mini / Micro Kit

SuperScript III Reverse Transcriptase

Vectastain Elite ABC Kit

Western Lightning Plus ECL
Agilent

BioRad

Nexttec

Promega

Qiagen

Invitrogen

Vector

Perkin Elmer Life Sciences 


\section{Machines}

AFS II

Agilent 2100 Bioanalyzer

Axiophot Observer inverted

Centrifuge 5415R

Diamond knife Histo $\left(45^{\circ} / \mathrm{Ultra}^{\circ} 5^{\circ}\right)$

Embedding center AP280-1/2/3

EMTP (Epon infiltration)

EM900

EM912AB

HPM100

IntasChemoStar(a luminescence Imager

348)

IntasChemoStar (Western Lightning Plus-347

ECL, Enhanced Chemiluminescence Substrate)

Light Cycler 480

NanoDrop200 Spectraphotometer

Optima TLX Ultracentrifuge

Precellyse24

PCR-machine

Sled microtome

Thermomax microplate reader

Tissue Processor HMP110

Ultracut

UV illuminator

Wet Chamber Blotting System

7500 Fast Real-Time PCR System
Leica

Agilent

Zeiss

Eppendorf

Diatome

Microm

Lynx

Zeiss

Zeiss

Leica

Intas Science Imaging

\section{Perkin Elmer}

Roche

Thermo Scientific

Beckman

Bertin Technologies

PeqLab

Microm

MGW Biotech

Microm

Leica

Intas

BioRad

Applied Biosystems 


\title{
Solutions and buffers
}

Avertin

2,2,2-Tribrome ethanol $99 \%$

Amyl alcohol
$2 \%[\mathrm{w} / \mathrm{v}]$

$2 \%[\mathrm{v} / \mathrm{v}]$

Mix at $40^{\circ} \mathrm{C}$ for $30 \mathrm{~min}$ while stirring. To be filtered before storage at $-20^{\circ} \mathrm{C}$.

\section{Anesthetic}

\author{
Xylazinhydrochloride (Rompun, BayerVital) $\quad 8 \mathrm{mg}$ \\ ketaminhydrochloride (Ketamin, WDT) $100 \mathrm{mg}$ \\ Intraperitoneal injection of $8 \mathrm{mg}$ Xylazinhydrochloride and $90 \mathrm{mg}$ \\ ketaminhydrochloride per $\mathrm{kg}$ of bodyweight per mouse.
}

1x Phosphate buffered saline (PBS)
Sodium chloride
$170 \mathrm{mM}$
Potassium chloride
$3.4 \mathrm{mM}$
di-Sodium hydrogen phosphate
$4 \mathrm{mM}$
di-Potassium hydrogene phosphate
$1.8 \mathrm{mM}$
Adjust to $\mathrm{pH} 7.4$ with $1 \mathrm{~N} \mathrm{NaOH}$.

\section{Fixatives}

16\% Paraformaldehyde (PFA stock solution)

Paraformaldehyde

Stir for 20 min at $60^{\circ} \mathrm{C}$ and subsequently increase $\mathrm{pH}$ with $\mathrm{NaOH}$ to allow full dissolution. Store at $-20^{\circ} \mathrm{C}$. 
4\% PFA in PBS (Fixative)

Paraformaldehyde

Phosphate buffer

Sodium chloride

Adjust $\mathrm{pH}$ to 7.4 before use.
$4 \%[\mathrm{v} / \mathrm{v}]$

$0,1 \mathrm{M}$

$0,8 \%[\mathrm{w} / \mathrm{v}]$

K\&S fixative (according to Schultz and Karlsson, 1965)

16\% Paraformaldehyde

Glutardialdehyde

$0.2 \mathrm{M}$ phosphate buffer

Sodium chloride

Adjust $\mathrm{pH}$ to 7.4 before use

$25 \%[\mathrm{v} / \mathrm{v}]$

$2,5 \%[\mathrm{v} / \mathrm{v}]$

$50 \%[\mathrm{v} / \mathrm{v}]$

$0,08 \mathrm{M}$

$\underline{\text { Molecular biology (PCR, cDNA, qRT-PCR) }}$

dNTPs (50x stock solution)

dATP, dGTP, dCTP, dTTP (Boehringer, $\quad 25 \mathrm{mM}$ Mannheim)

TBE 20x (stock solution)

TrisBase

$1.8 \mathrm{M}$

Boric acid

$1.8 \mathrm{M}$

EDTA

$200 \mathrm{mM}$

$\underline{\text { Protein biochemical solutions }}$

Sucrose buffer (Homogenisation)

Sucrose

$320 \mathrm{mM}$

Tris- $\mathrm{HCl} \mathrm{pH} 7.4$

$10 \mathrm{mM}$

Sodium hydrogen carbonate

$1 \mathrm{mM}$

Magnesium chloride

$1 \mathrm{mM}$

Add proteinase inhibitors and optionally phosphatase inhibitors before use.

Running buffer (Laemmli buffer working solution)

TrisBase

Glycine

SDS
$25 \mathrm{mM}$

$192 \mathrm{mM}$

$1 \%[\mathrm{w} / \mathrm{v}]$ 
Transfer buffer (1x for wet chamber blotting)

TrisBase

Glycine

Methanol

Tris buffered saline with Tween20 (TBST)

Tris- $\mathrm{HCl}(\mathrm{pH} 7.4)$

Sodium chloride

Tween20

Protein loading dye (6x)

Glycine

Tris-HCl pH 6.8

SDS

Bromphenole blue
$48 \mathrm{mM}$

$39 \mathrm{mM}$

$20 \%[\mathrm{v} / \mathrm{v}]$
$50 \mathrm{mM}$

$150 \mathrm{mM}$

$0.05 \%[\mathrm{v} / \mathrm{v}]$

$40 \%[\mathrm{w} / \mathrm{v}]$

$240 \mathrm{mM}$

$8 \%[\mathrm{w} / \mathrm{v}]$

$0,04 \%[\mathrm{w} / \mathrm{v}]$

$10-16 \%[\mathrm{v} / \mathrm{v}]$

$0,4 \mathrm{M}$

$0,1 \%[\mathrm{w} / \mathrm{v}]$

$0,03 \%[\mathrm{v} / \mathrm{v}]$

$0,08 \%[\mathrm{v} / \mathrm{v}]$

Ammonium persulfate

TEMED

$4 \%[\mathrm{v} / \mathrm{v}]$

$125 \mathrm{mM}$

$0,1 \%[\mathrm{w} / \mathrm{v}]$

$0,05 \%[\mathrm{w} / \mathrm{v}]$

$0,1 \%[\mathrm{w} / \mathrm{v}]$

Acrylamide / Bisacrylamide $29: 1$

Tris-HCl pH 6.8

SDS

Ammonium persulfate

TEMED

Sucrose solution for myelin purification

Sucrose

Sucrose

Add protease inhibitors to the solutions.
$0.29 \mathrm{M}$

$0.85 \mathrm{M}$

Gel fixative (for silver and coomassiestainings)

Ethanol

Acetic acid
$40 \%[\mathrm{v} / \mathrm{v}]$

$10 \%[\mathrm{v} / \mathrm{v}]$ 


\section{Solutions for electron microscopy}

Reynolds lead citrate solutions (Reynolds, 1963)

Lead nitrate

$1.33 \mathrm{~g}$

Sodium citrate $1.76 \mathrm{~g}$

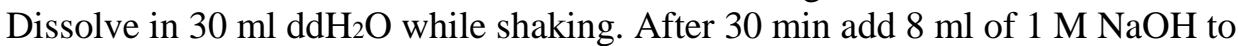
adjust the $\mathrm{pH}$ to 12 . Add $\mathrm{ddH}_{2} \mathrm{O}$ to $50 \mathrm{ml}$. Sterile filter before use.

Uranyl acetate

Uranyl acetate $4 \%[\mathrm{w} / \mathrm{v}]$

Aqueous solution has to be filtered before use.

Epoxy resin (Epon)

21.4 g Glycid ether 100

14.4 g DDSA (Serva, 20755)

11.3 g MNA (Serva, 29452)

Stir for $10 \mathrm{~min}$ and subsequently add $0.84 \mathrm{ml} \mathrm{DMP-30.} \mathrm{Stir} \mathrm{for} \mathrm{another} 20 \mathrm{~min}$.

Formvar solution

$\begin{array}{ll}\text { Formvar } & 1.25 \%[\mathrm{w} / \mathrm{v}] \\ \text { Chloroform } & 50 \mathrm{ml}\end{array}$

Stir for at least $30 \mathrm{~min}$. Protect from light. Store at room temperature.

Richardson's Methylene blue / Azure II blue (Richardson et al., 1960)

Azure II in $\mathrm{ddH}_{2} \mathrm{O}$ (Stock solution 1)

$1 \%[\mathrm{w} / \mathrm{v}]$

Methylene Blue in 1\% Borax (Sodium

$1 \%[\mathrm{w} / \mathrm{v}]$

borate) (Stock solution 2)

Mix equal amount of stock solutions and filter before use.

\section{$\underline{\text { Histological staining solutions }}$}

Tris buffer (50 mM, pH 7.6)

Tris- $\mathrm{HCl} \mathrm{pH} 7.6$

$50 \mathrm{mM}$

Sodium chloride

$0.9 \%[\mathrm{w} / \mathrm{v}]$

Prepare freshly and adjust $\mathrm{pH}$ to 7.6.

Tris buffered milk ( Blocking solution)(TBS / milk)

Tris-HCl pH 7.6

$50 \mathrm{mM}$ 
Sodium chloride

Low fat milk powder

Stir for $20 \mathrm{~min}$ at room temperature and filter before use.
$0.9 \%[\mathrm{w} / \mathrm{v}]$

$2 \%[\mathrm{w} / \mathrm{v}]$

\section{Blocking solution (TBS / BSA)}

Sodium dihydrogen phosphate

Disodium hydrogen phosphate

Sodium chloride

Bovine serum albumin
$40 \mathrm{mM}$

$160 \mathrm{mM}$

$1.8 \%[\mathrm{w} / \mathrm{v}]$

$1.0 \%[\mathrm{w} / \mathrm{v}]$

Blocking buffer for teased fiber staining

$10 \%[\mathrm{v} / \mathrm{v}]$ Horse serum

$0.1 \%[\mathrm{v} / \mathrm{v}]$ Tween 20

Add freshly to phosphate buffered saline (1x PBS).

Table 1: Antibodies

Primary antibodies:

\begin{tabular}{|c|c|c|c|}
\hline Antibody & Company & source & $\begin{array}{l}\text { Dilution (for WB unless } \\
\text { otherwise stated) }\end{array}$ \\
\hline Actin & Sigma \#A3853 & mouse & $1: 5000$ \\
\hline $\mathrm{AKT}$ & Cell signaling \#4691 & rabbit & $1: 1000$ \\
\hline p-AKT & Cell signaling \#3787 & rabbit & $1: 1000$ \\
\hline Caspr & Neuromab (\#P97846) & mouse & $1: 750(\mathrm{WB}) / 1: 200(\mathrm{IHC})$ \\
\hline GAPDH & Stressgene \#CSA-335 & mouse & $1: 5000$ \\
\hline MAPK & Cell signaling \#4695 & rabbit & $1: 1000$ \\
\hline p-MAPK & Cell signaling \#9101 & rabbit & $1: 1000$ \\
\hline MBP & Dako \#A0623 & rabbit & $1: 5000(\mathrm{WB}) / 1: 500(\mathrm{ICC})$ \\
\hline MBP & Serotec (\#MCA409S) & rat & $1: 500$ \\
\hline MAG & Chemicon \#MAB1567 & mouse & $1: 500(\mathrm{WB}) / 1: 50(\mathrm{IHC})$ \\
\hline Nav1.6 & Alomone Labs (\#ASC009) & rabbit & $1: 500(\mathrm{IHC})$ \\
\hline Tuj1 (tubulin beta III) & Covance (\#PRB-435P) & rabbit & $1: 400($ ICC) \\
\hline \multicolumn{4}{|l|}{ Secondary antibodies } \\
\hline Mouse-HRP & Dianova (\#115-035-003) & goat & $1: 5000(\mathrm{WB})$ \\
\hline Rabbit-HRP & Dianova (\#111-035-003) & goat & $1: 5000(\mathrm{WB})$ \\
\hline Mouse-A488 & Invitrogen (\#A21202) & donkey & $1: 2000$ (IHC) \\
\hline Mouse-A555 & Invitrogen (\#A31570) & donkey & $1: 2000(\mathrm{IHC})$ \\
\hline Rabbit-A488 & Dianova (\#711-545-152) & donkey & $1: 2000(\mathrm{IHC})$ \\
\hline Rabbit-A555 & Dianova (\#111-545-144) & donkey & $1: 2000(\mathrm{IHC})$ \\
\hline Rat-Dyelight 633 & YoProteins (\#309) & donkey & $1: 500(\mathrm{IHC})$ \\
\hline
\end{tabular}




\section{Primers:}

All oligonucleotides were synthesized by the AGCT-laboratory of the Max Planck Institute for Experimental Medicine.

\section{Genotyping primers:}

CPMP line genotyping primer(rat model genotyping):

$$
\text { Fwd.:5'-CCAGAAAGCCAGGGAACTC-3' }
$$

Rev.:5'-GACAAACCCCAGACAGTTG-3'

Cspp line genotyping primer(mouse model genotyping):

$$
\text { Fwd.: 5'-TCAGGATATCTATCTGATTCTC-3' }
$$

Double mutant mouse model (Pmp22 tg::Nrg1fl/fl::DhhCre) primers:

In addition to the Cspp line genotyping primer:

DHHC

Nrg1 flox/flox

\section{qRT-PCR primer}

\section{Mouse primers: \\ Rplp0(mouse):}

Ppia (CyclophilinA):

Nrg1-I(mouse):

Nrg1-II(mouse):

Nrg1-III(mouse):

\section{Rat primers:}

Nrg1-I:

Rplp0:

Ppia(CyclophilinA):

Fwd.: 5'-GTGTTCTTCGACATCACGGCT-3'

Fasn:

Fwd: 5'-GTCCACCCCAAGCAGGCACA-3'

Pla2g4a:
Fwd.: 5'-CCTGCGGAGATGCCCAATTG-3'

Fwd.:5'-TCCTTTTGTGTGTGTTCAGCACCGG-3'
Rev.:5'-CAGCCCGGACCGACGATGAA-3'

Rev.: 5'-GCACCAAGTGGTTGCGATTGTTGCT-3'
Rev.: 5'-ACAATGAAGCATTTTGGATAATCA -3'

Rev.: 5'-TTCCCAAAGACCACATGCTT -3'

Rev.:5'-TTTCACACCGAAGCACGAGC -3'

Rev.: 5'-GACTCCTGGCTTTTCATCTCTT -3'

Rev.: 5'-GAAGCACTCGCCTCCATT -3'

Rev.: 5'-TTTCGCACCGGAGCACTAGC -3'

Rev.:5'-CACAATGAAGCATTTTGGGTAG-3'

Rev.: 5'-TCCCCAGTGCTCAGAGCAC-3'

Rev.:5'-ACTCACACCCACCCAGACGC-3'

Rev.:5'-CGTATGGACTAAATTCTACCCAATC-3' 
Materials and Methods

Hmgcr:

cJun :

Oct6 (Pou3f1):

Krox20:

Mpz:

Chka:

MBP:
Fwd: 5'-CAACCTTCTACCTCAGCAAGC-3'

Fwd: 5'-CCTATACTCATACCAGTTCGCACA -3'

Fwd: 5'-TGGGAACCATGTAAATATGTGAGA -3'

Fwd: 5'-CTACCCGGTGGAAGACCTC -3'

Fwd: 5'-GCTGCCCTGCTCTTCTCTT -3'

Fwd: 5'-TCCTTGCCAGACTCCATAGC -3'

Fwd: 5'-GGCACGCTTTCCAAAATCT -3'
Rev.:5'-CACAGTGCCACATACAATTCG-3'

Rev.: 5'-CGACAACTGTCCCCTCCTC -3'

Rev.: 5'-CCAAAAATAAAAACCAAGCACAA -3'

Rev.: 5'-TCAATGTTGATCATGCCATCTC-3'

Rev.: 5'-TTTCCCTGTCCGTGTAAACC -3'

Rev.: 5'-AACACTCTCCAGAACCATTGC -3'

Rev.: 5'-CCATGGGAGATCCAGAGC -3' 


\section{Methods:}

\section{$\underline{\text { Animals }}$}

All animal experiments were conducted according to the Lower Saxony State regulations for animal experimentation in Germany as approved by the NiedersächsischeLandesamtfürVerbraucherschutz und Lebensmittelsicherheit (LAVES) and in compliance with the guidelines of the Max Planck Institute of Experimental Medicine. Animals were kept in a 12h-light-dark-cycle and all handling and investigations were carried out in the light phase.

Pmp22 transgenic rats ${ }^{108}$, (SD-Tg(Pmp22)Kan) were used for RNAseq, disease progression analysis and phospholipids experimental therapy trials. Pmp22 transgenic mice (Tg(PMP22)C61Clh), Pmp22 transgenic-Nrg1 knockout mice (PMP22 tg::Nrg1fl/fl::DhhCre) and wild type-Nrg1 knockout (Nrg1fl/fl::DhhCre) were used for the evaluation of the Schwann cell NRG1 contribution in CMT1A disease progression.In addition, mice embryos were used for in vitro experiments. Animals were obtained from heterozygous breedings. Whenever possible, littermates of the same gender were housed in groups to reduce stress due to social isolation.

\section{Genotyping}

Tail and/or ear biopsies were collected digested and gDNA was extracted according to manufacturer's instructions using the Genomic DNA-Isolation Kit for Tissue and Cells (Nexttec). Extracted DNA was diluted 1:5 in order to exclude the overload of PCR and the incidence of unspecific bands. Variable volumes of diluted DNA were used for different genotyping reactions. For PCR product visualization GelRed was added (1:20000 ratio) to each PCR reaction. PCR products were electrophoresed with $1.5 \%$ agarose gels in TBE buffer.

\section{$\underline{\text { RNA isolation and analysis }}$}

\section{RNA extraction:}

Frozen materials (sciatic nerves, dorsal root ganglions (DRGs) and spinal cord pieces) were homogenized in Trizol (Invitrogen) using the Precellyse24 homogenizer (Bertin Technologies) 
through strong shaking for two times each for $10 \mathrm{~s}$ at $5500 \mathrm{rpm}$. Total RNA was extractedwith RNeasy ${ }^{\circledR}$ Lipid tissue Mini Kit (Qiagen) according to the manufacturer's instructions for RNA extraction from lipid rich tissue.Concentration and quality (absorption ratio at 260/280 nm) of RNA samples were determined using the NanoDrop spectrophotometer (ThermoScientific). Purity and Integrity of the extracted RNA were determined with the Agilent 2100 Bioanalyser using the RNA 6000 Pico LabChip kit (Agilent Technologies) according to the manufacturer's instructions. Total RNAs of all sample groups were stored at $-80^{\circ} \mathrm{C}$ and were processed in parallel.

\section{RNA-seq analysis:}

Only sciatic nerve samples were used for RNA-seq analysis. Quality control, read alignment and differentially expressed genes: RNA-sequencing resulted in $\sim 24$ million reads per sample. Quality assessment was based on the raw reads using the FASTQC quality control tool (v0.10.1). The sequence reads (single-end $50 \mathrm{bp}$ ) were aligned to the rat reference genome (rn6) with Bowtie2 (v2.0.2)using RSEM (v1.2.29) with default parameters. First, the rat reference genome was indexed using the Ensembl annotations (v84.6) with rsem-prepare-reference from RSEM software. Next, rsem-calculate-expression was used to align the reads and quantify the gene and isoform abundance. The output of rsem-calculate-expression gives the read count and TPM value (transcripts per million) for each gene and isoform separately.

\section{cDNA synthesis:}

cDNA was synthesized through reverse transcription of equal amounts, 300-500 ng per reaction, of isolated mRNA samples, from the various tissues, was carried out. Reaction mixture consisted of poly-Thymin random nonamer primers (N9), oligodesoxythymidine primers (dT) as well as deoxynucleotide (dNTPs) and the SuperScript III reverse transcriptase (Invitrogen).

\section{Table 2: cDNA synthesis protocol}

\section{First strand cDNA synthesis}

\begin{tabular}{ll}
\hline Reaction component & volume \\
\hline RNA $(\sim 500 \mathrm{ng})$ & $8 \mu \mathrm{l}$
\end{tabular}




\section{Master mix.1:}

Oligo dT mix primer $(0.6 \mu \mathrm{M}) \quad 2 \mu \mathrm{l}$

N9 random nonamer primer $(0.12 \mathrm{mM}) \quad 2 \mu \mathrm{l}$

Mixture was incubated at $70^{\circ} \mathrm{C}$ for $2 \mathrm{~min}$ in order to denature all double stranded RNAs and primers.

After wards, mixture was put on ice for short time until finishing the next step.

\section{Master mix. 2:}

\begin{tabular}{lc}
\hline $5 \mathrm{x} 1^{\text {st }}$ strand buffer & $4 \mu \mathrm{l}$ \\
$100 \mathrm{mM}$ DTT & $1 \mu \mathrm{l}$ \\
$10 \mathrm{mM}$ dNTPs & $2 \mu \mathrm{l}$ \\
SuperScript III reverse transcriptase $(200 \mathrm{U} / \mu \mathrm{l})$ & $1 \mu \mathrm{l}$
\end{tabular}

After adding $8 \mu 1$ of master mix. 2 to each reaction mixture, the final mixture was incubated at $25^{\circ} \mathrm{C}$ for $10 \mathrm{~min}$. After incubation at $50^{\circ} \mathrm{C}$ for $45 \mathrm{mins}$, a final incubation at $55^{\circ} \mathrm{C}$ for another $45 \mathrm{~min}$ and dilution of the produced cDNA to $1 \mathrm{ng} / \mu \mathrm{l}$ was carried out.

\section{Quantitative real time polymerase chain reaction (qRT-PCR):}

Quantitative real-time polymerase chain reaction (qRT-PCR) was carried out using the Roche LC480 Detection System. The reaction mixture composed, mainly, of SYBR Green Master Mix (Applied Biosystems, Darmstadt, Germany), 1-2 ng of cDNA per reaction and the respective primers, selected with the Universal Probe Library form Roche Applied systems (https://www.roche-applied-science.com), of the analyzed gene. The reaction mixture was prepared and conducted as described in the following scheme: 
Table 3: Pipetting scheme and program for qRT-PCR (per reaction):

\begin{tabular}{ll}
\hline Reaction compenent & Volume \\
\hline cDNA & $2 \mu \mathrm{l}$ \\
Power SybrGreen master mix & $5 \mu \mathrm{l}$ \\
Forward primer $(100 \mu \mathrm{M})$ & $0.2 \mu \mathrm{l}$ \\
Reverse primer $(100 \mu \mathrm{M})$ & $0.2 \mu \mathrm{l}$ \\
$\mathrm{ddH}_{2} \mathrm{O}$ & $2.6 \mu \mathrm{l}$
\end{tabular}

After reaction mixture preparation, it was briefly spun down and the following amplification program was applied:

\section{qRT-PCR program}

\begin{tabular}{llll}
\hline Step number & Temperature & Duration & Step \\
\hline 1 & $50^{\circ} \mathrm{C}$ & $120 \mathrm{~s}$ & warm up \\
2 & $95^{\circ} \mathrm{C}$ & $600 \mathrm{~s}$ & melting \\
3 & $60^{\circ} \mathrm{C}$ & $20 \mathrm{~s}$ & annealing \\
4 & $72^{\circ} \mathrm{C}$ & $30 \mathrm{~s}$ & elongation and detection \\
\hline
\end{tabular}

$95^{\circ} \mathrm{C} 10$ s melting $\rightarrow$ back to step $3 \rightarrow 45$ cycles.

4 technical replicates were prepared.

For qRT-PCRs data analysis; Raw data of the qRT-PCRs were collected with Light cycler 480 (Roche, 384 well plates) equipped via LightCycler®480 software 1.5.0SP4. Relative PCR products quantities (RQ), were calculated for the four technical replicates using the operating software. Retrieved values of each evaluated gene were normalized to the housekeeping genes including ribosomal protein, large, P0 (Rplp0), Peptidylprolyl isomerase A (Ppia) also know cyclophilin A ( СуpA). Averages of normalized RQ biological replicates values were depicted as histograms, prepared by GraphPad Prism 5, with mean RQ values in the given control group normalized to $100 \%$. The Student's t-test was used for p-value quantification. 


\section{Phospholipid therapy:}

\section{Animals' food specifications:}

Animals were fed a Standard rat chow(PS R-Z, SsniffSpezialdiäten GmbH) which is, according to the supplier, consisting of $35 \%$ starch, $21.2 \%$ crude protein, $6.7 \%$ crude ash, $5 \%$ sugar, $4.4 \%$ crude fiber and $3.8 \%$ crude fat. In order to investigate the impact of phospholipid supplementation on CMT1A disease progression, soy derived phospholipids mixture (Sigma, P3644; 55\% phosphatidylcholine, 20\% phosphatidylethanolamine) was mixed with the above described standard chow at two different concentrations, $0.3 \%$ and $3 \%$ forming what I will refer to as lecithin-chow in the following descriptions.

\section{Experimental therapy trials paradigms:}

Wild type and Pmp22-transgenic rats were fed with 3\% lecithin-chow, only the long term $0.3 \%$ or 3\%, in a multi-paradigm experimental therapy trial. Long term treatment from P2 to P112, early short term from P2 to P21 and early short term treatment-late effect in which the animals were fed with $3 \%$ lecithin-chow from P2 to P21 and then the animals were switched to normal food until P80. The last feeding paradigm was the late long term in which the animals received chow mixed with lecithin from P21 to P112. Animals were assigned randomly to each treatment paradigm and treatment arm. Upon reaching the end of each treatment paradigm's termination time point, motor phenotyping and in vivo electrophysiological assessments were carried out. Motor phenotyping of controls as well as treated animals via grip strength analysis of fore and hind limbs. Electrophysiological assessments include nerve conduction velocity (NCV) of Sciatic nerve and compound muscle action potential (CMAP) of the foot intrinsic muscle of controls as well as treated animals. For further histological and molecular analysis, tissues were collected after sacrificing the animals.

\section{Exogenous PC incorporation into myelin sheath:}

In order to test the possibility of circulating phospholipids incorporation into the myelin sheath, fluorescent phosphatidylcholine BODIPY labelled TopFluor PC (Avanti polar lipids, \#810281) was injected intravenously in wildtype animals. $500 \mu \mathrm{g}$ BODIPY-PC dissolved in $25 \mu \mathrm{l}$ of pure ethanol, were intravenously injected in the tail vein of 15 days old CMT rats. One week later, the 
rat was sacrificed and various peripheral nerves, sciatic and tibial nerves, were collected for further analysis.

\section{Motor Phenotyping:}

\section{Grip strength:}

Motor performance of Pmp22 overexpressing rats as well as lecithin treated CMT1A rats was evaluated via a standardized grip strength tests as described previously. For hindlimb measurements, the forelimbs of the animal were supported and the animal's tail was pulled against a horizontal T-bar connected to a gauge. In case of forelimb measurements, the animals gripped the same horizontal T-bar during pulling them away from the bar with increasing force without any support of the hindlimbs. The recorded maximum force (measured in Newton) exerted by the animals, before the animal loses the grip, on the T-bar was documented and the mean of 8 repeated measurements was calculated.All phenotyping analyses were performed by the same investigator who was blinded toward genotype and treatment arms.

\section{Electrophysiological assessment}

Assessment of nerve conduction velocities (NCVs) and compound muscle action potentials

(CMAPs), was carried out according to standard procedure as described previously ${ }^{139,140}$. Rats were anesthetized via intraperitoneal injection ofmixture of Xylazine / Ketamine in order to have an adequate time window (20 min.) to carry out all electrophysiological recordings under deep anesthesia.For distal stimulation, two steel electrodes (Schuler Medizintechnik, Freiburg, Germany) were placed along the tibial nerve above the ankle and for proximal stimulation other two steel electrodes were placed next to the sciatic nerve notch. Motor recording electrodes were positioned in the small foot muscle of the plantar surface. Supramaximal square wave pulses (100ms duration) were applied using a ToenniesNeuroscreen (Jaeger, Hoechsberg, Germany). Compound muscle action potentials (CMAPs) were recorded after proximal and distal supramaximal stimulation of the sciatic and respective tibial nerve. Sciatic nerve conduction velocities (NCVs) were calculated using the distance between the proximal and distal stimulation electrodes, while the animal's leg is completely extended, and sciatic nerve conduction latency measurements. 


\section{Muscle atrophy assessment:}

In order to assess the extent of muscle atrophy, the skin of the left forelimb was removed. The muscle circumference was measured by wrapping a non-sterile silk suture thread 10 times around the group of muscles (adjacent non overlying), attached to the radius and the ulna, starting from the joint toward the paw. The wrapped thread length was measured to the nearest millimeter using a normal desk ruler.

\section{Tissue preparation}

\section{Peripheral nerve preparation:}

In order to collect tissues for further analysis, animals were sacrificed by cervical dislocation. Sciatic nerves, and in some experiments brachial plexus, DRGs and spinal cord samples were collected. For immunohistological investigations, sciatic nerves were fixed through immersion in $4 \%$ PFA for $24 \mathrm{~h}$ at $4^{\circ} \mathrm{C}$ before switching them to $1 \%$ PFA for longer time fixation. Other sciatic nerves were cryo-embeddedin tissue tech and oriented properly to prepare longitudinal sections for further analysis.

For ultrastructural evaluation, nerves were immersed in K\&S-fixative (4\% PFA and 2.5\% glutaraldehyde, according to Schultz and Karlsson, 1965), for better ultrastructural evaluation, for at least one week before embedding them. For protein analysis or RNA profiling, various tissues were snap frozen using dry ice and kept at $-80^{\circ} \mathrm{C}$ for later processing.

\section{Teased fiber preparation:}

Freshly collected sciatic nerves were transferred to a small petri dish containing PBS. The perineurial sheath was removed and the nerve was subdivided longitudinally into several fascicles which were then divided into smaller fibers bundles. Single bundles transferred to small single drops of PBS on a superfrost glass slide, with an adhesive surface. Using very fine forceps, fibers were carefully separated in order to have individual nerves fibers as much as possible. Slides were dried and kept at $-20^{\circ} \mathrm{C}$ for later experimentation. 


\section{Light and Electron microscopy:}

After fixation for one week in K\&S-fixative, nerves were fixed in $2 \%$ osmium tetraoxide which was followed by dehydration and embedding in epoxy resin. Semithin $(0.5 \mu \mathrm{m})$ and ultrathin sections were prepared using ultramicrotome (Ultracut S ultramicrotome, Leica).

For light microscopy: Semi-thin sections $(0.5 \mu \mathrm{m})$ were prepared (Leica RM 2155, using a diamond knife Histo HI 4317, Diatome) and stained with a mixture of $1 \%$ toluidine blue and azur II-methylene blue for $1 \mathrm{~min}$ at $60^{\circ} \mathrm{C}$. Microscopic images were collected using a $100 \times$ lens (Leica DMRXA), and digital images were obtained using Axiophot microscope (Zeiss) equipped with AxioCam MRC (Zeiss) and zen 2012 software. Counting of myelinated axons was carried out on whole sciatic or tibial nerve cross-sections, manually using ImageJ (NIH).

For electron microscopy: Ultrathin $(50-70 \mathrm{~nm})$ sciatic nerve or tibial cross-sections were contrasted with $4 \%$ uranyl acetate solution for $30 \mathrm{~min}$ and lead citrate for $7 \mathrm{~min}$ (according to Reynolds, 1963). Electron micrographs collection was carried out with the aid of EM900 (Zeiss; 3.500x - 30000x magnification) electron microscope which is equipped with a wide-angle dual speed 2K-CCD-Cameras (TRS, Moorenweis) using the Image SP software (TRS, SysProg, ImageSPvers. 1.1.4.62). Myelin sheath thickness comparison was carried out via calculation of the $g$ ratio which is a numerical ratio between the fiber's diameter and the diameter of the same fiber and the myelin sheath wrapping it. For $g$ ratio comparison at least 150 fibers were randomly analyzed from each sciatic nerve at 3000X magnification. Ultrastructural analysis was performed by measuring the periodicity, i.e. the distance between major dense lines, for at least 20 periods per myelinated fiber of at least 20 myelinated fibers per sample at a $30000 \mathrm{X}$ magnification. For all histological quantification, the experimenter was blinded with respect to genotype and treatment of all animals. ImagJ (ImageJ 1.48v, Wayne Rasband, National Institute of Health. USA; http://imagej.nih.gov/ij) was used for image analysis. 


\section{Embedding protocols}

Table 4: Conventional embedding of tissue in epoxy resin protocol:

\begin{tabular}{|c|c|c|}
\hline Step & duration & Temperature \\
\hline 0.1 M Phosphate buffer (PB) & $\begin{array}{l}3 \times 10 \mathrm{~min} \\
4 \mathrm{~h}\end{array}$ & $\begin{array}{l}4^{\circ} \mathrm{C} \\
4^{\circ} \mathrm{C}\end{array}$ \\
\hline \multicolumn{3}{|l|}{$\begin{array}{l}2 \% \text { Osmium tetraoxide in } 0.1 \\
\mathrm{MPB}\end{array}$} \\
\hline 0.1 M Phosphate buffer $3 x$ & $10 \mathrm{~min}$ & $4^{\circ} \mathrm{C}$ \\
\hline $30 \%$ Ethanol & $20 \min$ & $4^{\circ} \mathrm{C}$ \\
\hline $50 \%$ Ethanol & $20 \mathrm{~min}$ & $4^{\circ} \mathrm{C}$ \\
\hline $70 \%$ Ethanol & $20 \mathrm{~min}$ & $4^{\circ} \mathrm{C}$ \\
\hline $90 \%$ Ethanol & $20 \mathrm{~min}$ & $4^{\circ} \mathrm{C}$ \\
\hline \multirow[t]{2}{*}{$100 \%$ Ethanol } & $3 \mathrm{x} 10 \mathrm{~min}$ & $4^{\circ} \mathrm{C}$ \\
\hline & $10 \mathrm{~min}$ & $4^{\circ} \mathrm{C}$ \\
\hline \multicolumn{3}{|l|}{ 2-Propanol } \\
\hline & $3 x 10 \min$ & RT \\
\hline \multicolumn{3}{|l|}{ Propylene oxide } \\
\hline $2: 1$ Propylene oxide : Epon & $\begin{array}{l}2 \mathrm{~h} \\
2 \mathrm{~h}\end{array}$ & $\begin{array}{l}\text { RT } \\
\text { RT }\end{array}$ \\
\hline \multicolumn{3}{|l|}{$1: 1$ Propylene oxide : Epon } \\
\hline $1: 2$ Propylene oxide : Epon & $4 \mathrm{~h}$ & RT \\
\hline
\end{tabular}


pure Epon

$4 \mathrm{~h}$

RT

Transfer tissue from bucket to embedding molds and polymerize for $24 \mathrm{~h}$ at $60^{\circ} \mathrm{C}$

\section{Immunohistochemistry}

\section{Longitudinal sciatic nerve sections:}

In order to check whether intravenously injected fluorescent PC (Bodipy-PC) was incorporated into the myelin sheath during developmental myelination, longitudinal sciatic nerve sections $(20 \mu \mathrm{m})$ were prepared with a cryostat (Leica, Wetzlar, Germany). The sections were collected on glass slide and dried at RT and stored at $-20^{\circ} \mathrm{C}$. After hydration in PBS (0.1M)for 20min and fixation in 4\% PFA (diluted in in 0.1M PBS), sections were washed three times with PBS (0.1M) and permeabilized with triton $(0.4 \%)$ dilluted $\operatorname{PBS}(0.1 \mathrm{M})$ for 30 mins. Sections were blocked using (horse serum (4\%), triton (0.2\%) in PBS for 30 min. and primary antibody (anti MBP poly clonal rabbit (1:500; Dako)) was diluted in PBS (1x) containing HS (1\%), triton (0.05\%) and applied overnight at $4^{\circ} \mathrm{C}$. Primary antibody was washed and secondary antibody (Alexa 555 antirabbit 1:500 (Invitrogen)) and DAPI, for nuclear staining, were diluted in PBS (1x)containing HS (1.5\%) and applied at room temperature for 2 hrs. sections were washed with PBS(1x), immersed shortly in double distilled water, excess water was dried and slides were covered with aqua-polymount (Polysciences).

\section{Teased fibers staining:}

Previously teased and frozen fibers, from isolated sciatic nerves, were moved to room temperature and rehydrated using 1xPBS for $20 \mathrm{~min}$. The slides bearing the teased fibers were flooded with the PBS diluted fluoromyelin (300-folds) and incubated for 20 mins at room temperature. Staining solution was removed and slides were rinsed with PBS 3 times for 10 min each.At this point teased fibers were subjected to the usual antibody staining. Prestained teased fibers were fixed with 4\% PFA for 5 min and after washing with PBS for 3 times 5 mins each, they were permeabilized with ice-cold methanol for 5 mins. After washing with PBS (3X for 5 min), blocking of the fibers with $10 \%$ horse serum and $0.1 \%$ Tween20 in PBS for 2 hours at 
room temperature was carried out. Then the fibers were incubated with primary antibodies overnightat $4^{\circ} \mathrm{C}$. Slides were washed with PBS ( $3 X$ for $5 \mathrm{~min}$ ) and incubated with the respective secondary antibodies for 1 hour at room temperature. Finally the sildes were washed with PBS ( $3 \mathrm{X}$ for $5 \mathrm{~min}$ ) and mounted with aquapolymount for microscopic examination.

\section{Cell culture:}

\section{Impact of Pmp22 overexpression on PNS myelination:}

Dorsal root ganglia (DRGs) cultures were prepared by isolating DRGs from wild-type or Pmp22 transgenic mouse embryos (C61 line, ${ }^{141}$ at embryonic day 13.5 (E13.5)according to standard procedure $^{142}$. Collagen coated coverslips were seeded with the trypsin dissociated DRGs at a density of $10 \times 10^{4}$ cells per $1 \mathrm{~mm}$ coverslip. After one week incubation in growth medium, deactivated Hyclone fetal bovine serum (10\%) and NGF $(50 \mathrm{ng} / \mathrm{ml})$ in a minimal essential medium (MEM), for 1 week.In order to induce myelination, growth medium was supplemented with $50 \mathrm{ng} / \mathrm{ml}$ ascorbic acid (AA) (SIGMA) every other day until the termination time point. Investigated time points were 8, 10, 12 and 14 days postmyelination induction.

\section{Impact of exogenously supplied phosphatidylcholine (PC) on myelination in vitro:}

DRG neurons-Schwann cell cultures were switched to myelination medium composed of MEM containing 10\% lipoprotein-deficient serum (LPDS) (sigma), $50 \mathrm{ng} / \mathrm{ml} \mathrm{NGF,} \mathrm{50ng/ml} \mathrm{ascorbic}$ acid (AA) after being incubated for 1 week in normal growth medium. Pmp22 tg cultures grown on LPDS were supplemented with $2 \mu \mathrm{g} / \mathrm{ml}$ of L- $\alpha$-phosphatidylcholine derived from Soy (PC) (Avanti polar lipids, \#840054P), dissolved in ethanol. On the other hand, untreated cultures which have received equal amounts of ethanol, as in PC treated cultures, were considered as control cultures. Cocultures were fixed at 10 days post myelination induction for immunocytochemistry.

\section{Checking PC incorporated into the myelin sheath in vitro:}

At the time of myelination induction, wildtype DRG neurons-Schwann cell cultures were treated with $2 \mu \mathrm{g} / \mathrm{ml}$ of TopFluor® PC (1-palmitoyl-2-(dipyrrometheneboron difluoride) undecanoyl-sn- 
glycero-3-phosphocholine; Avanti polar lipids, \#810281) referred to as BODIPY-PC. On the hand, another set of wildtype cultures were treated with $2 \mu \mathrm{g} / \mathrm{ml}$ of 4,4-Difluoro-5,7-Dimethyl-4Bora-3a,4a-Diaza-s-Indacene-3-Pentanoic Acid referred to as BODIPY (ThermoFisher, \#D3834). Cocultures were fixed at 10 days post myelination induction for immunocytochemistry.

\section{Primary rat Schwann cells cultures:}

Schwann cells cultures were prepared from the sciatic nerves of rats at postnatal day 3 (P3) as described previously.() Briefly, the sciatic nerves were prepped from the newborn rats and the perineurium was removed. Then the nerve pieces were incubated in pre-degeneration medium (DMEM (Gibco) with 5\% HS, 1\% Pen/Strep and 2\% Glutamax) overnight. Predegenerated nerve pieces were dissociated through incubation in a medium containing $300 \mu 1$ trypsin (Gibco) \& $300 \mu \mathrm{l}$ collagenase (Gibco) for $45 \mathrm{mins}$ at $37{ }^{\circ} \mathrm{C}$ and $5 \% \mathrm{CO}_{2}$. In order to stop dissociation, horse serum was applied (1 ml HS (Horse Serum) $+3 \mathrm{ml}$ DMEM). The resulting suspension was triturated, spun at $1000 \mathrm{rpm}$ for $10 \mathrm{~min}$. The cell pellet was then resuspended in a resting medium (DMEM with 5\%HS, 1\% Pen/Strep and 2\% Glutamax), plated on a poly L lysine (PLL) coated plates $(35 \mathrm{~mm})$ and incubated overnight at $37{ }^{\circ} \mathrm{C}$ and $5 \% \mathrm{CO} 2$. In order to purify Schwann cell culture, cells were incubated in a selection medium (DMEM with 5\%HS, $1 \%$ Pen/Strep, 2\% Glutamax and $5 \mathrm{M}$ AraC) for three days. On the third day the selection medium was changed to expansion medium (DMEM, 10\%FCS, $10 \mathrm{ng} / \mathrm{ml}$ NRG1 (rhNRG1; Reprokine), 4uM Forskolin (SIGMA)). Pure Schwann cells were kept for 3 days in expansion medium. Cultures and have been spilt when confluence was reached and cells were harvested after another round of growth and stored in liquid nitrogen.

\section{Impact of PI3K/PAkt activator on lipid biosynthesis genes in CMT Schwann cell:}

Independent Schwann cell preparation were defrosted, to be used as biological replicates, and cultured in resting medium (DMEM + 10\% FCS) for 3 days. Afterwards, cultures were switched

to a serum-reduced medium (1\% FCS) and incubated for 1 day. Then the Schwann cells were harvested after being subjected to a treatment with a specific PI3K activator (740YP, Tocris) for 6 hours and kept at $-80^{\circ} \mathrm{C}$ for qRT-PCR analysis. 


\section{Immunocytochemistry}

Dissociated, DRG neurons-Schwann cells, cocultures were fixed (4\% paraformaldehyde (PFA) in 1x PBS for 10 min.) and permeabilized (ice-cold methanol $95 \%$ \& acetone $5 \%$ mixture at $-20^{\circ} \mathrm{C}$ for $4 \mathrm{~min}$.). Then, the fixed cultures incubated for $1 \mathrm{~h}$ in blocking solution (4\% horse serum, $2 \%$ bovine serum albumin (BSA), and $0.1 \%$ porcine gelatin). Primary antibodies (poly clonal rabbit anti-MBP (1:400; Dako) and monoclonal mouse anti-class III $\beta$ tubulin (1:500; Covance)) were diluted in blocking solution and applied at $4^{\circ} \mathrm{C}$ overnight. Coverslips were washed three times with 1x PBS. Then, secondary antibodies (alexa 488 donkey anti rabbit (1:400) (Invitrogen) and alexa 555 donkey anti mouse (1:400; Invitrogen) diluted in blocking solution containing $0.2 \mu \mathrm{g} / \mathrm{ml} \mathrm{4',6'-diamidino-2-phenylindole} \mathrm{(DAPI)} \mathrm{(Sigma),} \mathrm{were} \mathrm{applied} \mathrm{and}$ incubated at room temperature for $1 \mathrm{~h}$. In case experiments involving treatment with Bodipy-PC or Bodipy, alexa 555 donkey anti rabbit (1:400; Invitrogen) and Dyelight 633 anti rat (1:500; YoProteins). Finally, coverslips were washed with PBS, shortly immersed in distilled water and mounted on slides with aqua-polymount (Polysciences).

\section{Image collection and analysis:}

Fluorescence Images were obtained with fluorescence Zeiss Axioskop microscope equipped with MRM camera (Zeiss). Acquisition and processing of images was carried out with Zen2 -blue edition (Zeiss), ImageJ (NIH), Photoshop CS (Adobe) and Illustrator 10 (Adobe) software. For the quantification of myelination, the total number of myelin basic protein (MBP)-positive myelin segments on each coverslip was counted, and statistics were done using the two-tailed Student's t test.

\section{Myelin preparation:}

A myelin-enriched light-weight membrane fraction was purified from rats' sciatic nerves homogenized in $0.27 \mathrm{~m}$ as described previously ${ }^{143,144}$. The protein concentration was measured by Lowry assay using DC protein assay kit (BioRAD) according to the manufacturer's instructions and/or with protein gel silver staining as described previously ${ }^{145}$. The silver gel was imaged with hp Scan jet 6390C (HP intelligent scanning technology) and the density of each lane was measured with ImageJ (NIH). 


\section{Mass spectrometry:}

The amount of $1 \mu \mathrm{g}$ of myelin membranes per sample were subjected to lipid extractions using an acidic Bligh\&Dyer, except from plasmalogens, which were extracted under neutral conditions 146. Lipid standards were added prior to extractions, using a master mix containing 50 pmol phosphatidylcholine (13:0/13:0, 14:0/14:0, 20:0/20:0; 21:0/21:0, Avanti Polar Lipids) and sphingomyelin (d18:1 with $\mathrm{N}$-acylated 15:0, 17:0, 25:0, semi-synthesised as described in ${ }^{147}, 200$ pmol D6-cholesterol (Cambrigde Isotope Laboratory), 25 pmol phosphatidylinositol (16:0/16:0, 17:0/20:4, Avanti Polar Lipids), phosphatidylethanolamine and phosphatidylserine (both 14:1/14:1, 20:1/20:1, 22:1/22:1, semi-synthesisedas described previously ${ }^{147}$, diacylglycerol (17:0/17:0, Larodan), cholesterol ester (9:0, 19:0, 24:1, Sigma), and triacylglycerol (D5- Mix, LM-6000 / D5-17:0,17:1,17:1, Avanti Polar Lipids), 5 pmol ceramide and 20 pmol glucosylceramide (both d18:1 with $\mathrm{N}$-acylated 15:0, 17:0, 25:0, semi-synthesised as described 147, 10 pmol phosphatidic acid (17:0/20:4, Avanti Polar) and phoshatidylglycerol (14:1/14:1, 20:1/20:1, 22:1/22:1), semi-synthesised as described ${ }^{147}$. Phosphatidylethanolamine plasmalogen (PE P-)-containing standard mix was supplemented with 22 pmol PE P-Mix 1 (16:0p/15:0, 16:0p/19:0, 16:0p/25:0), 31 pmol PE P- Mix 2 (18:0p/15:0, 18:0p/19:0, 18:0p/25:0), 43 pmol PE P- Mix 3 (18:1p/15:0, 18:1p/19:0, 18:1p/25:0). Semi-synthesis of PE P was performed as described previously ${ }^{148}$. Lipid extracts were resuspended in $60 \mu 110 \mathrm{mM}$ ammonium acetate in methanol and samples were analysed in positive ion mode on an AB SCIEX QTRAP 6500+ mass spectrometer (Sciex, Canada) with chip-based (HD-D ESI Chip, Advion Biosciences, USA) electrospray infusion and ionization via a TriversaNanomate (Advion Biosciences, Ithaca, USA) as previously described ${ }^{147,149}$. Resuspended lipid extracts were diluted 1:10 in 96well plates (Eppendorf twintec 96, colourless, Sigma, Z651400-25A) prior to measurement. Precursor and neutral loss scanning was employed to measure phosphoglycerolipids and glycerolipids as described ${ }^{147,149}$. Remaining samples were subjected to cholesterol determination as described ${ }^{150}$. Data evaluation was done using LipidView (ABSciex) and an in house-developed software (ShinyLipids). 
The lipid classes' concentrations defined by mass spectrometric analysis were normalized to the measured protein concentration as assessed by standard Lowry assay (BioRad) and silver gel densitometry.

\section{Protein analysis:}

\section{Sample preparation:}

Rats' sciatic nerves were homogenized using precellys24 homogenizer (bertin instruments) in sucrose lysis buffer (320 mM sucrose, $10 \mathrm{mMTris}$ base, $1 \mathrm{mM} \mathrm{NaHCO} 3,1 \mathrm{mM} \mathrm{MgCl}$ 2, protease inhibitor (cOmplete Mini, EDTA-free, Roche)). For myelin fractions analysis, samples were prepared according the standard procedure mentioned above. Protein concentration of the samples was determined by Lawry assay using RC DC ${ }^{\text {TM }}$ Protein Assay biorad kit according to manufacturer's instructions.

\section{Electrophoresis and Blotting:}

Protein electrophoresis was carried out using precast gradient gels (NuPAGE 4-12\% Bis-Tris, Invitrogen). Western blots were incubated overnight with primary antibodies against p-AKT, pERK, ERK (all polyclonal rabbit; 1:1,000, Cell Signaling), polyclonal rabbit anti-PMP22 (1:2000; Assay biotech), monoclonal mouse anti-AKT (1:1,000, Cell Signaling), and monoclonal mouse anti-MBP (1:1000, Biolegend ). Detection was performed by anti-rabbit and anti-mouseHRP coupled sencondary antibodies respectively (1:5000, Dianova) and the Western Lightning Plus-ECL, Enhanced Chemiluminescence Substrate (Perkin Elmer) and using an luminescence Imager (Intas Science Imaging). For better normalization of the obtained results afterwards, relative protein concentration of the actual protein amount loaded two methods were used on different occasions. First: Coomassie staining (Imperial stain, Biorad) of the SDS gel after electrophoresis. Second: Total protein staining of the whole blot after the transfer step was carried out. 


\section{$\underline{\text { Statistics }}$}

Differential expression analysis: It was carried out using gene read counts with DESeq2 package. Genes with less than 5 reads (baseMean) were filtered out. Genes with a p-value $<0.05$ were considered to be differentially expressed.

Gene ontology enrichment analysis: Gene ontology (GO) analysis was conducted using WebGestalt. An adjusted p-value $<0.1$ using the Benjamini-Hochberg method for controlling the false discovery rate was set as significant for GO terms in biological processes. Results were confirmed using DAVID database for down-regulated genes at P18.

Lipidomics data was analyzed using LIMMA package ${ }^{151}$. Note, NA values were changed to 0. Linear fit was performed using lmFit function for 2 groups at P18 (Wt, $\mathrm{Tg}$ ) and 3 groups for P112 (Wt, Tgpla and Tg_Tx3). For the latter, pairwise comparison was performed using contrasts.fit function for Wt-Tg_pla and Tg_pla-Tg_Tx3. We considered an adjusted (P18) and non-adjusted (P112) p-value $<0.05$ significant.

Unless indicated otherwise, all other data was processed using MS Excel and GraphPad Prism v6.04. The statistical test that was used to analyze the data is indicated in the figure legends respectively. Briefly, for comparing two groups Student's T-test was used, for comparing more than two groups one way ANOVA with appropriate post test was used and for comparing two or more groups for more than one time point (longitudinal analysis) two way ANOVA with appropriate post test was used and a p-value $<0.05$ was considered significant. 
Results

\section{Results}




\section{Results}

\section{Impact of Pmp22 overexpression on CMT1A Schwann cell developmental transcriptional program:}

Pmp22 -overexpression leads to remarkable transcriptional dysregulation in CMT Schwann cells:

The previously reported perturbation in peripheral nerves myelination in CMT1A patients as well as in the CMT1A animal models strongly indicates an obvious reduction in Pmp22 tg Schwann cell myelination efficiency ${ }^{136,138}$. A deeper understanding of the progressive nature of CMT1A disease and defining the disturbed cellular process which leads to the development of the characteristic demyelination neuropathy will help to define novel therapeutic approaches. Therefore, we have applied a multi-omics approach combining longitudinal sciatic nerveSchwann cell total RNA sequencing (RNA-seq) and mass spectroscopic analysis of myelin fractions.

Since studying disease progression mechanisms is not amenable in humans, availability of reliable disease models is advantageous for such purpose. Therefore we have carried out a longitudinal unbiased RNA sequencing analysis of the total m RNA isolated from wildtype (Wt) as well as Pmp22 transgenic rat (Tg) sciatic nerves during developmental myelination starting at embryonic stage (E21), postnatal day 6 (P6) and ending with postnatal day18 (P18). Interestingly, gene ontology of the analysed regulated mRNA data set has revealed a remarkable disturbance of various cellular and biological processes indispensible for Schwann cell differentiation and myelination.

In our attempt to group the analysed set of genes according to their patterns of regulation, we have categorized the genes according to expression profile similarities derived from transcript per million (TPM) averages values comparison over the investigated timeline. According to our analysis, the observed transcriptional dysregulation in CMT1A Schwann cells starts postnataly and become more obvious at P18 during developmental myelination. In order to get an insight regarding the dysregulation patterns of the global RNA transcription, we have grouped the individual transcripts into four distinct patterns based on expression profile similarity (Fig. 1A; left and middle panels). 


\section{Results}

Interestingly, the transcriptional levels of two major clusters of genes appeared to be remarkably dysregulated in Pmp22-tg Schwann cells compared to wildtype Schwann cells. Differentiation associated genes, in second and fourth patterns, comprise the first cluster. In the second pattern, one the most prominent candidates for further analysis was Schwann cell neuregulin1 type I (Nrg1_I) which has been proved to play a crucial role in Schwann cell redifferentiation and remyelination after acute nerve injury ${ }^{152}$ (Fig.5A; right panel). The second cluster of genes is comprised of the lipid biosynthesis genes, falling in the first pattern of genes and highlighted in the right panel in figure1. These genes includes genes encoding the enzymes mediating lipid biosynthesis, metabolic, sterol biosynthesis and cellular lipid metabolic processes which fail to increase expression during postnatal developmental myelination when compared to wildtype Schwann cells (Fig5; middle panel pattern 1).

\section{Endogenous Schwann cell-NRG1 is continuously upregulated in Pmp22 tg Schwann cells:}

The observed subtle transcriptional upregulation of Schwann cell derived neuregulin1 type I (ScNrg1_I) in CMT1A is intriguing as it is similar to the previously reported Schwann cell Nrg1_I after acute nerve injury ${ }^{152}$. Since Schwann cell NRG1-I was shown to be only transiently upregulated after acute nerve injury, we wanted to examine whether upregulation in chronic injury is similar to that of the acute nerve injury or not. Therefore, we analyzed the transcriptional level of Schwann cell Nrg1_I mRNA over a timeline starting from postnatal developmental myelination until adulthood in a rodent model of CMT1A $\operatorname{Tg}(P M P 22) C 61 C l h$, termed PMP22 tg mice). In contrast to its transient upregulation in acute nerve injury, we could notice a continuous upregulation of Sc-Nrg1_I mRNA in CMT1A mouse sciatic nerves during postnatal developmental myelination (P6-P18). Such upregulation was continually increasing with age and could be detected early at P7 during postnatal developmental myelination until adulthood (P300) (Fig.6). Such remarkable NRG1 upregulation has motivated us to check whether it is contributing to CMT1A disease progression and disease hallmarks development. 
Results

A

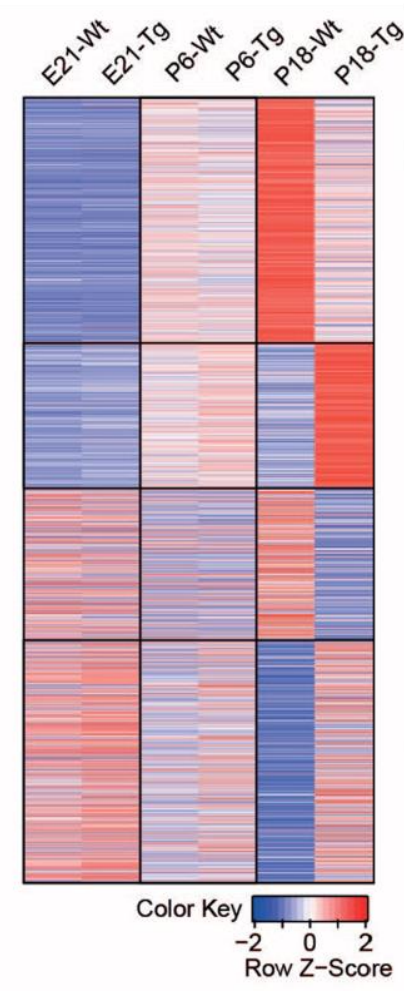

B
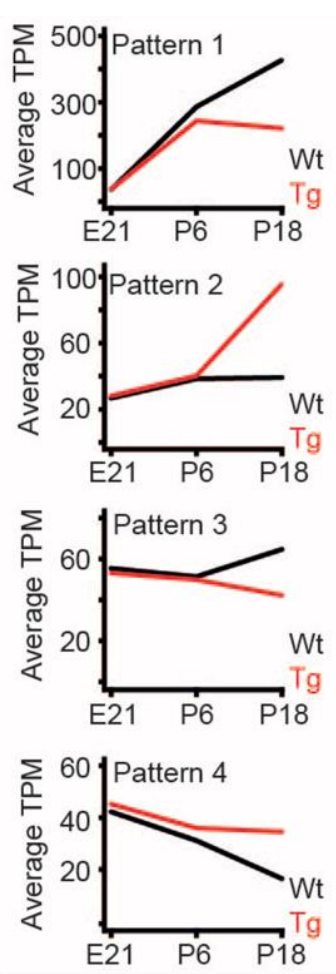

C

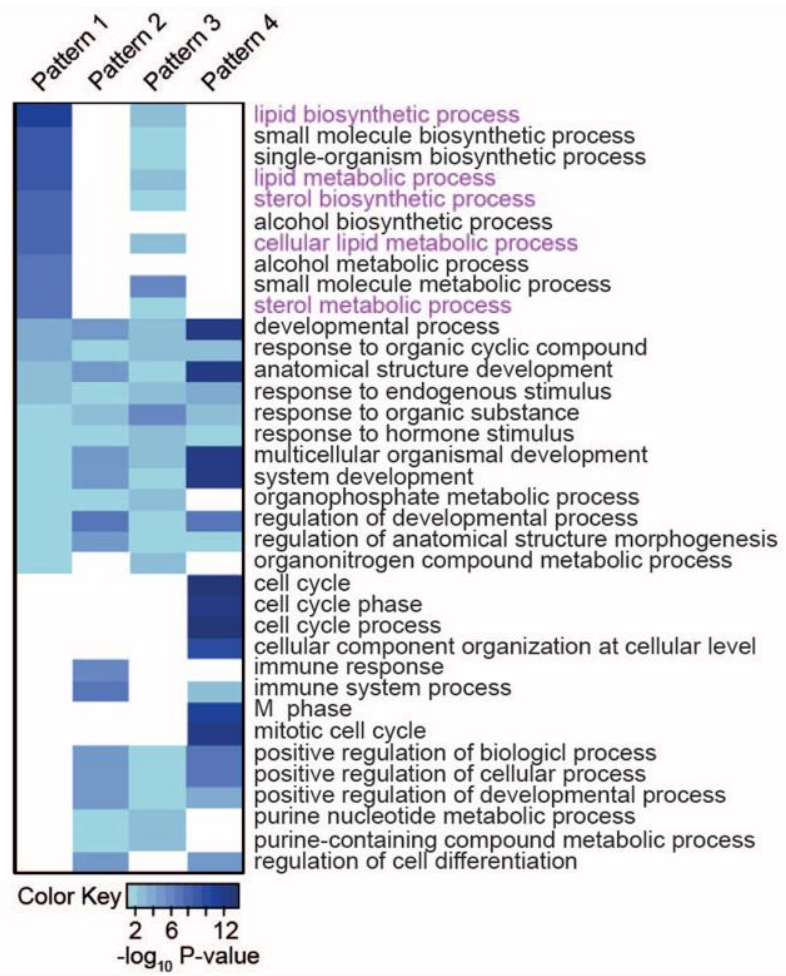

Figure 5: Various growth and Schwann cell process are disturbed in CMT Schwann cells especially lipid metabolism related processes: (A) Heatmap shows the scaled TPM values (transcripts per million) for differentially expressed genes (adjusted p-value $<0.05$ and $\log 2$ fold change $>|0.5|$ ) at P18. Genes downregulated in Tg (Pmp22 transgenic) versus Wt (wildtype) at P18 were further divided into two patterns - genes with increasing TPM value in Wt from E21 to P18 in pattern1 and the ones which has a plateau behavior in pattern3 as shown in (B). Likewise but in the other direction, Genes up-regulated in Tg vs Wt at P18 were further divided into two patterns - In pattern2 genes with increasing TPM value in Tg from E21 to P18 were depicted and in pattern 4 genes with which has shown a plateau behavior were depicted as shown in (B) also. (C) A heatmap is showing top ten biological process terms (from WebGestalt) for each pattern, demonstrating, among others, lipid biosysnthesis genes transcription is not increasing in Pmp22 transgenic rat Schwann cell as in the case of the wildtype rat Schwann cells from E21 to P18. Bioinformatics analysis has been carried by Prof. Stefan Bonn group (DZNE Göttingen) 

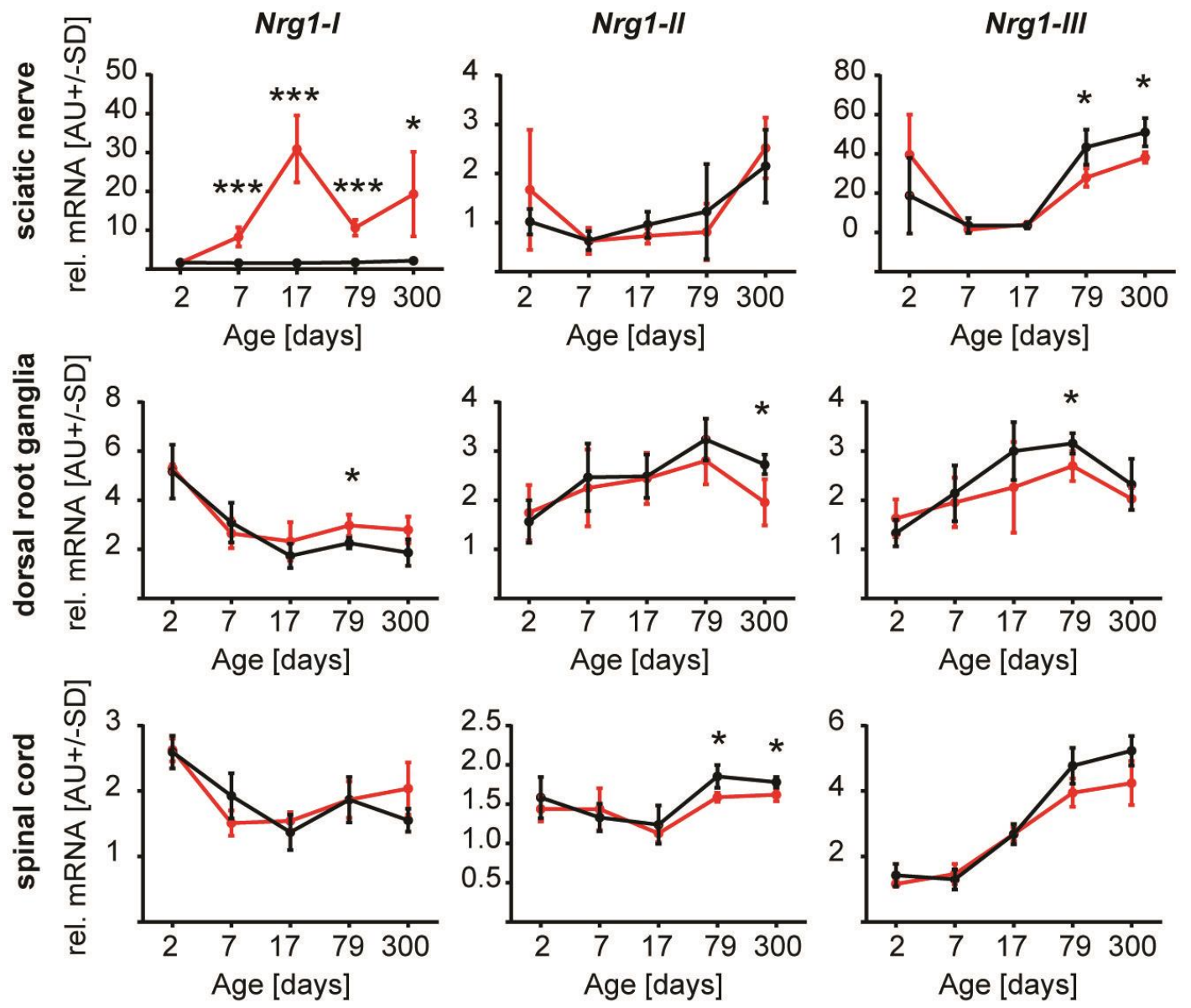

wildtype PMP22 tg

Figure 6:Nrg1-I transcription is induced in sciatic nerves of CMT1A rodent models. Different behavior of different $\mathrm{Nrg} 1$ isoforms (NRG1 type I\&II\&III) relative mRNA transcription in different tissues: sciatic nerve (upper row), dorsal root ganglia (middle row) and spinal cord (bottom row) of PMP22 tg (red) compared to wildtype (black) mice at the age of 2, 7, 17, 79 and 300 days. Only NRG1-1 is the most significantly upregulated isoform over the investigated timeline (during postnatal development, myelination, and adulthood) in Pmp22-tg mice compared to wildtype mice. ( $n=3-6$ per group and time point, multiple Student's T tests).

\section{Sc-Nrg1 I ablation in CMT1A mice could reduce hypermyelination of small to mid caliber axons in peripheral nerves:}

In order to determine the impact of Sc-Nrg1_I ablation in Pmp22 tg mice on the myelination capacity of Schwann cells, we have examined light and electron microscopic transverse sections of tibial and sciatic nerves (Fig.7A). On the other hand, electronmicroscopic examination of the myelin sheath thickness as measured by the $g$ ratio, has revealed that there is an amelioration of the reported hypermyelination of small to mid-caliber axons (Fig. C) in the double mutant mice. 


\section{Results}

A
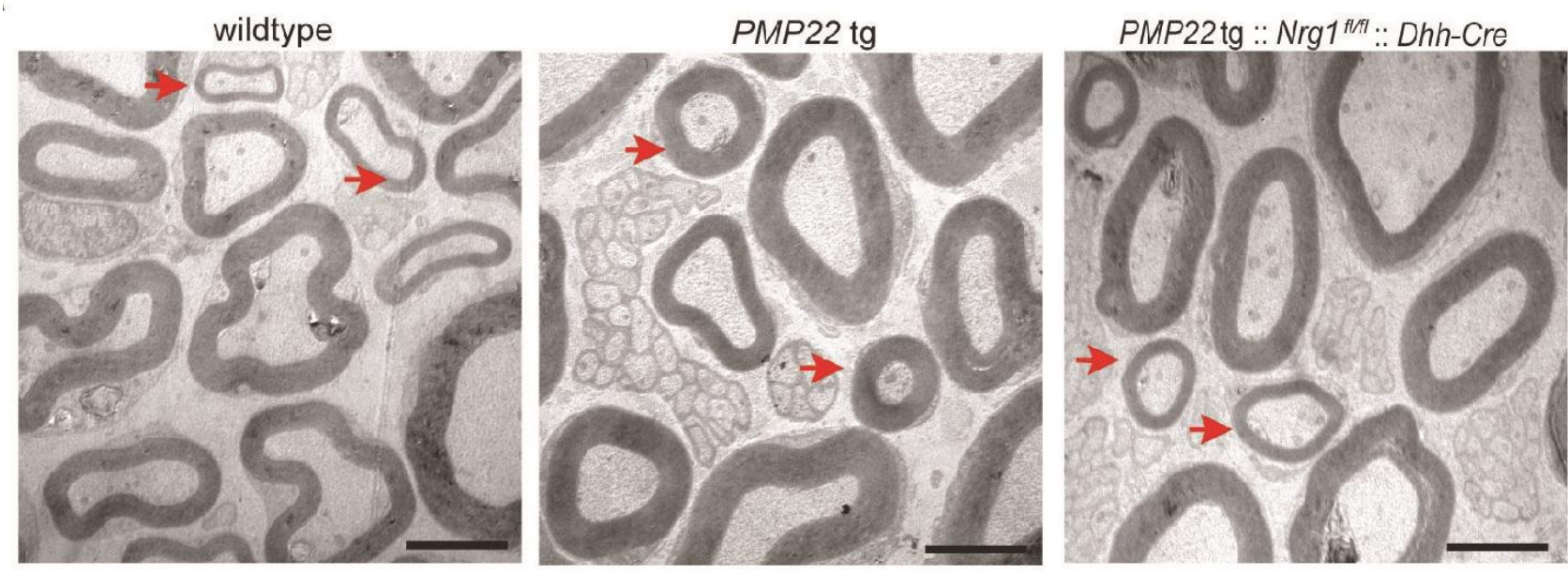

B
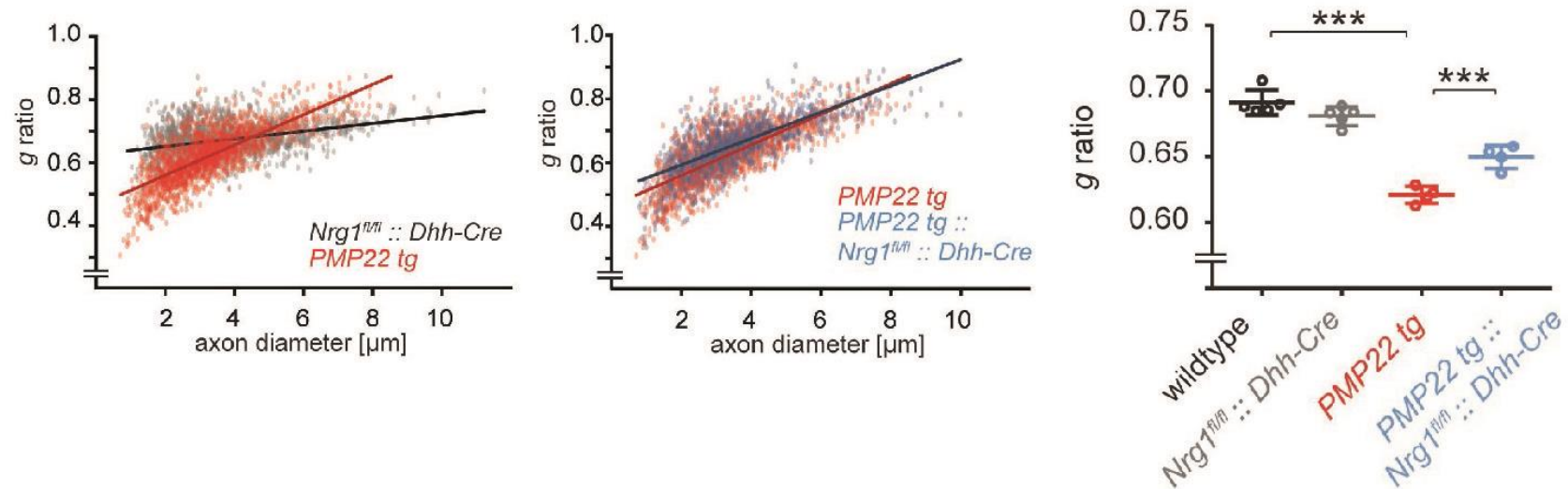

Figure 7: Glial Nrg1-I induces hypermyelination of small to mid-caliber axons and its deletion ameliorates the pathological hypermyelination in PMP22 tg mice: (A) A representative electron micrographs of sciatic nerve cross sections exhibiting hypermyelination of small caliber axons and hypermyelination of small caliber axons in four months old PMP22 tg compared to wildtype mice which is ameliorated in PMP22 $\operatorname{tg}:: N r g 1 f l / f l:: D h h C r e$ mutants (scale bar 2.5 $4 \mathrm{~m}$ ). (B) Scatterplots of measured individual g-ratio values (averaged in B) of single fibers plotted against axon diameter shows hypermyelination of small to mid-caliber and hypomyelination of large caliber fibers in PMP22 tg mice compared to controls (Nrg1fl/fl::DhhCre, left panel). The regression line in PMP22 tg::Nrg1fl/fl::DhhCre mice compared to PMP22 tg indicates ameliorated hypermyelination of small to mid-caliber axons in PMP22 tg mice upon ablation of Nrg1 in Schwann cells (right panel). (C) Quantification of the mean myelin sheath thickness ( $g$-ratio) in sciatic nerves from A revealed an amelioration of the decreased $g$-ratio in PMP2-tg mice after Schwann cell Nrg1 ablation (wildtype $\mathrm{n}=5, \mathrm{Nrg} 1 \mathrm{fl} / \mathrm{fl}:: D h h C r e \mathrm{n}=5, \mathrm{PMP} 22 \mathrm{tg}$ $\mathrm{n}=5$, PMP22tg::Nrg1fl/fl::DhhCre $\mathrm{n}=5,221-375$ fibers were measured per animal, one-way ANOVA with Tukey's post test).

Such partial amelioration of hypermyelination implies that Nrg1_I upregulation in CMT1A

Schwann cell contributes partially to the hypermyelination in Pmp22 tg mice's peripheral nerves.

On the other hand, Sc-Nrg1_I ablation didn't ameliorated the overall myelin sheath thickness as can be appreciated from the scatter plot of $g$ ratios values against axons size (Fig.7B; right panel). 
Sc-Nrg1 I ablation in CMT1A mice didn't rescue the reduced number of myelinated axons per peripheral nerve:

In contrary, light microscopic quantification of the number of myelinated axons per sciatic nerve has revealed that the reduced number of myelinated axons per sciatic nerve in the double mutant mice (Pmp22 tg::Nrglfl/fl::DhhCre) was not rescued (Fig.8A\&B). This is in line with the absence of any improvement in compound muscle action potential, after Sc-Nrg1_I knockout, which is a read out of the amount of myelinated axons per peripheral nerve (data not shown). As a proof of principle, overexpression of Sc-Nrg_I in wildtype mice has led to the same hypermyelination phenotype of the small caliber axons which is a characteristic feature of the CMT1A disease (data are not shown).

A

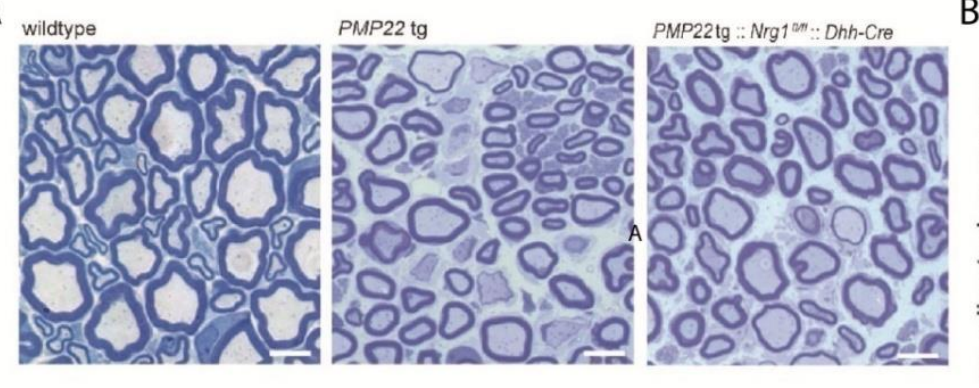

B

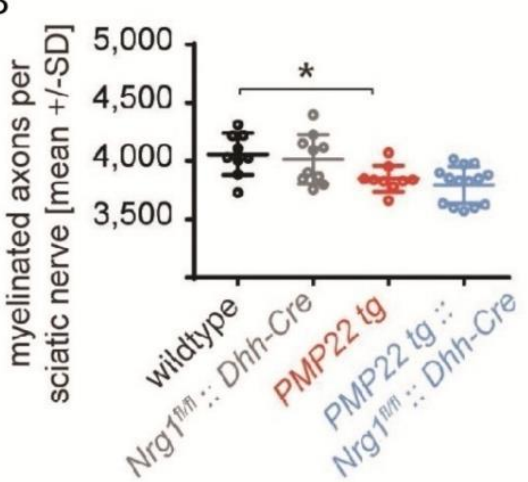

Figure 8:Glial Nrg1-I knockout doesn't improve the number of myelinated axons in PMP22 tg mice: (A) Representative light microscopic images of semi-thin cross sections from sciatic nerves of four months old wildtype, $P M P 22$ tg and $P M P 22$ $\operatorname{tg}:: N r g 1 f l / f l:: D h h C r e$ adult mice (left panels, scale bar $5 \mu \mathrm{m}$ ). (B) Quantification of the number of myelinated axons per sciatic nerve cross section (right panel) is reduced in PMP22 $\operatorname{tg}(\mathrm{n}=6)$ compared to wildtype $(\mathrm{n}=7)$ mice but not altered by ablation of glial Nrg1 in PMP22 tg (PMP22 tg::Nrg1fl/fl::DhhCre, $\mathrm{n}=7)$ when compared to single PMP22 tg mice (one-way ANOVA, Tukey's post test).

\section{Impact of Pmp22 overexpression on lipid biosynthesis in CMT1A Schwann cell:}

\section{Significant reduction of major lipid classes in CMT1A peripheral nerves' myelin:}

Transcriptional downregulation of lipid biosynthesis genes in CMT1A Schwann cells has motivated us to check if it has an impact on the myelin lipid classes' stoichiometery and levels in the myelin sheath fraction. Therefore, in collaboration with Prof. Britta Bürgger at University of Heidelberg, we have carried out a comparative lipidomic analysis via mass spectrometric analysis of myelin fraction lipid composition. 


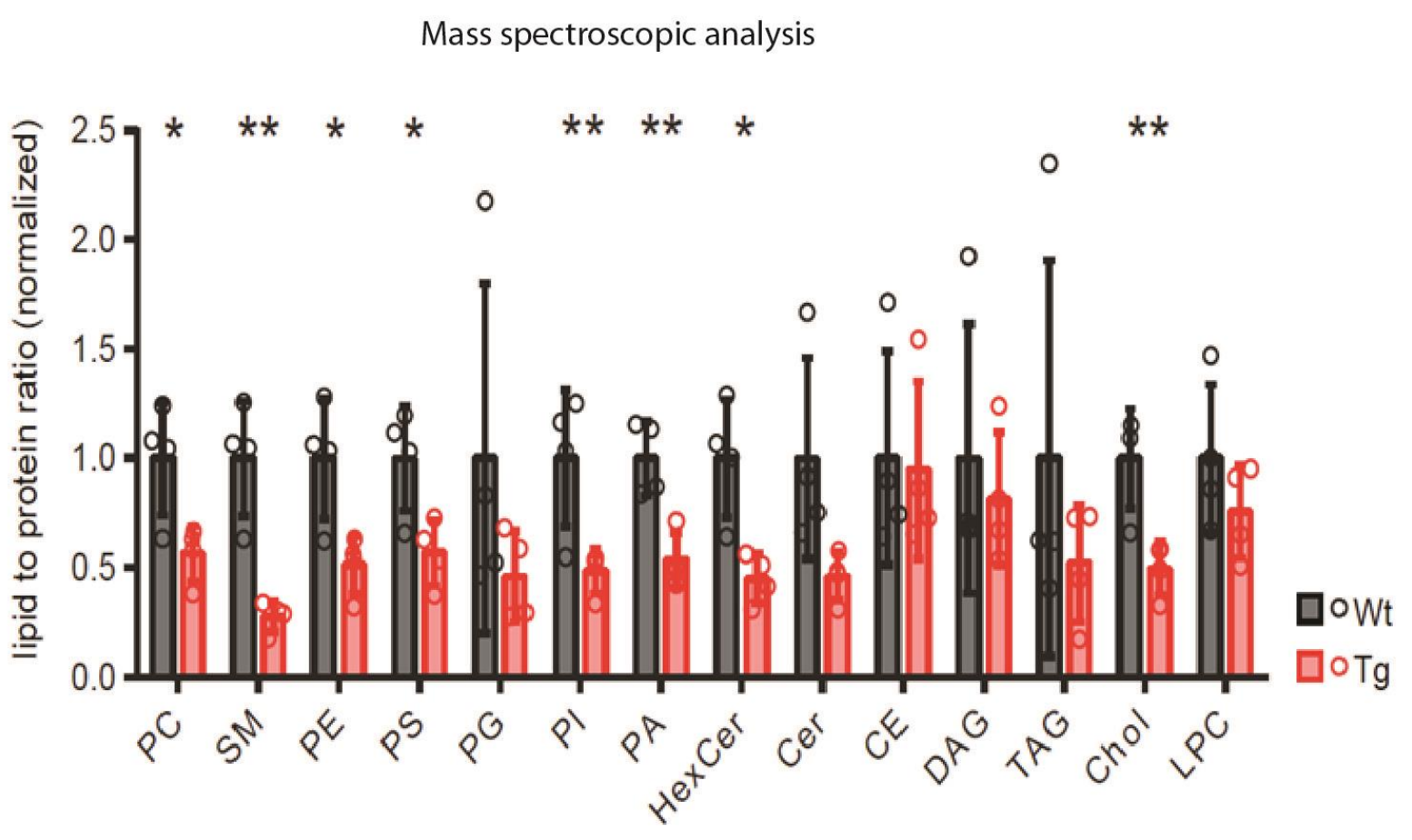

Figure 9: Disturbed lipid biosynthesis is leading to disturbed lipid to protein ratio: Normalization of the measured lipid classes amount pre sample to the myelin fraction protein content has revealed a significant reduction in lipid to protein ratios of lipid classes (PC: phosphatidylcholine, SM: sphingomyelin, PE: phosphatidylethanolamine, PS: phosphatidylserine, PI: phosphatidylinositol, PA: phosphatidic acid, HexCer: hexylceramide, Chol: cholesterol) in transgenic rats compared to wildtype rats while other lipid classes (PG: phosphatidylglycerol, Cer: ceramide, CE: cerebroside, DAG: diacylglycerol, TAG: triacylglycerol) showed a non significant reduction in lipid to protein ratio. Nonadjusted $p$-values are shown (student Ttest). In collaboration with Prof. Britta Brügger at Heidelberg University.

In order to compare lipid/protein ratios of wildtype versus Pmp22 tg lipid classes amount in myelin fraction, measured lipid classes amounts were normalized to myelin fraction's protein content. We could record a significant reduction of major lipid classes including phospholipids (phosphatidylcholine, phosphatidylethanolamine, phosphatidylserine, phosphatidylinositol) phosphatidic acid, sphingomyelin, hexylceramide and cholesterol in transgenic rats compared to wildtype rats. Other lipid classes, including phosphatidylglycerol, ceramide, cerebroside, diacylglycerol, triacylglycerol also seemed to be reduced but without reaching significance (Fig.9). In line, previous assessment by thin layer chromatography has revealed a remarkable reduction of major lipid classes in Pmp22 tg compared with wildtype myelin (Sereda etal. unpublished). 


\section{Results}

Such remarkable reduction of phospholipids, plasmalogens and cholesterol is clearly indicative not only of a strong reduction of lipid biosynthesis but also a disturbed stoichiometry of myelin lipid composition. Therefore, we hypothesized that counteracting the consequences of Pmp22 overexpression on lipid biosynthesis and eventually myelin sheath formation via lipid supplementation could be a potential therapeutic approach. This in turn has raised the question which lipid class or category we should supplement and in which paradigm it should be applied.

In depth analysis of omics data revealed that phospholipids could be the most suitable lipid class for supplementation:

In order to decide about which lipid class should be supplemented and support myelination, we have carried out an in-depth bioinformatics analysis combining the RNA-seq and lipidomics analysis results and comparing the wildtype and Pmp22 tg data sets. Interestingly, genes encoding the enzymes mediating the biosynthesis of the downregulated lipid classes were significantly reduced transcriptionally during developmental myelination especially the ones involved in phospholipids (Fig.10), cholesterol and glycosphingolipid biosynthesis.

Among phospholipids, phosphatidylcholine is considered as a major myelin component. Hence combined omics analysis has revealed that its biosynthesis is severely impaired in sciatic nerves's Schwann of CMT1A rats (Fig.11). Strong downregulation of anabolic enzymes' genes (CHKA: choline kinase alpha, PCYT1a \& PCYT1b phosphate cytidylyltransferase 1, choline, alpha and beta and CHPT1: choline phosphotransferase 1) as well as catabolic enzymes's genes (PLA2(PLA2G4A): phospholipase A2 group IVA and GPC-PDE (GPCPD1): glycerophosphocholine phosphodiesterase 1) was prominent during developmental myelination. This suggested that phospholipids may be best lipid class which can be used for lipid supplementation in CMT1A. 


\section{Results}

Phospholipid metabolism
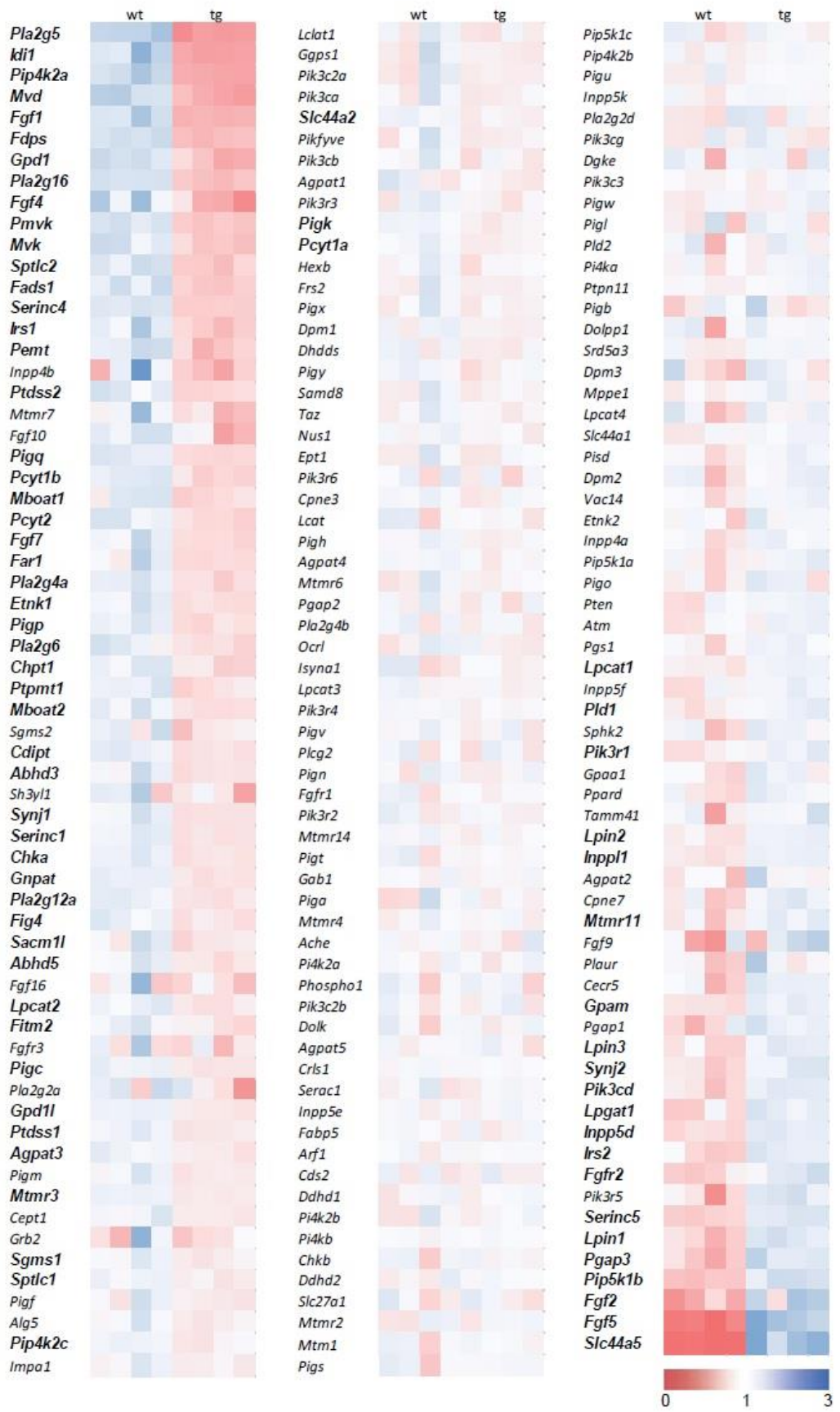

Figure 10: Gene Ontology (GO) gene sets for the major myelin lipid classes. Shown here are visualization of alterations between wildtype ( $\mathrm{Wt}$, $\mathrm{n}=4)$ and CMT rat $(\mathrm{Tg}, \mathrm{n}=4)$ mRNA expression in sciatic nerve at P18. The presented gene sets is for phospholipid biosynthetic process (M11978). The gene identifier is given to left of each color coded expression and bold indicates statistically significant regulation. In collaboration with Prof. Stefan Bonn, DZNE Göttingen. 


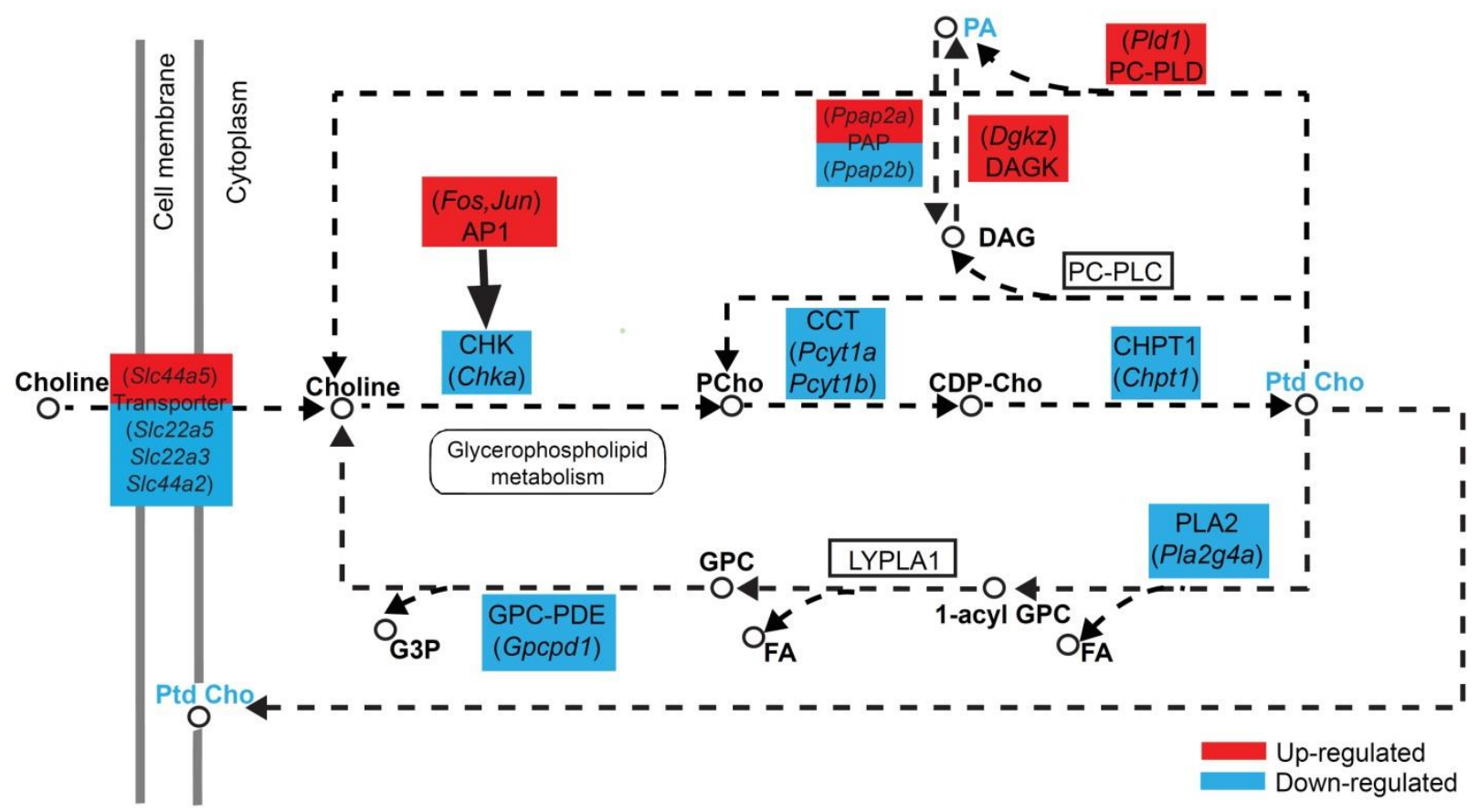

Figure 11: Choline pathway is downregulated in CMT1A Schwann cell: Downregulation in the choline metabolism pathway is shown as a representative pathway for the observed major downregulation of lipid biosynthesis on the transcriptomic (based on RNAseq data) and lipidomic (based on mass spectroscopic analysis of the myelin fraction) levels. Differentially expressed genes involved in choline metabolism as well as pathway intermediates in Pmp22 Tg versus wildtype sciatic nerves at age P18 are depicted. Choline metabolism pathway is drawn on the basis of "Choline metabolism in cancer" KEGG pathway. Transcriptional status of the depicted genes as well as pathway intermediates is explained by the different colors given and explained in the legends (blue: downregulated in transgenics compared to wildtype \& Red: upregulated in transgenics compared to wildtype). Up and down regulated genes (adjusted p-value < 0.05). Circles are representing the lipid products. In collaboration with Prof. Stefan Bonn, DZNE Göttingen.

\section{Improvement of myelination through exogenous lipid supplementation:}

\section{$\underline{\text { In vitro phospholipids supplementation }}$}

\section{Phospholipid supplementation could significantly improve myelination efficiency in in vitro:}

In order to test the hypothesis of phospholipids supplementation, I have evaluated, previously, the impact of phospholipids supplementation in vitro. Using mouse DRG cocultures, I could show that there is a strong reduction in the number of myelinated segments, per culture, in Pmp22 tg (Tg) cocultures compared to wildtype (Wt) cocultures. 
Given the fact that these cocultures were prepared using similar numbers of cells per coverslip, this indeed showed that this in vitro system is recapitulating the CMT1A Schwann cell reduced myelination efficiency in vivo. I, then, treated Pmp22 tg as well as wildtype cocultures with phosphatidylcholine $(2 \mu \mathrm{g} / \mathrm{ml}$ delipidated serum medium) at the same time of myelination induction.Upon quantification of myelinated segments number, I have noticed a significant increase in the number of myelinated segments, as revealed by myelin basic protein (MBP)
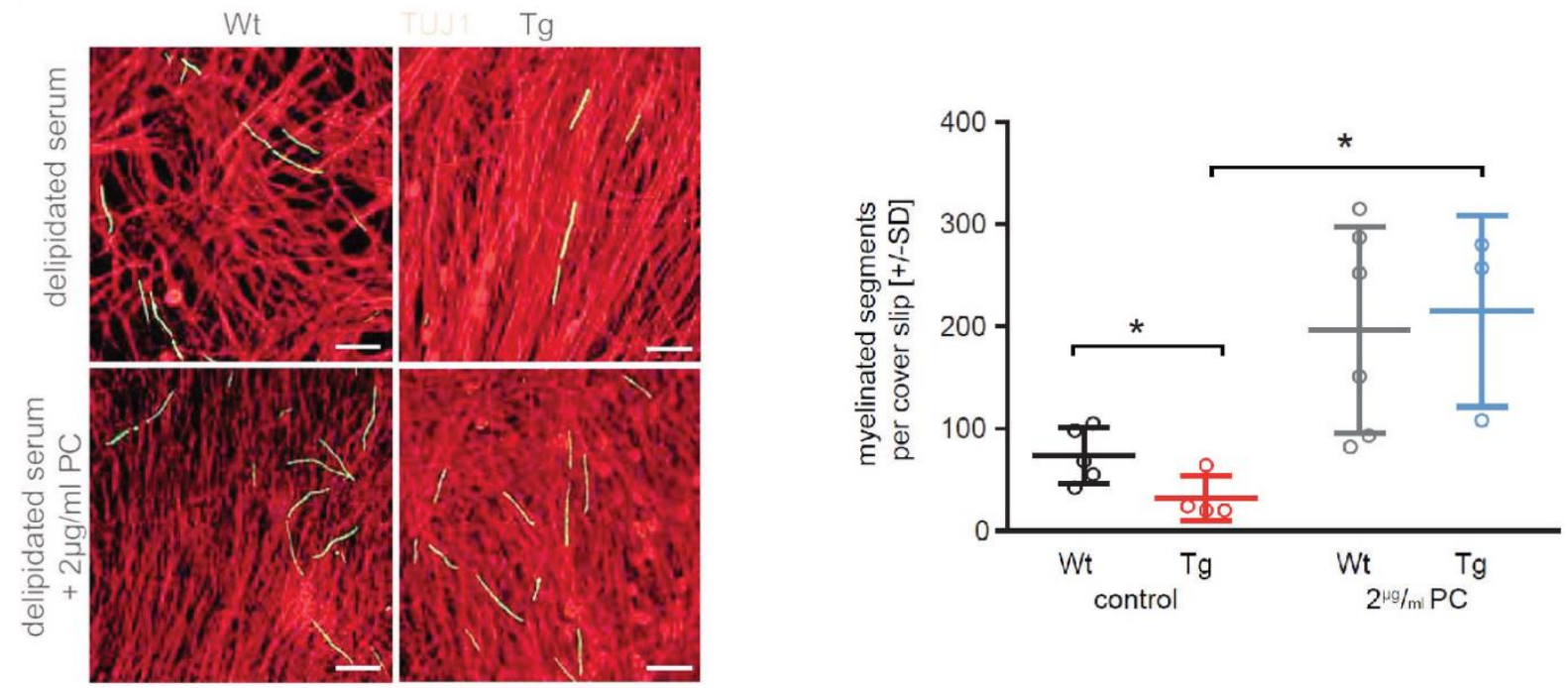

Figure 12:Pmp22-tg (CMT1A) Schwann cell Phosphatidylcholine supplementation improves myelination in vitro: Wild type (Wt) and Pmp22 transgenic (Tg) cocultures show a reduced myelination capacity in a myelination medium supplemented with delipidated serum. Addition of $2 \mu \mathrm{g} / \mathrm{ml}$ phosphatidylcholine to the culture medium, supplemented with delipidated serum, strongly improved myelination in $\mathrm{Wt}$ as well as $\mathrm{Tg}$ cocultures. Representative images of cultures 10 days post-myelination induction are shown (left) as well as quantification of the number of myelin segments (left). Myelin is immunostained for MBP (green), neuronal fibers for TUJ1 (red). n=3-6 per group, one way ANOVA and Sidak's multiple comparison post test, *p-value $<0.05$.

stainning, per coverslip in Pmp22 tg as well as wildtype cocultures (Fig.12). Such improvement is indicating the beneficial impact of phospholipid supplementation on myelination in vitro.

\section{Exogenous phospholipids are incorporated into myelin membrane directly in vitro and in vivo:}

The remarkable improvement of myelination in vitro due to exogenous lipids supplementation has lead us to question whether the supplemented lipids are actively incorporated into myelin sheath directly or it just a passive accumulation of the assimilated lipids. In order to answer this question, I have supplemented wildtype DRG neurons-Schwann cells cocultures with 


\section{Results}

Phosphatidylcholine fluorescently labeled at one of fatty acid tails (Bodipy-PC) in the same treatment paradigm of the previous experiment. Interestingly, I could notice an evident colocalization of myelin specific signal, myelin basic protein (MBP) signal, and fluorescently labeled phosphatidylcholine (Bodipy-PC) (Fig.13A; upper panel). This is indicating that exogenously supplemented lipids could rescue the disturbed myelination through direct incorporation into myelin sheath. Upon treatment of the wildtype cultures with Bodipy, fluorescent head group attached to pentanoic acid, alone in the same treatment paradigm, the examination of the myelinated segments has revealed that there is no Bodipy signal which is colocalized with the myelin, MPB, signal (Fig.13A; lower panel). This, in turn, is ruling out the possibility that the Bodipy-PC fluorescent signal, in the previous treatment, is due a passive accumulation of Bodipy-PC in the myelin sheath layers.

In order to check the possibility of translating the in vitro findings in vivo, I have checked the possibility of exogenous phosphatidylcholine incorporation in the myelin sheath when increasing its systemic level. Therefore, I have injected Bodipy-PC (PC; $500 \mu \mathrm{g} / 25 \mu 1$ ethanol) in the tail vein of wildtype rats, at postnatal day 15 (P15), during the peak of developmental myelination. At P22, examination of the longitudinal sciatic nerves' section immunostained for MBP has revealed that there is a clear colocalization of MBP signal and Bodipy-PC (Fig.13B). Such colocalization is indicating that exogenously injected fluorescent phosphatidylcholine has been incorporated in the newly formed myelin layers formed during developmental myelination after injection. 


\section{Results}

Taken together, exogenous phospholipids active incorporation into myelin sheath in vitro and in vivo is implying that increasing phospholipids systemic bioavailability during developmental myelination may improve myelination efficiency in the peripheral nerves of CMT1A (Pmp22 $\mathrm{tg})$ rats. Therefore, we have decided to translate the previously described findings in vivo through conducting an experimental therapy treatment trial to evaluate the impact of phospholipids supplementation therapy on peripheral nervous system myelination.

A
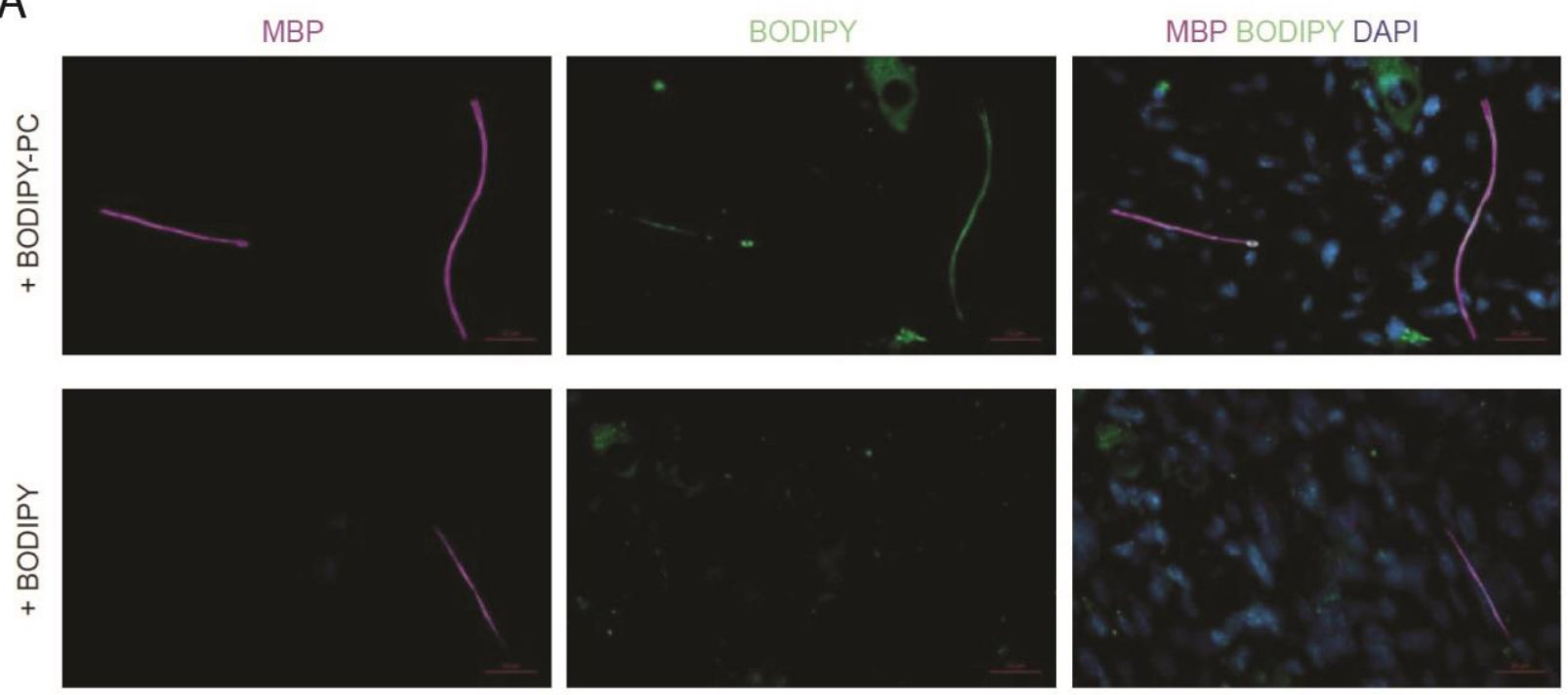

B

MBP

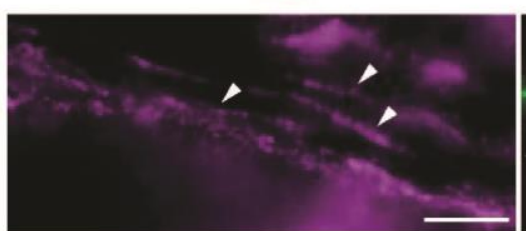

BODIPY

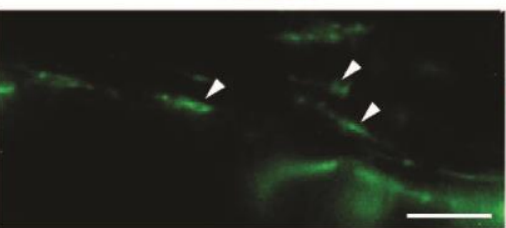

MBP BODIPY

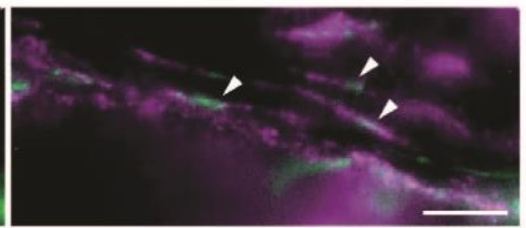

Figure 13:Phosphatidylcholine (PC) is incorporated in the myelin internodes in vitro and in vivo: Supplemented fluorescent labled-PC, BODIPY-phosphatidylcholine (BODIPY-PC); $2 \mu \mathrm{g} / \mathrm{ml}$ medium to the delipidated serum supplemented-myelination medium was assimilated by the myelinating Schwann cells and incorporated in the newly formed myelin internodes in vitro (Upper panel in A). Control BODIPY (tagged to pentanoic acid) was not incorporated into the myelin membranes (lower panel in A) showing that BODIPY-PC in not passively taken up by the myelinating Schwann cells. Likewise, upon BODIPY-PC injection into the tail vain of a 15 days old CMT rat, i.e. during developmental myelination, longitudinal sciatic nerve, seven days after injection, cryo-sections have shown incorporation of BODIPY-PC into the myelin internodes (arrow heads) in vivo (B). (BODIPY-PC, green) and (magenta, MBP). Scale bar $=20 \mu \mathrm{m}$. 


\section{Results}

\section{In vivo phospholipids supplementation}

\section{Early short term (P2-P21) lecithin therapy treatment could improve myelination in CMT1A rat models' peripheral nerves:}

In order to check whether phospholipids supplementation can promote myelination in vivo, I have carried out a lecithin, composed of Phosphatidylcholine, phosphatidylethalonamine and trace amounts of other lipids, experimental therapy treatment. In this early short term paradigm, we have fed Pmp22 transgenic rats with 3\% lecithin enriched chow food. The treatment was commenced from postnatal day 2 (P2) until postnatal day 21(P21) in order to check the impact of the treatment on developmental myelination (Fig. 14A). Muscle strength phenotyping through rats' limbs grip strength assessment, at the end of the treatment, has revealed that early short term lecithin therapy treatment could improve muscle strength of the Pmp22 tg rats compared with the non-treated transgenic group (Fig.14B; left panel). On the other hand, the lipid diet was well tolerated by the animals and had no effect on animals' weight as no weight difference was detected after the treatment (Fig.10B; right panel). Histological, light microscopic, examination of tibial nerve cross sections revealed that lecithin treatment could significantly increase the number of myelinated axons per nerve. Quantification of the number of myelinated axons per tibial nerve has confirmed such significant improvement in the treated transgenic group (Fig.14 C\&D).

This indicates that the treatment could enhance developmental myelination efficiency in Pmp22 tg peripheral nerves. Electrophysiological evaluation of nerve conduction velocity (NCV) of sciatic nerve and compound muscle action potential (CMAP) of the foot muscle has shown no improvement in the treated versus untreated Pmp22 transgenic rats (data not shown). 


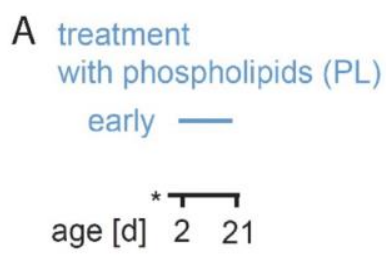

B

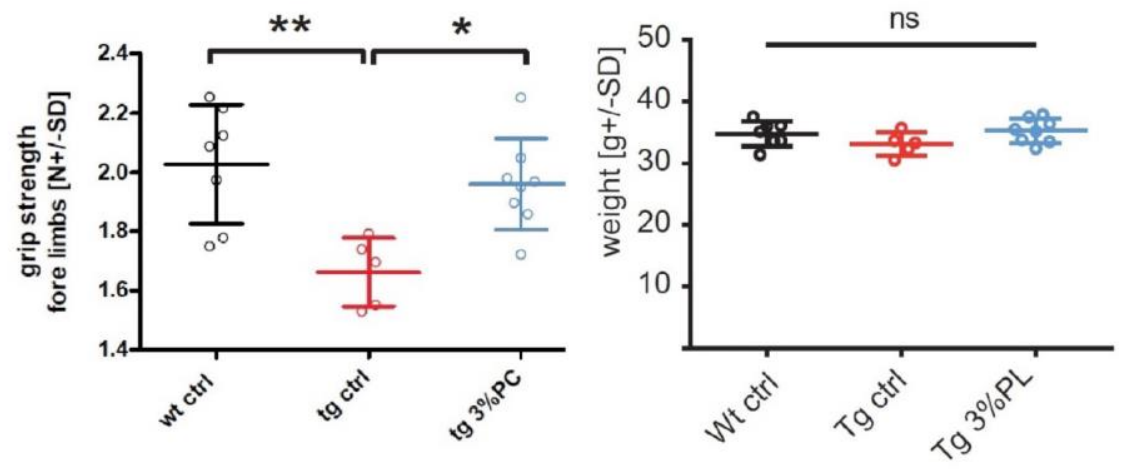

C

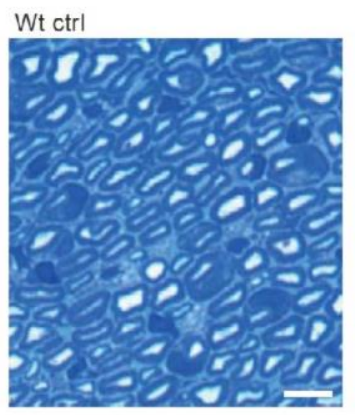

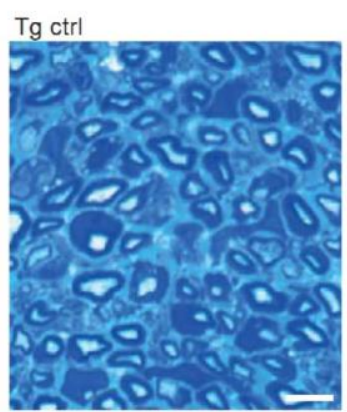

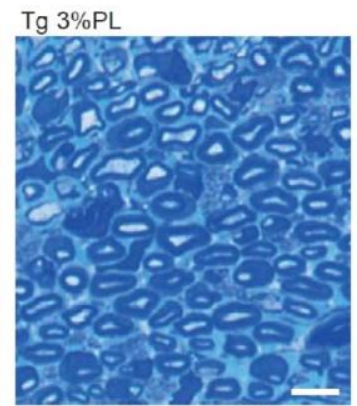

D

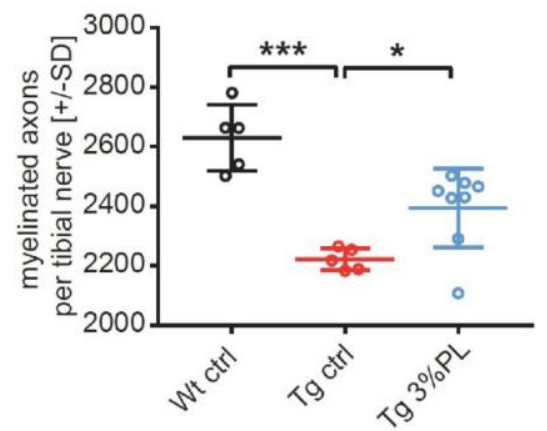

Figure 14:Early short term phospholipid therapy ameliorates CMT neuropathy symptoms: (A)Two cohorts of CMT rats were fed with either normal diet or a food enriched with 3\% phospholipids (PL, see methods section for detail) from postnatal day (P) 2 to P21 (early short term. (B) Treatment of one cohort was terminated and the cohort was analyzed at P21. Tg ctrl rats (red, n=5) showed a reduction in grip strength compared to Wt controls (black, $n=7$ ). Treatment with $3 \%$ PL from P2 to P21 improves grip strength in CMT rats (blue, $n=8$ ) (Left panel). Body weight measurement reveals no difference between the groups (right panel). One way ANOVA, Sidak's post test p-value: $*<0.05, * *<0.01$, ns: not significant. (C) Representative light microscopic images obtained from tibial nerve cross section at P21. Microscopic examination reveals a reduction in the number of myelinated axons in the Tg ctrl rats compared to Wt rats which was partially ameliorated in the Tg treated group (Tg3\% PL). (D) Quantification of the number of myelinated fibers per tibial nerve in the groups represented in (C) CMT rats (red, $n=5$ ) reveals less myelinated fibers compared to Wt controls (black, $n=5$ ). Treatment of CMT rats with 3\% PL (red, $n=8$ ) significantly improves the number of myelinated fibers. Oneway ANOVA, Tukey's post test, p-value: $*<0.05, * * *<0.001$. Scale bar: $10 \mu \mathrm{m}$.

\section{Cessation of the lecithin treatment leads to lose of the beneficial effect:}

Since early short term treatment paradigm has been proven beneficial, I wanted to check whether or not the treatment impact is long lasting after treatment cessation. Therefore, I have subjected another rat's cohort to the same treatment paradigm (P2-P21) and monitored the treatment 


\section{Results}

impact afterswitching to normal food. Grip strength analysis has revealed that although the beneficial treatment effect was still noticeable at postnatal day 30 (P30), it has disappeared at latter time points; P50 and P75 (Fig.15). This indicates that lecithin treatment may be needed to be applied continuously to maintain the treatment beneficial effect.

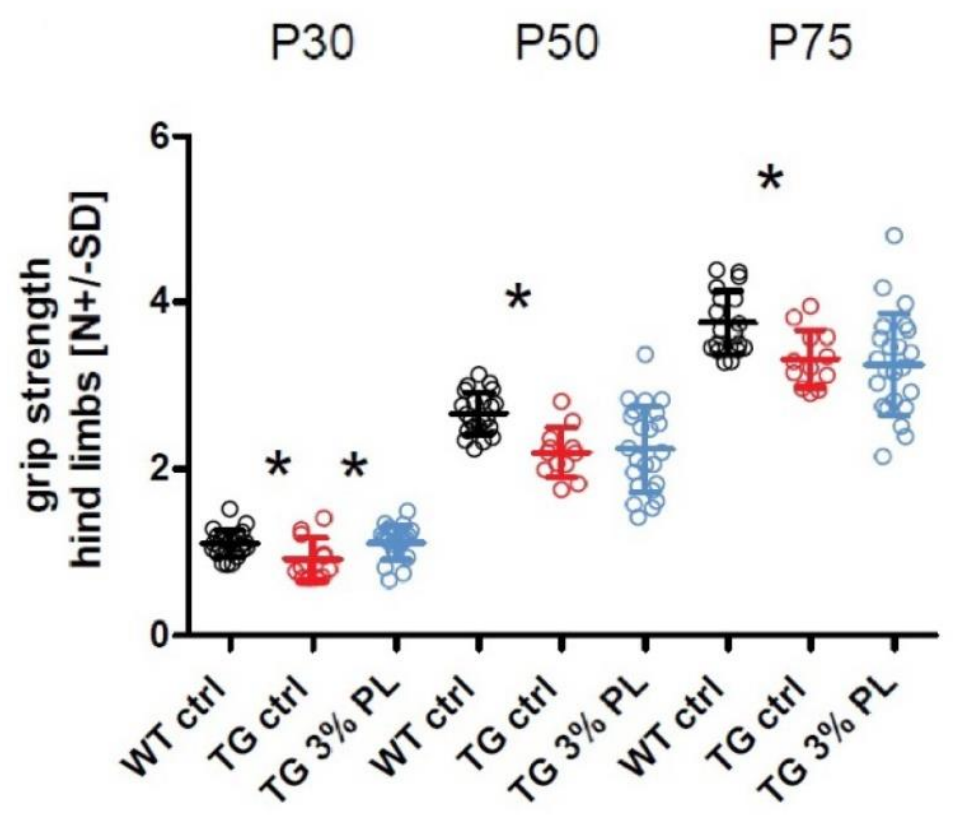

Figure 15: Late effect of early short term lecithin treatment: The second cohort of treated (P2-P21) rats was switched to normal food and it motor performance was analyzed at P30, P50 and P75. An improvement-due to-treatment in grip strength is observed in $\mathrm{Tg} 3 \% \mathrm{PL}$ (blue, $\mathrm{n}=21$ ) at P30 compared to $\mathrm{Tg}$ ctrl ( $\mathrm{red}, \mathrm{n}=12)$. Such improvement wasn't visible at latter time points $\mathrm{P} 50$ and P75, while both groups were weaker than Wt ctrl (black, $n=22$ ). One-way ANOVA, Tukey's post test, pvalue: $*<0.05$.

\section{Long term (P2-P112) lecithin therapy treatment could remarkably rescue some of disease histological features in CMT1A rat models:}

In order to check whether lengthening the duration of the lecithin treatment will have more beneficial impact on myelination and disease progression of CMT1A disease in the rat model. Lennart Rash (MD student) has conducted a long term treatment paradigm in which has fed the rats with the lecithin enriched chow food, either at $0.3 \%$ or $3 \%$ soy bean derived phospholipids, from postnatal day $2(\mathrm{P} 2)$ to postnatal day 112(P112). In his analysis, motor phenotyping (grip strength), muscle circumference analysis have shown that there a remarkable improvement in motor in the lecithin treated CMT1A rats compared with the untreated transgenic group. In line, there was a significant improvement in rat's sciatic nerve conduction velocities (NCV) as well as compound action potential (CMAP, unpublished). This in turn has motivated us to find out the histological correlates of such remarkable improvement on the level of myelination efficiency in peripheral nerves. 


\section{Results}

\section{Lecithin long term supplementation rescues the number of myelinated axons in peripheral nerves of CMT1A rodents:}

Light microscopic examination of the tibial nerves has revealed that there is a remarkable increase in the number of myelinated axons per nerve in 3\% lecithin treated group compared with the untreated transgenic group (Fig. 16B; left panel). Furthermore, quantification of the number of myelinated axons per tibial nerve has revealed that there is a significant rescue of the number of myelinated axons per tibial nerve of 3\% lecithin treated Pmp22 transgenic rats group to an extent reaching the wildtype level (Fig. 126; right panel). In order to evaluate the impact of long term treatment paradigm on the myelin morphology characteristics including myelin sheath thickness and myelin ultrastructure.

Examination of electron micrographs of the tibial nerve cross sections, carried out by Lennart Rasch, has revealed that the treatment couldn't rescue the disturbed myelination phenotype characteristic for CMT neuropathy. The treatment couldn't rescue the hypermyelination of the small to mid-caliber axons and the hypomyelination of the large caliber axons. Precise quantification of the myelin sheath thicknesses relative to the corresponding axons' calibers, i.e.: $g$ ratio, has revealed that the $g$ ratio of the $3 \%$ lecithin treated transgenic group was even lower than the already reduced $g$ ratio of untreated transgenic control group. This is indicating an increase in hypermyelinated axons per tibial nerve. These observations could be even more obvious when the g ratio data was plotted against the axons caliber as the treatment did not change the steepness degree of the regression line of the Pmp22 $\operatorname{tg} g$ ratio in case of the 3\% lecithin treated transgenic group. 


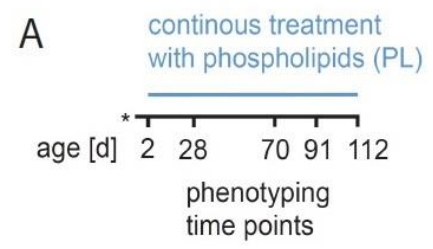

B
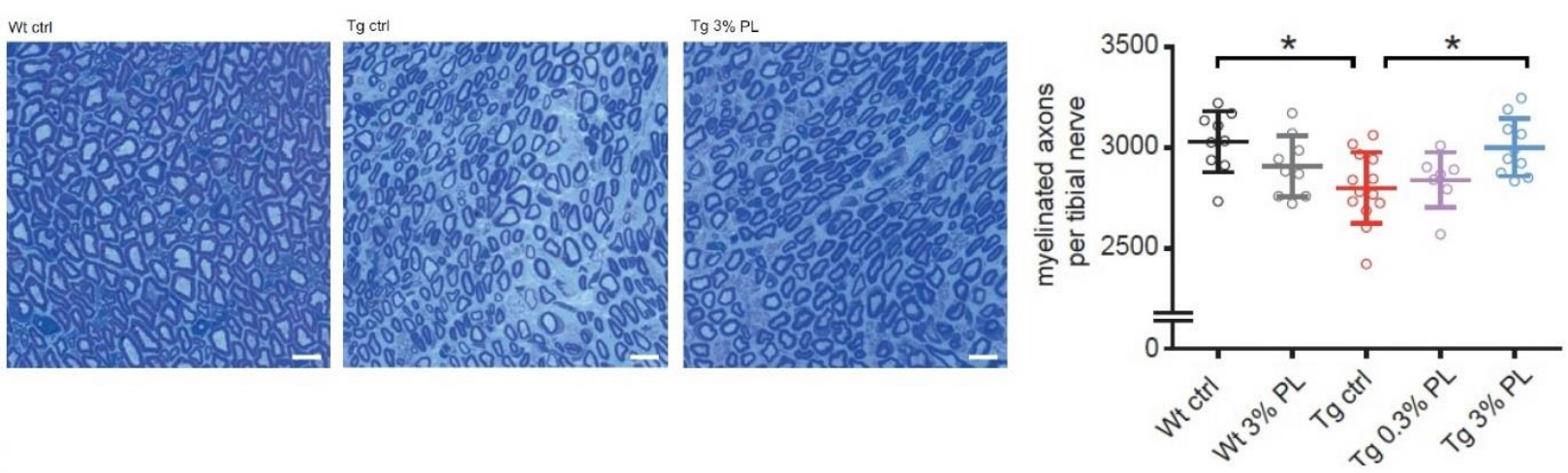

Figure 16:Improved motor phenotype and electrophysiological aspects due to long term phospholipid therapy are coinciding with improved number of myelinated axons per peripheral nerve : (A) Treatment scheme. CMT rats (Tg) as well as wildtype rats $(\mathrm{Wt})$ where fed with either normal diet, or a food enriched with $0.3 \%$ or $3 \%$ phospholipids (PL) from postnatal day (P) 2 to P112. (B) Representative images of tibial nerve's semi-thin cross sections (left panel) of Wt ctrl (left), Tg ctrl (middle) and Tg 3\% PL (right) are showing a reduced myelinated fiberes density in Tg ctrl compared to Wt ctrl, which is remarkably ameliorated in Tg $3 \%$ PL. Scale bar: $10 \mu \mathrm{m}$. Quantification of the number of myelinted fibers per tibial nerve's cross sections (right panel) is reveling an increased number of myelinated fibers, at P112, in case of 3\% PL, but not in case of 0,3\% PL treatment (Wt ctrl, black, $\mathrm{n}=9$; Wt 3\% PL, grey, n=9; Tg ctrl, red, $n=13$; Tg 0.3\% PL, purple, $n=7$; Tg 3\% PL, blue, n=10). One-way ANOVA, Tukey's post test, pvalue $*<0.05$.

\section{Lecithin long term supplementation rescue the mild widening of myelin sheath lamellae in peripheral nerves of CMT1A rodents:}

The previously reported widening of myelin interperiodic distance observed in Pmp22 $\mathrm{tg}$ myelinating cocultures of DRG neurons-Schwann cells ${ }^{153}$ has motivated us to check whether this phenotype is present in vivo. Analysis of Pmp22 transgenic myelin sheath ultrastructure in highly magnified electron micrographs $(80000 \mathrm{x})$ has revealed that there is a mild, but significant, widening of the interperiodic distances compared to the wildtype ones (Fig. 17A). Interestingly, quantification of the interperiodic distances in the myelin sheath of 3\% lecithin treated Pmp22 $\mathrm{tg}$ rats has shown a remarkable rescue of the above described widening of the distance between myelin lamellae reaching the wildtype level (Fig. 13B). 
A

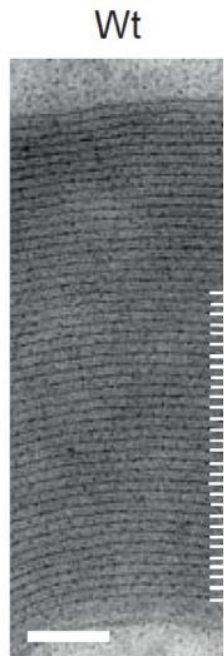

rat tibial nerves
B

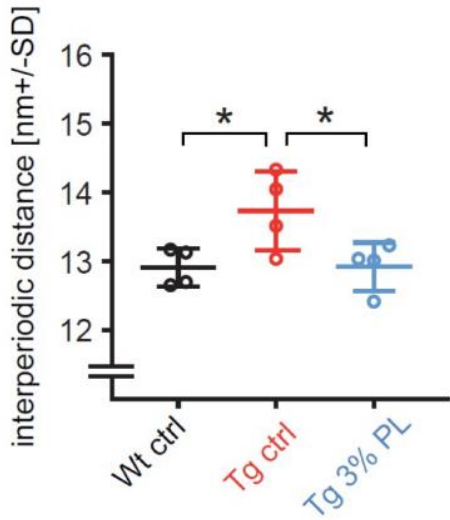

Figure 17:Long term phospholipid therapy improves myelin lamellae periodicity in CMT1A rats: (A) Increased myelin periodicity in CMT (Tg ctrl) rats compared with wildtype (Wt) rats. Representative electron micrographs of tibial nerves cross sections of $\mathrm{Wt}$ and $\mathrm{Tg}$ at $30000 \mathrm{x}$ magnification; scale bar: $50 \mathrm{~nm}$. In the representative electron micrographs, 30 consecutive major dense lines are marked with white ticks in $\mathrm{Wt}$ and well as $\mathrm{Tg}$ micrographs. The ticks are spanning longer distance on the Tg side compared with Wt side indicating an increased periodicity in Tg. (B) Ameliorated myelin periodicity in CMT rats after PL treatment. Interperiodic distance quantification of $\mathrm{Wt}, \mathrm{Tg}$ as well as Tg 3\% PL (P2P112) rats ( $\mathrm{n}=4$ per group, one way ANOVA, Holm-Sidak's multiple comparison post test). A minimum of 20 periods per fiber in at least 20 fibers per animal were measured.

\section{Lecithin treatment couldn't rescue the disturbed myelin morphology in CMT1A rat model:}

In our quest to try to find a histological correlate which may explain the slightly improved nerve conduction velocity, we conducted a deeper myelin morphology analysis. Therefore, I have prepared teased fibers specimens from the sciatic nerves of the wildtype (Wt), Pmp22 $\operatorname{tg} \operatorname{ctrl}(\mathrm{Tg}$ ctrl) and 3\% lecithin treated Pmp22 tg (Tg 3\% PL) rats. Fluoromyelin staining, a stain which is absorbed preferably by the lipid enriched membranes, of the myelin sheath in the teased fibers samples has enabled myelin intermodal length determination. Analysis of the intermodal length measurements has revealed that there is a striking reduction in the intermodal length of $\mathrm{Tg}$ ctrl rats' peripheral nerves compared with Wt ctrl. Such reduction couldn't be rescued in the 3\%lecithin treated transgenic rats $(\mathrm{Tg} 3 \% \mathrm{PL})$. This can be readily perceived from intermodal length averages comparison (Fig. 18A) as well as the relative frequency distribution of the measured intermodal length (Fig. 18B). 
Since the nodes of Ranvier are characterized by enrichment of sodium channels, $\mathrm{Na}_{\mathrm{v}} 1.6$ subtype, I have made use if that in order to measure the nodal length. Analysis of immunohistochemically stained teased fibers samples for $\mathrm{Na}_{\mathrm{v}} 1.6$ has revealed that there is a significant increase in the nodal length in Tg ctrls compared to Wt ctrls. Such nodal length increase couldn't be rescued in 3\% lecithin treated group (Tg 3\% PL) (Fig.18C).

A

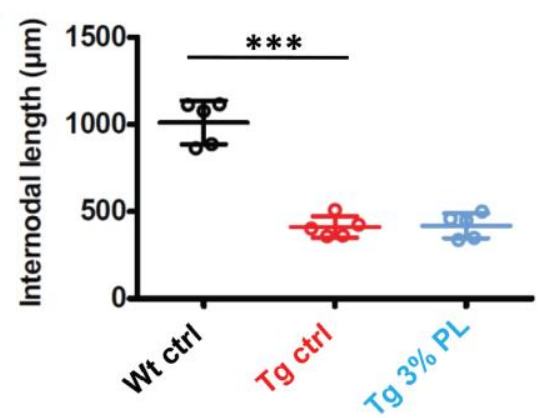

C

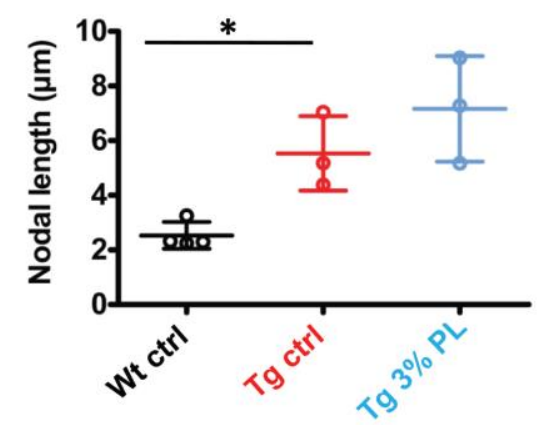

E

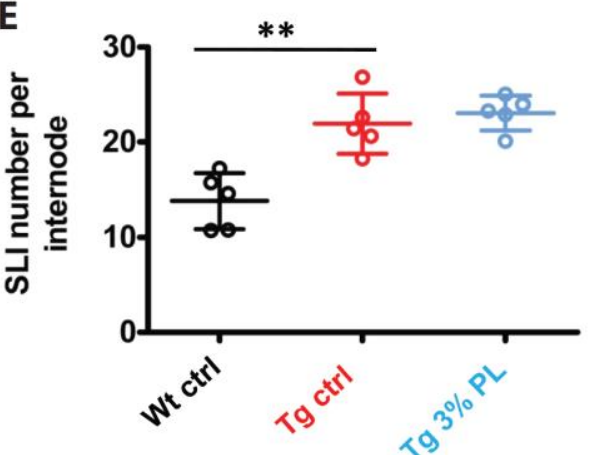

B

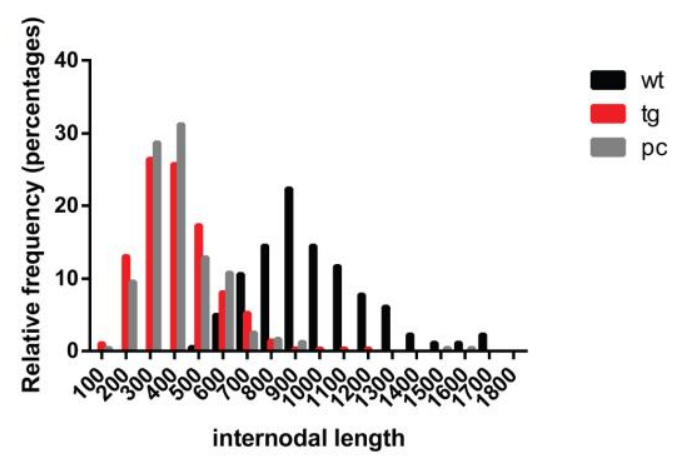

D

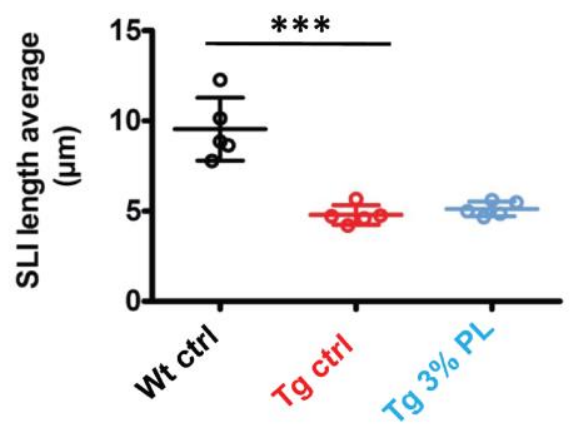

$\mathbf{F}$

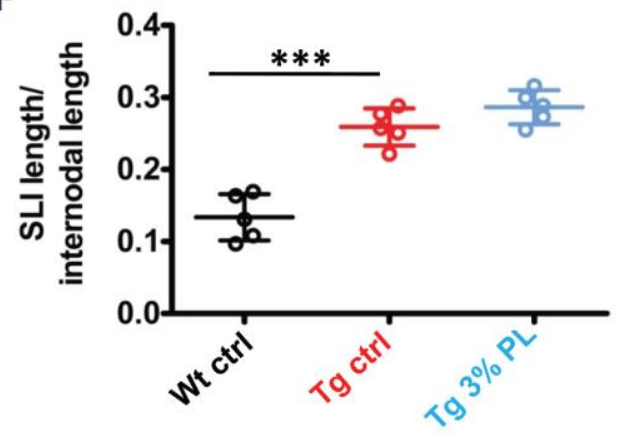

Figure 18:long term phospholipid therapy had no impact on myelin morphology: (A) Myelin sheath internodal length measured in teased fibers, of wildtype (Wt ctrl)\& Pmp22 tg (Tg ctrl) and 3\% lecithin treated Pmp22 tg (Tg 3\% PL), samples prepared from sciatic nerves revealed that long term treatment couldn't rescue the reduced intermodal length in $P m p 22 \mathrm{tg}$ (Tg ctrl). (B) Relative frequency distribution of intermodal length measurements presented in A showing that the $3 \%$ lecithin treatment couldn't rescue the shift in Tg ctrl intermodal length relative to wildtype. (Wt ctrl, black, $\mathrm{n}=5 ; \mathrm{Tg}$ ctrl, red, $\mathrm{n}=5 ; \mathrm{Tg} 3 \%$ $\mathrm{PL}$, light blue or gray, $\mathrm{n}=5$ ). One-way ANOVA, Tukey's post test, $\mathrm{p}$-value $* * *<0.0001$. (C) Nodal length comparison derived from sodium channel ( $\mathrm{Na} \mathrm{v} \mathrm{1.6)} \mathrm{staining} \mathrm{is} \mathrm{showing} \mathrm{a} \mathrm{significant} \mathrm{increase} \mathrm{in} \mathrm{nodal} \mathrm{length} \mathrm{on} \mathrm{Tg} \mathrm{ctrl} \mathrm{compared} \mathrm{to} \mathrm{Wt} \mathrm{ctrl} \mathrm{which}$ was rescued in Tg 3\% PL. (Wt ctrl, black, $n=4$; Tg ctrl, red, $n=3$; Tg 3\% PL, light blue, $n=3$ ). One-way ANOVA, Tukey's post test, p-value $*<0.05$. Schmidt Lantermann incisures analysis derived from teased fibers stained for myelin associated glycoprotein (MAG) revealed that there is no improvement in Tg ctrl group's reduced SLI length (D), pathologically increased SLI (E) and total SLI length per intermodal length (F) in the 3\% Tg PL group. (Wt ctrl, black, n=5; Tg ctrl, red, n=5; Tg 3\% PL, light blue or gray, $\mathrm{n}=5$ ). One-way ANOVA, Tukey's post test, $\mathrm{p}$-value $* *<0.001, * * *<0.0001$. 


\section{Results}

Schmidt Lantermann incisures (SLIs) which is a myelin unique morphological structure, in the peripheral nervous system, is characterized by the abundance of specific proteins including myelin associated glycoprotein (MAG). Quantification of SLI number per myelin internode has shown that there is a significant increase in the number of SLIs in CMT1A rats' peripheral nerves compared with wildtype peripheral nerve. However, the long term treatment couldn't reduce the number of SLIs per peripheral nerve transgenic treated rats (Tg 3\% PL) (Fig.18D). Moreover, the treatment couldn't rescue the reduction in the single SLI length (Fig.18E) and the increased total sum SLIs length relative to intermodal length in the Tg ctrl group (Fig.18F). 


\section{Results}

\section{Impact of dietary phospholipids supplementation on myelin lipid as well as protein composition:}

\section{Impact on myelin lipid composition:}

Myelin fraction mass spectrometric analysis of wildtype and Pmp22 tg rats' sciatic nerve at P18 has revealed that there is an obvious reduction of all the major lipid classes (Fig. 9). Therefore, I examined whether lipid treatment could rescue that reduction. In order to achieve that, we have prepared sciatic nerve myelin fraction of wildtype, Pmp22 tg and 3\% lecithin treated Pmp22 tg at P112 and subjected them to lipid classes mass spectrometric analysis in collaboration with Prof.Britta Brügger at Heidelberg University. Although stoichiometry of the major lipid classes appeared to be barely altered in CMT1A rat's myelin fraction compared to wildtypes'; only two lipid classes were the mostly disturbed. A relatively significant reduction in phosphatidylethanolamine (plasmalogen) was detected in CMT1A rat's sciatic nerves control which couldn't be rescued by lecithin treatment. The triacylglycerols lipid class was relatively increased in control Pmp22 tg rats as well as treated Pmp22 tg rats compared to wildtypes (Fig.19A).

In order to check whether the lecithin treatment could improve the lipid to protein ratio in myelin fraction, we have normalized the lipid classes measured values to the protein content of the myelin fraction. Normalized Lipid classes' values comparison of wildtype (Wt) as well as untreated (Tg ctrl) and treated transgenic (Tg 3\% PL) rats has revealed that there is a remarkable significant reduction in almost all lipid classes in CMT1A rat myelin. More importantly, lipid to protein ratios in treated CMT1A rats showed obvious trends towards normalization, although the majority of individual lipid classes' did not reach significance when compared with non-treated CMT1A controls (Fig.19B). It is noteworthy that there the observed high variability may be is resulting from the disease severity variability of the animals within the same group which in turn may explain the lack of significance despite the obvious trends towards normalization. 


\section{Results}

\section{Impact on myelin lipid fatty acid chains:}

Another evidence for exogenously supplemented lipids incorporation into myelin sheath could be concluded from analyzing the acyl carbon chain length which is most likely abundant in phospholipids with two C18 acyl chains. Acyl carbon chain analysis has shown that acyl carbon chain 36 percentage is less abundant in CMT1A rats myelin lipids but was rescued after lecithin treatment. In addition, the percentage of 54 acyl carbons (most likely TAGs with three C18 acyl chains) is increased in CMT rats but again reduced after PL treatment (Fig.19C). It is noteworthy that the majority of the supplemented phospholipid species contained a total of 36 acyl carbons in two fatty acid residues and the lecithin enriched diet was comprised of 85\% 18-carbon fatty acids. Therefore, increase of 36 acyl carbon lipids after PL therapy suggests that dietary lipids have been incorporated into the myelin sheath.

\section{Impact on myelin lipid biosynthesis genes transcription:}

In order to check whether a rescue of the lipid biosynthesis genes' transcription is underlying the observed amelioration trend of lipid classes' levels in myelin sheath, we have evaluated the transcriptional levels of major lipid biosynthesis enzymes. Surprisingly, qRT-PCR analysis of sciatic nerve mRNA revealed no improvement of the transcriptional down-regulation of lipid genes including 3-hydroxy-3-methyl-glutaryl-coenzyme A reductase (Hmgcr), fatty acid synthase (Fasn) and choline kinase alpha (Chka) genes in Pmp22 tg rats after 3\% lecithin treatment (Fig.20).

\section{Impact on myelin's protein content:}

As cellular proteins translocation is mediated by lipids, we were interested to know if improving cellular lipids will improve myelin proteins translocation. Therefore, we have carried out a Western blot analysis of the myelin fraction as well as whole nerve lysate isolated the treated Pmp22 tg rats as well as wildtype and untreated transgenic controls. 
A

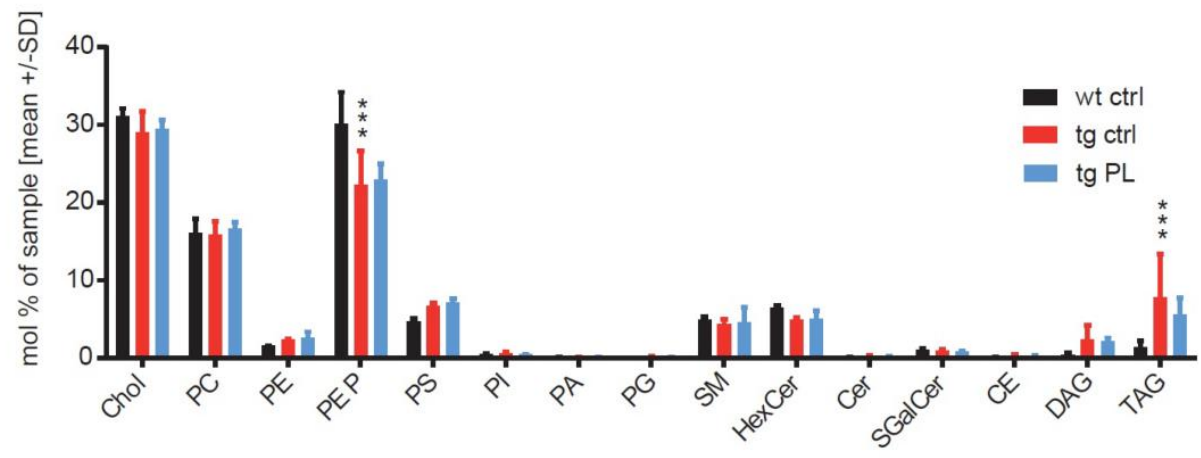

B

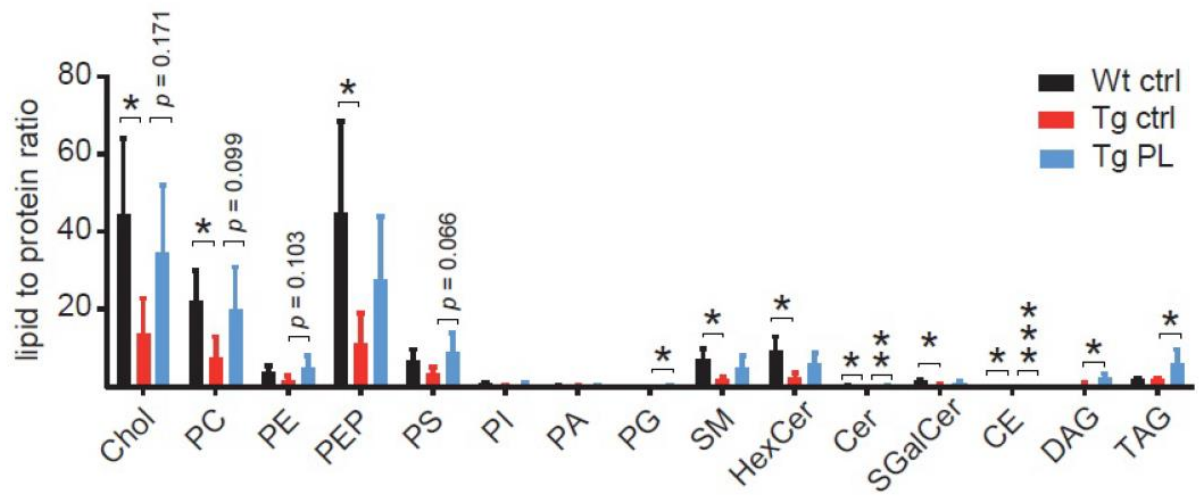

C

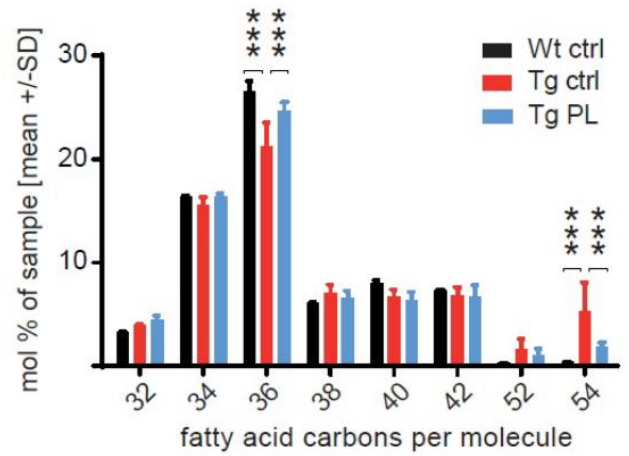

Figure 19:Dietary phospholipid improved myelin's lipid/protein ratio in CMT1A rat model: (A) Mass spectrometric analysis, in collaboration with Prof. Britte Brügger (Heidelberg University), of sciatic nerve myelin from Wt ctrl (black, $n=4)$, Tg ctrl (red, $n=3$ ) and Tg 3\% PL (blue, $n=3$ ) rats, purified after study end (P112), normalized to total lipid content in the samples, shows widely unaltered stoichiometry (mol \%) between Wt, Tg ctrl and Tg PL, except for lower PEP and higher TAG in CMT rats compared to Wt. Adjusted p-values are shown (twoway ANOVA). (B) Normalized lipid classes concentration, in sciatic nerve myelin shown in (A), to myelin protein shows a reduction in many lipid classes in Tg ctrl rats compared to Wt ctrl rats. Despite the observed trend toward increasing lipid classes levels, PL treatment did not significantly improve lipid to protein ratios in purified myelin. Chol: cholesterol, PC: phosphatidylcholine, PE: phosphatidylethanolamine, PEP: PE plasmalogens, PS: phosphatidylserine, PI: phosphatidylinositol, PA: phosphatidic acid, PG: phosphatidylglycerol, SM: sphingomyelin, HexCer: hexylceramide, Cer: ceramide, SGalCer: S-galactosylceramide, CE: cerebroside, DAG: diacylglycerol, TAG: triacylglycerol. Non-adjusted p-values are shown (One way ANOVA). (C) Mass spectrometric analysis of sciatic nerve myelin with respect to the fatty acid chain length abundance displaying the number of acyl carbons per lipid molecule as mol percent per sample (only species $>1$ mol\%). Note that 36 acyl carbon molecules are less abundant in CMT compared to Wt rat myelin and is normalized after PL therapy, suggesting that the supplemented phospholipids (mostly comprised of C18 fatty acids, see methods) have reached the myelin sheath. 

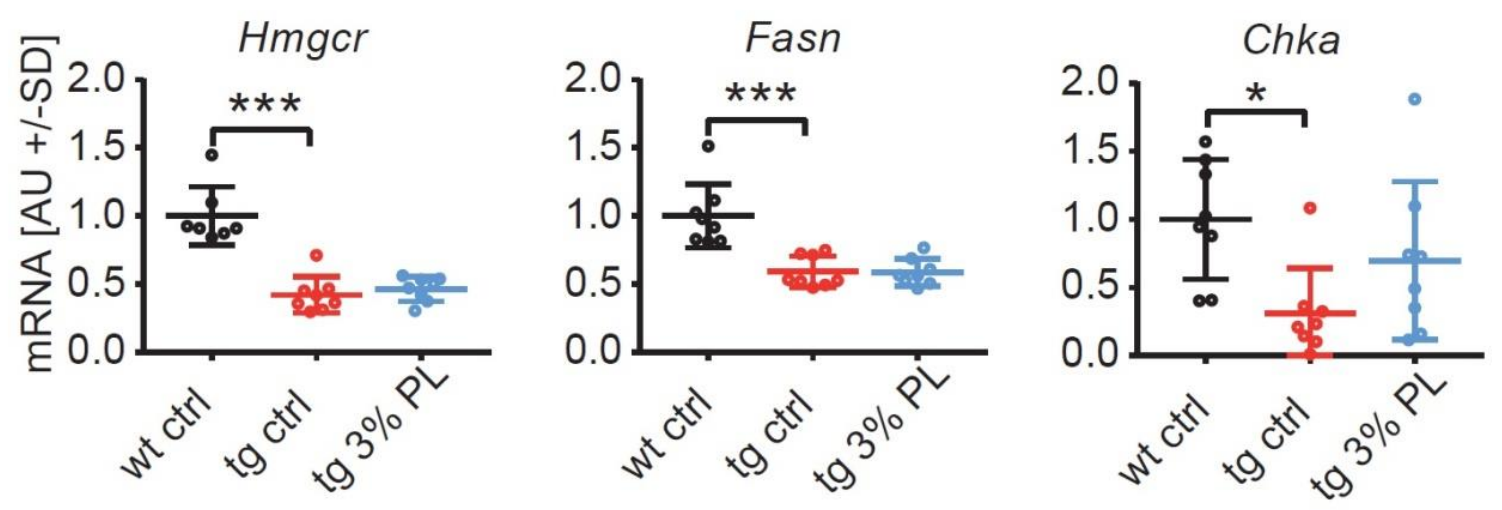

Figure 20:Dietary phospholipids treatments couldn't induce lipid biosynthesis genes transcription: qRT-PCR of P21 sciatic nerve mRNA from treated CMT rats (early short term) shows no improvement of the transcriptionally downregulated lipid genes like Hmgcr, Fasn, Chka, while an improvement of pla2g4a is obvious in Tg rats after $3 \% \mathrm{PL}$ treatment (P2-P21, $\mathrm{n}=8$ per group, one way ANOVA).

Western blot analysis has revealed that there was no major differences in protein content between peripheral myelin protein 22 (PMP22) and myelin protein zero (MPZ) in untreated and Lecithin (PL) treated CMT rats, and when compared to wildtype controls (Fig.21; B left panel \&C right panel).

Interestingly, Myelin Basic protein (MBP) level was slightly increased in myelin after lecithin therapy in CMT rats, but remained unaltered in full nerve lysates (Fig.21; B right panel \& E). Interestingly, upon comparing the relative levels of PMP22 to MBP in the myelin, we could see amelioration of the perturbed ratio in CMT rats' myelin fraction reaching the wildtype level (Fig.21; C left panel).

\section{Impact of dietary long term phospholipids supplementation on Schwann cell differentiation:}

Alleviating CMT1A disease progression on functional, histological levels and myelin lipid composition has motivated us to examine whether such improvements were due to improved Schwann cell differentiation and downstream signaling pathways. Therefore, I have carried out a western plot analysis, using the whole nerve lysate, of the two major Schwann cell differentiation and dedifferentiation pathways; PI3K/AKT and MEK/ERK. Signaling pathway activation 


\section{Results}

A
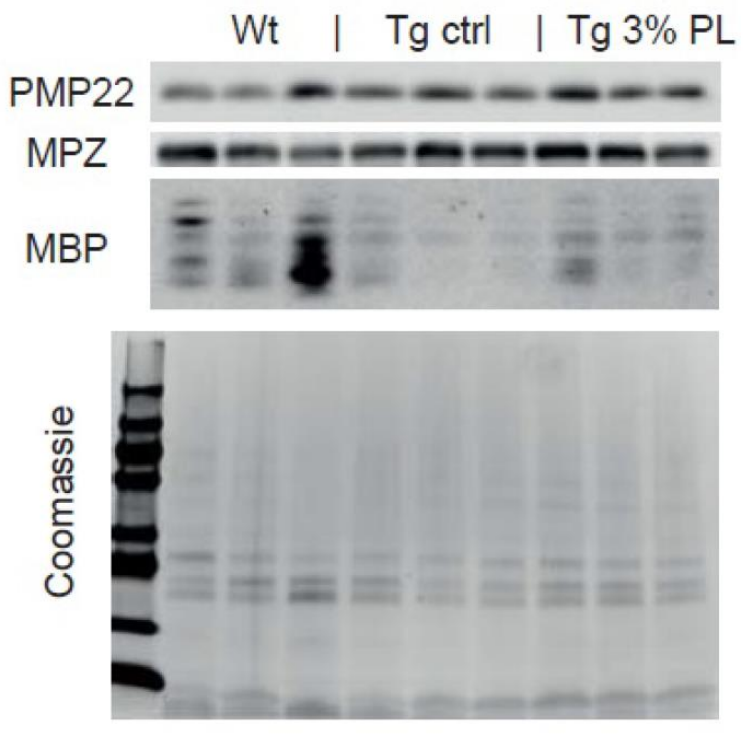

D
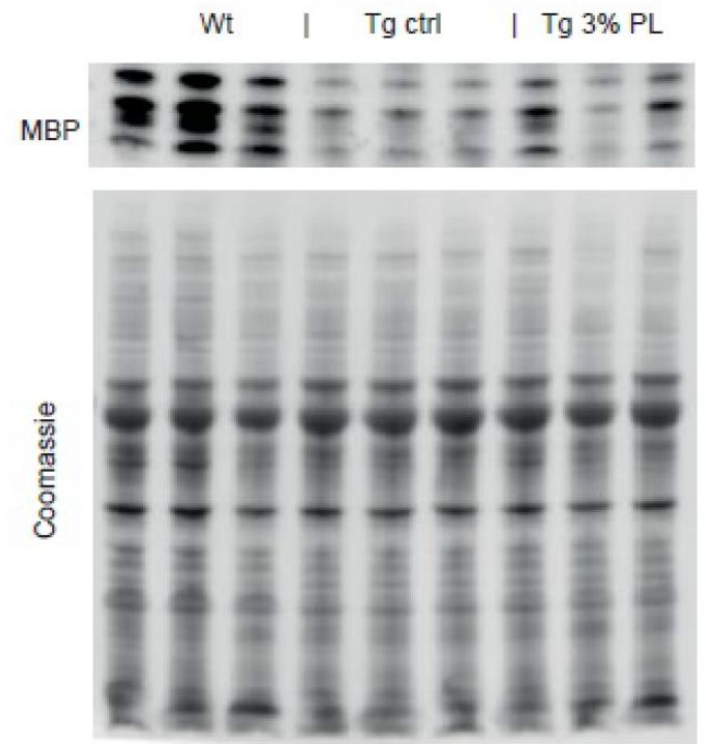

B
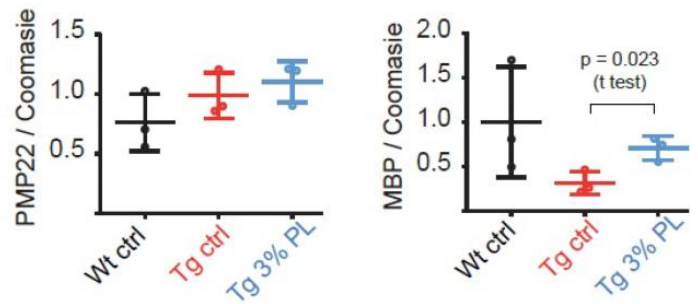

C
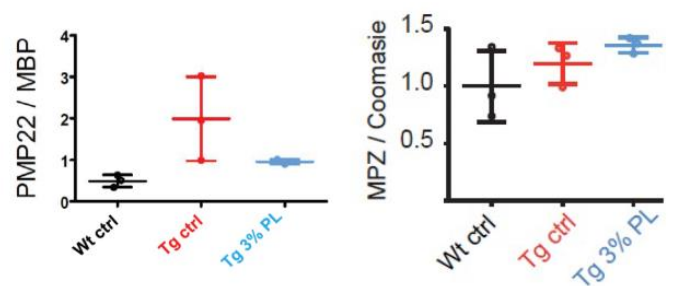

$\mathrm{E}$

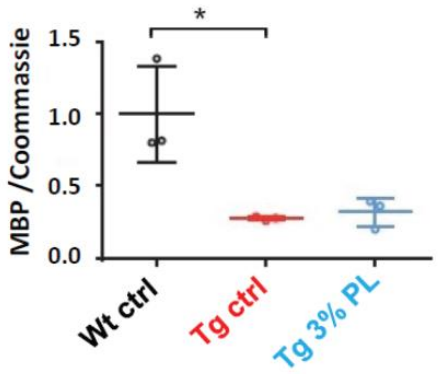

Figure 21:Dietary phospholipid couldn't rescue myelin's protein content in CMT1A rat model: (A) Western blot analysis of PMP22, MBP and MPZ in purified P112 sciatic nerve's myelin fraction isolated from wildtype control (Wt ctrl), Pmp22 tg control (Tg ctrl) and 3\% lecithin treated Pmp22 tg (Tg 3\% PL) rats. As loading control, a coomassie staining of the gel was performed (n=3 per group). Shown is the coomassie gel for the PMP22 and MBP blot. MPZ was analyzed on a second blot (coomassie gel not shown). (B) Quantification of A (first and third panel) shows that there is an increased PMP22 concentration, normalized to coomassie, in CMT1A rat myelin fraction and no reduction has been observed in 3\% lecithin (Tg 3\%PL) treated transgenic rats (left panel). On the other hand, an obvious reduction of myelin MBP, normalized to coomassie, has been observed in CMT1A (Tg ctrl) rats but a significant partial rescue, increase, in case of 3\% lecithin (Tg 3\%PL) treated transgenic rats has observed (right panel, student's T test). (C) An increased PMP22 / MBP ratio in myelin of Tg compared to Wt controls (left panel, one way ANOVA). Quantification of A (second panel) has revealed that there is no rescue of the reduced myelin MPZ concentration in CMT1A myelin fraction in 3\% lecithin treated transgenic (Tg 3\%PL) rats compared to CMT1A control rats (Tg ctrl). (D) a Western blot analysis of MBP from P112 sciatic nerve full protein preparations from Wt, Tg ctrl and Tg 3\% PL treated (P2-P112) treated rats. As loading control, a coomassie staining of the gel was performed ( $\mathrm{n}=3$ per group, left panel). (E) Quantification of D shows decreased MBP abundance in Tg compared to Wt nerves). In non-treated (Tg ctrl) versus treated (Tg 3\%PL) CMT rats, no quantitative difference of MBP abundance could be detected, when normalized to Coomassie ( $\mathrm{n}=3$ per group, One way ANOVA with Tukey's post test). 


\section{Results}

determination through phosphorylation extent evaluation has revealed that lecithin treatment couldn't rescue the downregulated PI3K/AKT activity in CMT Schwann cells at early, postnatal, stage P21 (Fig.22A). Likewise, the treatment couldn't reduce the pathologically upregulated MEK/ERK pathway in CMT Schwann cell at later, adulthood, stage P112 (Fig.22B). In line, transcriptional evaluation of major differentiation transcription factors, including early growth response 2(Egr2); also known as Krox-20, POU domain class 3 transcription factor 1 (Pou3f1); also known as Oct-6, myelin protein zero $(M p z)$, myelin basic protein $(M b p)$ has revealed that the treatment couldn't rescue their disease related significant reduction. Moreover, the treatment couldn't reduce the pathological upregulation of the dedifferentiation transcription factors as the in the case of c-Jun (Fig.22C). Interestingly, when we treated primary Schwann cells purified from CMT rats with a cell permeable PI 3-kinase (PI3K) activator, we could detect a significant increase in mRNA transcription of major lipid biosynthesis genes including Hmgcr, Fasn and Chka (Fig.22D). 


\section{Results}

A

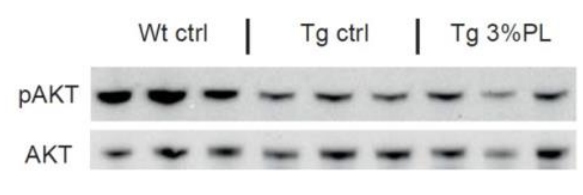

B

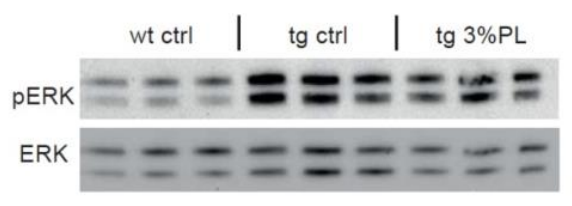

C
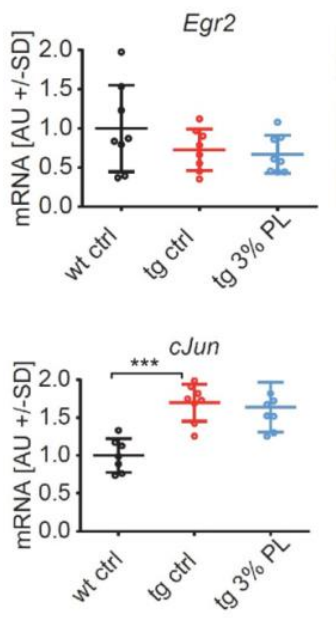

D

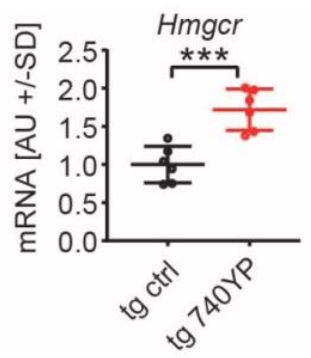

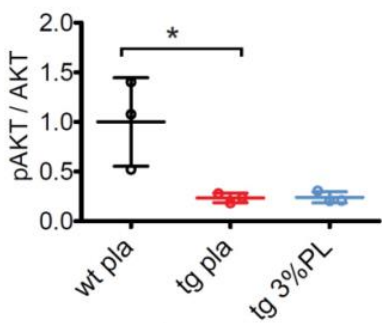
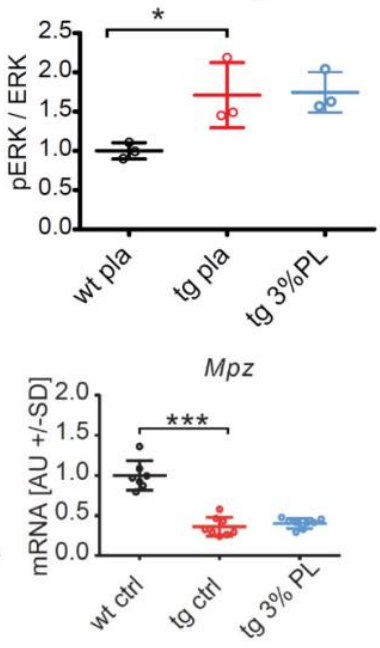

Pou3f1
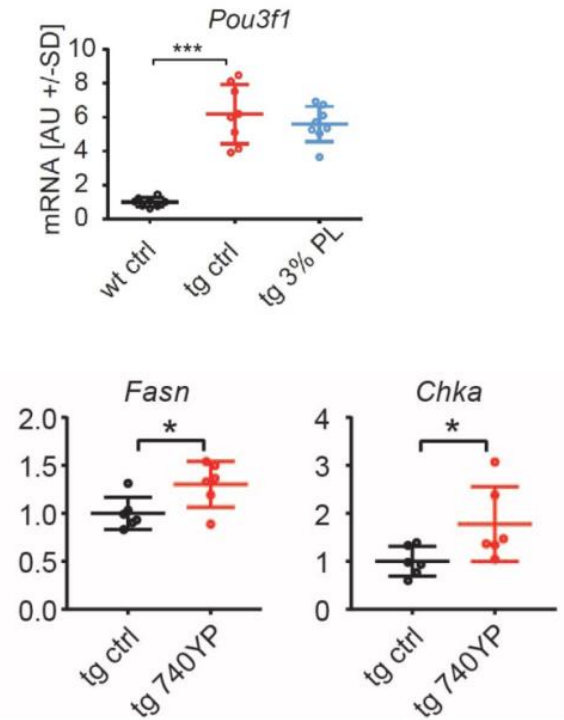

Figure 22:Dietary phospholipids supplementation couldn't rescue the perturbed CMT1A Schwann cell differentiation: (A) Western blot analysis with full nerve lysates from Wt, Tg ctrl and Tg 3\%PL (P2- P21) treated rats was performed at P21 and shows less AKT activity in Tg rats as measured by phosphorylated AKT over constitutive AKT. No alteration was revealed after PL treatment. Quantification is shown in the right panel ( $\mathrm{n}=3$ per group, one way ANOVA). (B) Western blot analyses with full sciatic nerve lysates from P112 Wt ctrl, Tg ctrl and Tg 3\%PL (P2.P112) rats shows no amelioration of the increased ERK activity in CMT rats after PL treatment, as assessed by ERK phosphorylation over constitutive ERK. Quantification is shown in the right panel ( $\mathrm{n}=3$ per group, One way ANOVA with Tukey's post test.). (C) qRT-PCR analysis with sciatic nerve mRNA extracts of P112 wildtype rats (wt), non treated CMT rats (tg ctrl) and CMT rats treated from P2-P112 with 3\% PL. No treatment effect can be detected for the differentiation markers Egr2, Pou3f1, Mpz, Mbp and the dedifferentiation marker $c J u n$ (n=8 per group, One way ANOVA with Tukey's post test.). (D) Treatment of purified primary Schwann cells from CMT rats with a specific PI3K activator (740YP) resulted in an increased mRNA expression of the lipid genes Hmgcr, Fasn and Chka, as assessed by qPCR 6h after treatment began ( $\mathrm{n}=6$ per group, student's T test). 
Discussion

\section{Discussion}




\section{Discussion}

Pmp22 duplication in the Schwann cell during postnatal developmental myelination leads to slowly progressive demyelination and axonal loss in adult peripheral nerves which are characteristics for Charcot-Marie-Tooth Disease 1A (CMT1A). Relying on human patients' samples for understating progression of CMT1A is difficult due to tissue in availability. Therefore, the availability of reliable CMT1A rodent models is advantageous. We have used two rodent models for understanding CMT1A disease progression as well as experimental therapy trials. CMT Schwann cell timeline RNA-seq analysis, during developmental myelination (E21-P18), has revealed a remarkable overexpression of Schwann cell NRG1 in CMT sciatic nerves of the rat model. Interestingly, validation of such noticed upregulation with real time PCR has revealed that it is continuously upregulated over the investigated timeline from early postnatal days until adulthood in both rat and mouse models.

The observed continuous upregulation of Schwann cell $N R G 1 \_I$ is a remarkable response to the chronic overexpression in CMT Schwann cell in particular when compared to the transient upregulation in the case of acute nerve injury ${ }^{152}$. In contrast to the beneficial impact of the transient Sc-NRGI_I upregulation on Schwann cell remyelination after acute nerve injury ${ }^{152}$, Schwann cell continuous upregulation of NRG1_I has detrimental effects on developmental myelination. We could demonstrate that through the double Sc-NRG1_I knockout and PMP22 overexpressing mice which has led to an amelioration of the characteristic CMT hypermyelination of the small caliber axons in the peripheral nerves. Indeed, this finding is clearly indicative that continuous Sc-NRGI_I upregulation is contributing, via Schwann cell NRG1_I paracrine/autocrine stimulation in addition to normal axonal NRG1_III stimulation, to the small caliber axons hypermyelination observed in CMT1A animal models ${ }^{138}$ which leads eventually to motor deficits.

In contrast to the transient upregulation of Sc-NRG1_I in wildtype, denervated, Schwann cells in response to acute nerve injury ${ }^{152}$, Sc-NRG1_I is contentiously over expressed in CMT Schwann cells which still in contact with axons. Therefore, we suggest that such continuous upregulation of Sc-NRG1_I is due to ongoing rounds of de and remyelination in adulthood as has been reported in peripheral nerves of various demyelinating neuropatheis ${ }^{65}$. In contrast to Schwann cells remyelinating mature axons with low level of NRG1 expression in case of CMT, higher 


\section{Discussion}

levels of axonal neuregulin (NRG1_III) are evident during developmental myelination. Therefore, the difference in Sc-NRGI_I expression onset and level may set the grounds for explaining the observed perturnbed Schwann cell response in case of CMT1A demyelinating neuropathy.

Another striking observation which we learned from the timeline RNA-seq analysis is that lipid biosynthesis genes are strongly downregulated. This is in line with the previously concluded persistent transcriptional downregulation of lipid biosynthesis genes in the same animal model at P7 and P63 compared to wildtype Schwann cells ${ }^{140}$. In line, we have shown a strong reduction in all major myelin lipid classes including cholesterol, phospholipids and plasmalogens. Both findings demonstrate a defective lipid biosynthesis machinery in CMT Schwann cell which may explain the delayed onset of myelination and perturbed myelin sheath ultrastructure including intermodal length, thickness and compaction. Such reduced Schwann lipid biosynthesis efficiency due to transcriptional downregulation of lipid biosynthesis genes is in agreement with the previously reported downregulation of PI3K/Akt/mTOR signaling pathway activity ${ }^{138}$ which controls lipid biosynthesis in the Schwann cell ${ }^{22,154}$. We could experimentally address such hypothetical link by using a specific activator of AKT in order to stimulate PI3K/AKT pathway in Pmp22 tg Schwann cell in vitro. Indeed, enhanced PI3K/AKT pathway activity has could improve lipid biosynthesis genes transcriptional levels. Taken together, the enumerated observations are indicating that lipid biosynthesis is a result of the PI3K/AKT pathway, major Schwann cell differentiation pathway, downregulation.

As a result, the previously described slowed and hence prolonged myelination in CMT1A ${ }^{138}$, together with ongoing de- and remyelination in adult disease stages require a continuous lipid biosynthesis by Pmp22 transgenic Schwann cells, next to physiological myelin turnover. In addition, fluorescent phospholipid molecules tracing has revealed that they are actively incorporated in to the myelin sheath in vitro as well as in vivo. Such observation has been also described in pulse chase experiments in which intraperitoneal application of phospholipid precursors could be rapidly taken up by Schwann cells and incorporated into myelin ${ }^{155}$. Taken together, these observations are indicating that the myelin sheath is highly plastic and its lipid 


\section{Discussion}

composition improvement is amenable via improving Schwann cell lipid biosynthesis and/or exogenous lipids availability.

In light of the abovementioned findings and in accordance with previous successful attempts of treating lipid biosynthesis deficiency related disorders, we hypothesized that increasing lipids availability may improve myelin sheath formation by CMT Schwann cells. To our interest, we could recapitulate the reduced myelination efficiency of CMT Schwann cell ${ }^{138}$ in vitro. In line with previous reports ${ }^{126}$, we could notice a significant reduction in the CMT Schwann cell myelination efficiency in DRG neurons-Schwann cells cocultures compared to wildtype cultures. More importantly, treatment of transgenic as well as wildtype cocultures could enhance myelination efficiently. Furthermore, translating this finding in vivo using a CMT1A rat model through feeding the animals with phospholipids, lecithin, enriched chow food has led to a remarkable improvement on the functional (muscle strength), electrophysiological (NCV and/or CMAP) and histological (number of myelinated axons) level.

Although the various lecithin treatment paradigms have alleviated CMT1A disease progression with different extents, it is not worthy that cessation of lecithin treatment after the early short term paradigm has resulted in a treatment effect loss. This can be explained by the persistent defect of Schwann cell differentiation and the reduced PI3K/AKT signaling which leads to transcriptional downregulation of lipid biosynthesis. Such assumption was evident upon evaluation of lipid biosynthesis genes transcriptional levels in CMT Schwann cells at adulthood time points. In line, comparison of the various paradigms outcomes has revealed that the long term treatment was the most efficient treatment paradigm in alleviating CMT1A disease progression which indicate the continues need for the lipid supplementation.

Importantly, commencing the treatment at later stages, as concluded from other parallel therapy trial carried out by Dipl. biol. Jan Stenzel from our group (late long term paradigm) has exerted noticeable therapeutic impact on CMT1A in the rat model. This observation is of valuable clinical relevance as it opens the possibility for translating thesis findings into clinical trials with patients affected by CMT1A disease as most of the patients seek medical help during the second decade of life ${ }^{129}$. In addition, the fact that CMT1A is a disease with a variable severity, 


\section{Discussion}

commencing the treatment at adult stages, symptomatic patients, can be adapted to the degree of severity which in turn help avoiding overtreatment and side effects in pediatric patients. In addition to the possible treatment adaptability, dietary phospholipids have been used in many clinical trials and had no substantial side effects ${ }^{156}$. Other phospholipid treatments has been associated with low cardiovascular risk, antiinflammatory effects in rheumatoid arthritis and a potential positive influence on memory and cognition in neurological disorders ${ }^{156}$.

Taken together, the outcomes of the various lecithin treatment paradigms are indicate that commencing the treatment at later stages still proved to be beneficial. It could improve electrophysiological, functional and histological aspects of the peripheral nerves of Pmp22 tg rats but to a lesser extent compared to the outcomes of the long term treatment which has been commenced at the beginning of the postnatal developmental myelination. On the other hand, the outcomes of the late long term treatment have shown that it is a bit better than the early short term treatment paradigm outcomes but again less than the early long term treatment impact.

Therefore, we concluded that the long term lecithin treatment starting at the beginning of the postnatal developmental myelination until adulthood is the most effective phospholipid supplementation paradigm in alleviating CMT1A like symptoms in the rat model.

Analysis of myelin ultrastructure has revealed that there a widening of the interperiodic distances between myelin layers in the myelin sheath of the tg animals compared to wildtype. Such interperiodic distances widening has been described in the peripheral nerve biopsies isolated from CMT1A patients as well as DRG-neuron Schwann cell cocultures ${ }^{153}$. Interestingly, lecithin treatment has resulted in restoration of normal interperiodic distances in the peripheral nerves' myelin sheath of CMT1A treated rats. Since myelin stoichiometry hasn't been affected dramatically in CMT rat's peripheral nerves, it can't explain the observed widening. On the other, the remarkable improvement in lipid classes, normalized to myelin protein content, in the lecithin treated CMT1A rats' myelin fraction can explain the normalized myelin lamellae periodicity. In line, it has been recently described that ablation of fatty acid or plasmalogen

phospholipids synthesis has led to a widened myelin periodicity ${ }^{157,158}$ which indicate that improved myelin lipid content can improve periodicity . 


\section{Discussion}

In summary, we have described a continuous upregulation of Schwann cell NRG1_I in CMT1A which we could show that it is underlying the observed hypermyelination of the small caliber axons in the peripheral nerves. In addition, we have identified a pronounced lipid biosynthesis downregulation in CMT1A Schwann cell which is consequence of the reduced $\mathrm{PI} 3 \mathrm{~K} / \mathrm{AKT} / \mathrm{mTOR}$ pathway axis activity. Dietary phospholipids supplementation in order to overcome the reduced endogenous CMT1A Schwann cell lipid biosynthesis has led to improved myelination efficiency. In turn, phospholipid treatment has improved myelin lipid composition, ultrastructure and number of myelinated axons per peripheral nerve which indeed had improved motor function. In summary, the improved myelin biosynthesis and the CMT1A clinical phenotype amelioration in the CMT1A rats show that dietary lipid supplementation may constitute a potential translatable therapeutic approach for CMT1A disease. 
Bibliography

\section{Bibliography}


1. Bullock, Theodore Holmes and GAH. Structure and Function in the Nervous System of Invertebrates. San Francisco and London; 1965. doi:10.1002/iroh.19660510312.

2. Arendt D, Denes AS, Jékely G, Tessmar-Raible K. The evolution of nervous system centralization. Anim Evol Genomes, Foss Trees. 2009;(January):1523-1528. doi:10.1093/acprof:oso/9780199549429.003.0007.

3. Zalc B, Goujet D, Colman D. The origin of the myelination program in vertebrates. Curr Biol. 2008;18(2005):511-512. doi:10.1016/j.cub.2008.04.010.

4. Hartline DK, Colman DR. Rapid Conduction and the Evolution of Giant Axons and Myelinated Fibers. Curr Biol. 2007;17. doi:10.1016/j.cub.2006.11.042.

5. Hartline DK. What is myelin? Neuron Glia Biol. 2008;4:153-163. doi:10.1017/S1740925X09990263.

6. Harrison RG. Neuroblast versus sheath cell in the development of peripheral nerves. $J$ Comp Neurol. 1924;37:123-205. doi:10.1002/cne.900370107.

7. Le Douarin NM, Dupin E. Cell lineage analysis in neural crest ontogeny. J Neurobiol. 1993;24:146-161. doi:10.1002/neu.480240203.

8. Adameyko I, Lallemend F, Aquino JB, et al. Schwann Cell Precursors from Nerve Innervation Are a Cellular Origin of Melanocytes in Skin. Cell. 2009;139:366-379. doi:10.1016/j.cell.2009.07.049.

9. Jessen KR, Mirsky R. The origin and development of glial cells in peripheral nerves. Nat Rev Neurosci. 2005;6:671-682. doi:nrn1746 [pii] \n10.1038/nrn1746.

10. Fraher JP, O’Leary D, Moran MA, Cole M, King RHM, Thomas PK. Relative growth and maturation of axon size and myelin thickness in the tibial nerve of the rat -1 . Normal animals. Acta Neuropathol. 1990;79:364-374. doi:10.1007/BF00308712.

11. Friede RL, Bischhausen R. How are sheath dimensions affected by axon caliber and internode length? Brain Res. 1982;235:335-350. doi:10.1016/0006-8993(82)91012-5.

12. Pannese E, Rigamonti L, Procacci P, Ledda M, Arcidiacono G, Frattola D. An electron microscope study of quantitative relationships between axon and Schwann cell sheath in myelinated fibres of peripheral nerves. Anat Embryol (Berl). 1987;175:423-430. doi:10.1007/BF00309678.

13. Williams PL, Wendell-Smith CP. Some additional parametric variations between peripheral nerve fibre populations. J Anat. 1971;109:505-526.

http://www.pubmedcentral.nih.gov/articlerender.fcgi?artid=1270992\&tool=pmcentrez\&re ndertype $=$ abstract. 


\section{Bibliography}

14. Berti C, Bartesaghi L, Ghidinelli M, et al. Non-redundant function of dystroglycan and 1 integrins in radial sorting of axons. Development. 2011;138:4025-4037.

doi:10.1242/dev.065490.

15. Birchmeier C, Nave KA. Neuregulin-1, a key axonal signal that drives schwann cell growth and differentiation. Glia. 2008;56:1491-1497. doi:10.1002/glia.20753.

16. Webster H. 1993. Development of peripheral nerve fi bers. In: In: Dyck PJ, Thomas PK, Griffin JW, Low PA PJ, ed. Peripheral Neuropathy. Philadelphia; 1993:243-266.

17. Scherer SS. The biology and pathology of Schwann cells. Curr Opin Neurol. 1997;10:386-397.

18. Webster H, Palkovits CG, Stoner GL, Favilla JT, Frail DE, Braun PE. Myelin-Associated Glycoprotein : Electron Microscopic Immunocytochemical Localization in Compact Developing and Adult Central Nervous System Myelin. 1983;0.

19. Mirsky R, Jessen KR. Schwann cell development, differentiation and myelination. Curr Opin Neurobiol. 1996;6:89-96. doi:10.1016/S0959-4388(96)80013-4.

20. Taveggia C, Zanazzi G, Petrylak A, et al. Neuregulin-1 type III determines the ensheathment fate of axons. Neuron. 2005;47:681-694. doi:10.1016/j.neuron.2005.08.017.

21. Cotter L, Ozçelik M, Jacob C, et al. Dlg1-PTEN Interaction Regulates Myelin Thickness to Prevent Damaging Peripheral Nerve Overmyelination. Science (80- ). 2010;328(May):1415-1418. doi:10.1126/science.1187735.

22. Pertusa M, Morenilla-Palao C, Carteron C, Viana F, Cabedo H. Transcriptional control of cholesterol biosynthesis in schwann cells by axonal neuregulin 1. J Biol Chem. 2007;282:28768-28778. doi:10.1074/jbc.M701878200.

23. Quintes S, Goebbels S, Saher G, Schwab MH, Nave KA. Neuron-glia signaling and the protection of axon function by Schwann cells. J Peripher Nerv Syst. 2010;15:10-16. doi:10.1111/j.1529-8027.2010.00247.x.

24. He Y, Kim JY, Dupree J, et al. Yy1 as a molecular link between neuregulin and transcriptional modulation of peripheral myelination. Nat Neurosci. 2010;13:1472-1482. doi:10.1038/nn.2686.

25. Newbern JM, Li X, Shoemaker SE, et al. Specific Functions for ERK/MAPK Signaling during PNS Development. Neuron. 2011;69(1):91-105. doi:10.1016/j.neuron.2010.12.003.

26. Ishii N, Harada N, Joseph EW, et al. Enhanced inhibition of ERK signaling by a novel allosteric MEK inhibitor, CH5126766, that suppresses feedback reactivation of raf activity. Cancer Res. 2013;73:4050-4060. doi:10.1158/0008-5472.CAN-12-3937. 
27. Grossmann KS, Wende H, Paul FE, et al. The tyrosine phosphatase Shp2 (PTPN11) directs Neuregulin-1/ErbB signaling throughout Schwann cell development. Proc Natl Acad Sci. 2009;106:16704-16709. doi:10.1073/pnas.0904336106.

28. Smith LG, Apostolakos P, Galatis B, et al. Calcineurin / NFAT Signaling Is. Science. 2009;6(January):651-654. doi:10.1126/science.1166562.

29. Garratt AN, Britsch S, Birchmeier C. Neuregulin, a factor with many functions in the life of a Schwann cell. BioEssays. 2000;22:987-996. doi:10.1002/15211878(200011)22:11<987::AID-BIES5>3.0.CO;2-5.

30. Nave KA, Salzer JL. Axonal regulation of myelination by neuregulin 1. Curr Opin Neurobiol. 2006;16:492-500. doi:10.1016/j.conb.2006.08.008.

31. Garratt AN, Voiculescu O, Topilko P, Charnay P, Birchmeier C. A dual role of erbB2 in myelination and in expansion of the Schwann cell precursor pool. J Cell Biol. 2000;148:1035-1046. doi:10.1083/jcb.148.5.1035.

32. Woldeyesus MT, Britsch S, Riethmacher D, et al. Peripheral nervous system defects in erbB2 mutants following genetic rescue of heart development. Genes Dev. 1999;13:25382548. doi:10.1101/gad.13.19.2538.

33. Leimeroth R, Lobsiger C, Lüssi A, Taylor V, Suter U, Sommer L. Membrane-bound neuregulin1 type III actively promotes Schwann cell differentiation of multipotent progenitor cells. Dev Biol. 2002;246:245-258. doi:10.1006/dbio.2002.0670.

34. Adlkofer K, Lai C. Role of neuregulins in glial cell development. Glia. 2000;29:104-111. doi:10.1002/(SICI)1098-1136(20000115)29:2<104::AID-GLIA2>3.0.CO;2-2.

35. Nave K-A, Schwab MH. Glial cells under remote control. Nat Neurosci. 2005;8:14201422. doi:10.1038/nn1105-1420.

36. Perlin JR, Lush ME, Stephens WZ, Piotrowski T, Talbot WS. Neuronal Neuregulin 1 type III directs Schwann cell migration. Development. 2011;138:4639-4648. doi:10.1242/dev.068072.

37. Svaren J, Meijer D. The molecular machinery of myelin gene transcription in schwann cells. Glia. 2008;56:1541-1551. doi:10.1002/glia.20767.

38. Jessen KR, Mirsky R. Negative regulation of myelination: Relevance for development, injury, and demyelinating disease. Glia. 2008;56(September):1552-1565. doi:10.1002/glia.20761.

39. Jagalur NB, Ghazvini M, Mandemakers W, et al. Functional Dissection of the Oct6 Schwann Cell Enhancer Reveals an Essential Role for Dimeric Sox 10 Binding. $J$ Neurosci. 2011;31:8585-8594. doi:10.1523/JNEUROSCI.0659-11.2011. 
40. Chen Y, Wang H, Yoon SO, et al. HDAC-mediated deacetylation of NF- $\mathrm{KB}$ is critical for Schwann cell myelination. Nat Neurosci. 2011;14:437-441. doi:10.1038/nn.2780.

41. Jacob C, Christen CN, Pereira JA, et al. HDAC1 and HDAC2 control the transcriptional program of myelination and the survival of Schwann cells. Nat Neurosci. 2011;14:429436. doi:10.1038/nn.2762.

42. Le N, Nagarajan R, Wang JYT, et al. Nab proteins are essential for peripheral nervous system myelination. Nat Neurosci. 2005;8:932-940. doi:10.1038/nn1490.

43. Mager GM, Ward RM, Srinivasan R, Jang SW, Wrabetz L, Svaren J. Active gene repression by the Egr2 $\cdot \mathrm{NAB}$ complex during peripheral nerve myelination. J Biol Chem. 2008;283:18187-18197. doi:10.1074/jbc.M803330200.

44. Mirsky R, Woodhoo A, Parkinson DB, Arthur-Farraj P, Bhaskaran A, Jessen KR. Novel signals controlling embryonic Schwann cell development, myelination and dedifferentiation. In: Journal of the Peripheral Nervous System. Vol 13. ; 2008:122-135. doi:10.1111/j.1529-8027.2008.00168.x.

45. Parkinson DB, Bhaskaran A, Arthur-Farraj P, et al. c-Jun is a negative regulator of myelination. J Cell Biol. 2008;181:625-637. doi:10.1083/jcb.200803013.

46. Woodhoo A, Alonso MBD, Droggiti A, et al. Notch controls embryonic Schwann cell differentiation, postnatal myelination and adult plasticity. Nat Neurosci. 2009;12:839-847. doi:10.1038/nn.2323.

47. Pereira JA, Baumann R, Norrmen C, et al. Dicer in Schwann Cells Is Required for Myelination and Axonal Integrity. J Neurosci. 2010;30:6763-6775. doi:10.1523/JNEUROSCI.0801-10.2010.

48. Bremer J, O’Connor T, Tiberi C, Rehrauer H, Weis J, Aguzzi A. Ablation of dicer from murine Schwann cells increases their proliferation while blocking myelination. PLoS One. 2010;5. doi:10.1371/journal.pone.0012450.

49. Yun B, Anderegg A, Menichella D, Wrabetz L, Feltri ML, Awatramani R. MicroRNADeficient Schwann Cells Display Congenital Hypomyelination. J Neurosci. 2010;30:7722-7728. doi:10.1523/JNEUROSCI.0876-10.2010.

50. Verheijen MHG, Camargo N, Verdier V, et al. SCAP is required for timely and proper myelin membrane synthesis. Proc Natl Acad Sci U S A. 2009;106:21383-21388. doi:10.1073/pnas.0905633106.

51. Saher G, Quintes S, Mobius W, et al. Cholesterol Regulates the Endoplasmic Reticulum Exit of the Major Membrane Protein P0 Required for Peripheral Myelin Compaction. $J$ Neurosci. 2009;29:6094-6104. doi:10.1523/JNEUROSCI.0686-09.2009. 
52. Giambonini-Brugnoli G, Buchstaller J, Sommer L, Suter U, Mantei N. Distinct disease mechanisms in peripheral neuropathies due to altered peripheral myelin protein 22 gene dosage or a Pmp22 point mutation. Neurobiol Dis. 2005; 18:656-668.

doi:10.1016/j.nbd.2004.10.023.

53. Nadra K, Charles ASDP, Médard JJ, et al. Phosphatidic acid mediates demyelination in Lpin1 mutant mice. Genes Dev. 2008;22:1647-1661. doi:10.1101/gad.1638008.

54. Saher G, Brügger B, Lappe-Siefke C, et al. High cholesterol level is essential for myelin membrane growth. Nat Neurosci. 2005;8:468-475. doi:10.1038/nn1426.

55. Saher G, Quintes S, Mobius W, et al. Cholesterol Regulates the Endoplasmic Reticulum Exit of the Major Membrane Protein P0 Required for Peripheral Myelin Compaction. $J$ Neurosci. 2009;29(19):6094-6104. doi:10.1523/JNEUROSCI.0686-09.2009.

56. Zhao S, Hu X, Park J, et al. Selective expression of LDLR and VLDLR in myelinating oligodendrocytes. Dev Dyn. 2007;236:2708-2712. doi:10.1002/dvdy.21283.

57. Verheijen MH, Chrast R, Burrola P, Lemke G. Local regulation of fat metabolism in peripheral nerves. Genes Dev. 2003;17:2450-2464. doi:10.1101/gad.1116203 $\backslash \mathrm{r} 17 / 19 / 2450$ [pii].

58. Goodrum JF, Fowler KA, Hostettler JD, Toews AD. Peripheral nerve regeneration and cholesterol reutilization are normal in the low-density lipoprotein receptor knockout mouse. J Neurosci Res. 2000;59:581-586. http://www.ncbi.nlm.nih.gov/pubmed/10679798.

59. Quarles RH. Myelin-associated glycoprotein (MAG): Past, present and beyond. J Neurochem. 2007;100:1431-1448. doi:10.1111/j.1471-4159.2006.04319.x.

60. Kirschner, D. A. and Blaurock AE. Organization, phylogenetic variations and dynamic transitions of myelin. In: Martenson RE, ed. Myelin: Biology and Chemistry. CRC Press; 1992:3-78.

61. Waxman SG, Bangalore L. Electrophysiologic Consequences of Myelination. In: Myelin Biology and Disorders. Vol 1. ; 2003:117-141. doi:10.1016/B978-012439510-7/50058-9.

62. Vabnick L, Shrager P. Ion channel redistribution and function during development of the myelinated axon. J Neurobiol. 1998;37:80-96. doi:10.1002/(SICI)10974695(199810)37:1<80::AID-NEU7>3.0.CO;2-4.

63. Nave KA. Myelination and support of axonal integrity by glia. Nature. 2010;468:244-252. doi:10.1038/nature09614.

64. Norton WT, Poduslo SE. MYELINATION IN RAT BRAIN: METHOD OF MYELIN ISOLATION. J Neurochem. 1973;21:749-757. doi:10.1111/j.1471-4159.1973.tb07519.x. 
65. Garbay B, Heape AM, Sargueil F, Cassagne C. Myelin synthesis in the peripheral nervous system. Prog Neurobiol. 2000;61:267-304. doi:10.1016/S0301-0082(99)00049-0.

66. Balakrishnan S, Goodwin H, Cumings JN. THE DISTRIBUTION OF PHOSPHORUS-CONTAINING LIPID COMPOUNDS IN THE HUMAN BRAIN. $J$ Neurochem. 1961;8:276-284. doi:10.1111/j.1471-4159.1961.tb13553.x.

67. Quarles RH, Macklin WB, Morell P. Myelin Formation, Sturcture, and Biochemistry. Basic Neurochem 6th Ed Mol Cell Med Asp. 2006:51-71.

68. Chrast R, Saher G, Nave K-A, Verheijen MHG. Lipid metabolism in myelinating glial cells: lessons from human inherited disorders and mouse models. J Lipid Res. 2011;52:419-434. doi:10.1194/jlr.R009761.

69. Saher G, Simons M. Cholesterol and myelin biogenesis. Subcell Biochem. 2010;51:489508. doi:10.1007/978-90-481-8622-8_18.

70. Simons K, Vaz WLC. Model systems, lipid rafts, and cell membranes. Annu Rev Biophys Biomol Struct. 2004;33:269-295. doi:10.1146/annurev.biophys.32.110601.141803.

71. Sankaram MB, Thompson TE. Modulation of phospholipid acyl chain order by cholesterol. A solid- state $2 \mathrm{H}$ nuclear magnetic resonance study. Biochemistry. 1990;29:10676-10684.

72. Huang J, Feigenson GW. A microscopic interaction model of maximum solubility of cholesterol in lipid bilayers. Biophys J. 1999;76:2142-2157. doi:10.1016/S00063495(99)77369-8.

73. Kakorin S, Brinkmann U, Neumann E. Cholesterol reduces membrane electroporation and electric deformation of small bilayer vesicles. Biophys Chem. 2005;117:155-171. doi:10.1016/j.bpc.2005.05.001.

74. Pan J, Tristram-Nagle S, Nagle JF. Effect of cholesterol on structural and mechanical properties of membranes depends on lipid chain saturation. Phys Rev E - Stat Nonlinear, Soft Matter Phys. 2009;80. doi:10.1103/PhysRevE.80.021931.

75. Hofsäß C, Lindahl E, Edholm O. Molecular Dynamics Simulations of Phospholipid Bilayers with Cholesterol. Biophys J. 2003;84:2192-2206. doi:10.1016/S00063495(03)75025-5.

76. Chrast R, Saher G, Nave K-A, Verheijen MHG. Lipid metabolism in myelinating glial cells: lessons from human inherited disorders and mouse models. J Lipid Res. 2011;52:419-434. doi:10.1194/jlr.R009761. 
77. Lee A. Lipid-protein interactions in biological membranes: a structural perspective. Biochim Biophys Acta - Biomembr. 2003;1612:1-40. doi:10.1016/S0005-2736(03)000567.

78. Simons M, Krämer EM, Thiele C, Stoffel W, Trotter J. Assembly of myelin by association of proteolipid protein with cholesterol- and galactosylceramide-rich membrane domains. $J$ Cell Biol. 2000;151:143-153. doi:10.1083/jcb.151.1.143.

79. Kramer-Albers E-M, Gehrig-Burger K, Thiele C, Trotter J, Nave K -a. Perturbed Interactions of Mutant Proteolipid Protein/DM20 with Cholesterol and Lipid Rafts in Oligodendroglia: Implications for Dysmyelination in Spastic Paraplegia. J Neurosci. 2006;26(45):11743-11752. doi:10.1523/JNEUROSCI.3581-06.2006.

80. Hirahara Y, Bansal R, Honke K, Ikenaka K, Wada Y. Sulfatide Is a Negative Regulator of Oligodendrocyte Differentiation: Development in Sulfatide-Null Mice. Glia. 2004;45:269277. doi:10.1002/glia.10327.

81. Patzig J, Jahn O, Tenzer S, et al. Quantitative and Integrative Proteome Analysis of Peripheral Nerve Myelin Identifies Novel Myelin Proteins and Candidate Neuropathy Loci. J Neurosci. 2011;31:16369-16386. doi:10.1523/JNEUROSCI.4016-11.2011.

82. Quarles RH. Myelin sheaths: Glycoproteins involved in their formation, maintenance and degeneration. Cell Mol Life Sci. 2002;59:1851-1871. doi:10.1007/PL00012510.

83. Kirschner, D. A., Wrabetz, L. and Feltri ML. The P0 gene. In: Myelin Biology and Disorders. Lazzarini. San Diego, CA: Elsevier Academic Press; 2004:523-545.

84. Giese KP, Martini R, Lemke G, Soriano P, Schachner M. Mouse P0gene disruption leads to hypomyelination, abnormal expression of recognition molecules, and degeneration of myelin and axons. Cell. 1992;71:565-576. doi:10.1016/0092-8674(92)90591-Y.

85. Yin X, Kidd GJ, Wrabetz L, Feltri ML, Messing A, Trapp BD. Schwann cell myelination requires timely and precise targeting of P0 protein. J Cell Biol. 2000;148:1009-1020. doi:10.1083/jcb.148.5.1009.

86. Shy ME. Charcot-Marie-Tooth disease: an update. Curr Opin Neurol. 2004;17:579-585. doi:00019052-200410000-00008 [pii].

87. Previtali SC, Quattrini A, Fasolini M, et al. Epitope-tagged P0 glycoprotein causes charcot-marie-tooth-like neuropathy in transgenic mice. J Cell Biol. 2000;151:1035-1045. doi:10.1083/jcb.151.5.1035.

88. Stromnes IM, Goverman JM. Active induction of experimental allergic encephalomyelitis. Nat Protoc. 2006;1:1810-1819. doi:10.1038/nprot.2006.285.

89. Pierre Morell. Myelin. New York; London: Plenum Press; 1984. 
90. Campagnoni a T, Skoff RP. The pathobiology of myelin mutants reveal novel biological functions of the MBP and PLP genes. Brain Pathol. 2001;11:74-91. doi:10.1111/j.17503639.2001.tb00383.x.

91. Campagnoni, A. T. and Campagnoni CW. Myelin basic protein gene. In: Myelin Biology and Disorders. R. A. Lazz. San Diego, CA: Elsevier Academic Press; 2004:387-400.

92. Aruga J, Okano H, Mikoshiba K. Identification of the New Isoforms of Mouse Myelin Basic Protein: The Existence of Exon 5a. J Neurochem. 1991;56:1222-1226. doi:10.1111/j.1471-4159.1991.tb11414.x.

93. Trapp BD, Kidd GJ, Pfeiffer SE, Anitei M. Cell Biology of Myelin Assembly. In: Myelin Biology and Disorders. Vol 1. ; 2003:29-55. doi:10.1016/B978-012439510-7/50055-3.

94. Kirschner DA, Ganser AL. Compact myelin exists in the absence of basic protein in the shiverer mutant mouse [20]. Nature. 1980;283:207-210. doi:10.1038/283207a0.

95. Taylor V, Zgraggen C, Naef R, Suter U. Membrane topology of peripheral myelin protein 22. J Neurosci Res. 2000;62:15-27. doi:10.1002/1097-4547(20001001)62:1<15::AIDJNR3>3.0.CO;2-F.

96. Tobler a R, Notterpek L, Naef R, Taylor V, Suter U, Shooter EM. Transport of Trembler-J mutant peripheral myelin protein 22 is blocked in the intermediate compartment and affects the transport of the wild-type protein by direct interaction. $J$ Neurosci. 1999;19:2027-2036. http://www.ncbi.nlm.nih.gov/pubmed/10066256.

97. Liu N, Yamauchi J, Shooter EM. Recessive, but not dominant, mutations in peripheral myelin protein 22 gene show unique patterns of aggregation and intracellular trafficking. Neurobiol Dis. 2004;17:300-309. doi:10.1016/j.nbd.2004.07.010.

98. Fabbretti E. gas3/PMP22: 1995;22:1846-1856.

99. Brancolini C, Marzinotto S, Edomi P, et al. Rho-dependent regulation of cell spreading by the tetraspan membrane protein Gas3/PMP22. Mol Biol Cell. 1999;10(July):2441-2459. doi:10.1091/mbc.10.7.2441.

100. Roux KJ, Amici SA, Notterpek L. The temporospatial expression of peripheral myelin protein 22 at the developing blood-nerve and blood-brain barriers. J Comp Neurol. 2004;474:578-588. doi:10.1002/cne.20154.

101. Carenini S, Neuberg D, Schachner M, Suter U, Martini R. Localization and functional roles of PMP22 in peripheral nerves of P0-deficient mice. Glia. 1999;28:256-264. doi:10.1002/(SICI)1098-1136(199912)28:3<256::AID-GLIA9>3.0.CO;2-O.

102. Neuberg DHH, Sancho S, Suter U. Altered molecular architecture of peripheral nerves in mice lacking the peripheral myelin protein 22 or connexin32. J Neurosci Res. 
1999;58:612-623. doi:10.1002/(SICI)1097-4547(19991201)58:5<612::AID-

JNR2>3.0.CO;2-X.

103. Adlkofer K, Naef R, Suter U. Analysis of compound heterozygous mice reveals that the Trembler mutation can behave as a gain-of-function allele. J Neurosci Res. 1997;49:671680. doi:10.1002/(SICI)1097-4547(19970915)49:6<671::AID-JNR2>3.0.CO;2-4.

104. Lupski JR, Chance PF. Hereditary Motor and Sensory Neuropathies Involving Altered Dosage or Mutation of PMP22: The CMT1A Duplication and HNPP Deletion. In: Peripheral Neuropathy. Vol 2. ; 2005:1659-1680. doi:10.1016/B978-0-7216-94917.50073-9.

105. Saifi GM, Szigeti K, Snipes JG, Garcia CA, Lupski JR. Molecular Mechanisms, Diagnosis, and Rational Approaches to Management of and Therapy for Charcot-MarieTooth Disease and Related Peripheral Neuropathies. J Investig Med. 2003;51:261-283. doi:10.1136/jim-51-05-14.

106. Huxley C, Passage E, Manson A, et al. Construction of a mouse model of Charcot-MarieTooth disease type 1A by pronuclear injection of human YAC DNA. Hum Mol Genet. 1996;5:563-569. doi:10.1093/hmg/5.5.563.

107. Magyar JP, Martini R, Ruelicke T, et al. Impaired differentiation of Schwann cells in transgenic mice with increased PMP22 gene dosage. J Neurosci. 1996;16:5351-5360.

108. Sereda M, Griffiths I, Pühlhofer a, et al. A transgenic rat model of Charcot-Marie-Tooth disease. Neuron. 1996;16(5):1049-1060.

109. Pareek S, Notterpek L, Snipes GJ, et al. Neurons promote the translocation of peripheral myelin protein 22 into myelin. J Neurosci. 1997;17:7754-7762.

110. Notterpek L, Ryan MC, Tobler AR, Shooter EM. PMP22 accumulation in aggresomes: Implications for CMT1A pathology. Neurobiol Dis. 1999;6:450-460. doi:10.1006/nbdi.1999.0274.

111. Ryan MC, Shooter EM, Notterpek L. Aggresome formation in neuropathy models based on peripheral myelin protein 22 mutations. Neurobiol Dis. 2002;10:109-118.

doi:10.1006/nbdi.2002.0500.

112. Niemann S, Sereda MW, Suter U, Griffiths IR, Nave K a. Uncoupling of myelin assembly and schwann cell differentiation by transgenic overexpression of peripheral myelin protein 22. J Neurosci. 2000;20:4120-4128. doi:20/11/4120 [pii].

113. Chies R. Alterations in the Arf6-regulated plasma membrane endosomal recycling pathway in cells overexpressing the tetraspan protein Gas3/PMP22. J Cell Sci. 2003;116:987-999. doi:10.1242/jcs.00326. 
114. Naef R, Adlkofer K, Lescher B, Suter U. Aberrant protein trafficking in Trembler suggests a disease mechanism for hereditary human peripheral neuropathies. Mol Cell Neurosci. 1997;9:13-25. doi:10.1006/mcne.1997.0604.

115. D’Urso D, Prior R, Greiner-Petter R, Gabreëls-Festen a a, Müller HW. Overloaded endoplasmic reticulum-Golgi compartments, a possible pathomechanism of peripheral neuropathies caused by mutations of the peripheral myelin protein PMP22. J Neurosci. 1998;18:731-740.

116. Tobler AR, Ning Liu, Mueller L, Shooter EM. Differential aggregation of the Trembler and Trembler J mutants of peripheral myelin protein 22. Proc Natl Acad Sci U S A. 2001;99:483-488. doi:10.1073/pnas.012593399.

117. Shames I, Fraser A, Colby J, Orfali W, Snipes GJ. Phenotypic differences between peripheral myelin protein-22 (PMP22) and myelin protein zero (P0) mutations associated with Charcot-Marie-Tooth-related diseases. J Neuropathol Exp Neurol. 2003;62:751-764. doi:10.1093/jnen/62.7.751.

118. Dickson KM, Bergeron JJM, Shames I, et al. Association of calnexin with mutant peripheral myelin protein-22 ex vivo: A basis for "gain-of-function" ER diseases. Proc Natl Acad Sci. 2002;99:9852-9857. doi:10.1073/pnas.152621799.

119. Southwood CM, Garbern J, Jiang W, Gow A. The unfolded protein response modulates disease severity in pelizaeus-merzbacher disease. Neuron. 2002;36:585-596. doi:10.1016/S0896-6273(02)01045-0.

120. Suter U, Moskow JJ, Welcher AA, et al. A leucine-to-proline mutation in the putative first transmembrane domain of the 22-kDa peripheral myelin protein in the trembler-J mouse. Proc Natl Acad Sci U S A. 1992;89:4382-4386. doi:10.1073/pnas.89.10.4382.

121. Isaacs AM, Jeans A, Oliver PL, et al. Identification of a new Pmp22 mouse mutant and trafficking analysis of a Pmp22 allelic series suggesting that protein aggregates may be protective in Pmp22-associated peripheral neuropathy. Mol Cell Neurosci. 2002;21:114125. doi:10.1006/mcne.2002.1158.

122. Dunn WA. Studies on the mechanisms of autophagy: Maturation of the autophagic vacuole. J Cell Biol. 1990;110:1935-1945. doi:10.1083/jcb.110.6.1935.

123. Skre H. Genetic and clinical aspects of Charcot-Marie-Tooth's disease. Clin Genet. 1974;6:98-118. doi:10.1111/j.1399-0004.1974.tb00638.x.

124. Emery AEH. Population frequencies of inherited neuromuscular diseases-A world survey. Neuromuscul Disord. 1991;1:19-29. doi:10.1016/0960-8966(91)90039-U.

125. Reilly MM, Murphy SM, Laura M. Charcot-Marie-Tooth disease. J Peripher Nerv Syst. 2011;16:1-14. doi:10.1111/j.1529-8027.2011.00324.x. 
126. Schenone A, Nobbio L, Bragadin MM, Ursino G, Grandis M. Inherited neuropathies. Curr Treat Options Neurol. 2011;13:160-179. doi:10.1007/s11940-011-0115-z.

127. Siskind CE, Shy ME. Genetics of neuropathies. Semin Neurol. 2011;31:494-505. doi:10.1055/s-0031-1299788.

128. Pareyson D, Marchesi C. Diagnosis, natural history, and management of Charcot-MarieTooth disease. Lancet Neurol. 2009;8:654-667. doi:10.1016/S1474-4422(09)70110-3.

129. Harding a E, Thomas PK. The clinical features of hereditary motor and sensory neuropathy types I and II. Brain. 1980;103:259-280. doi:10.1136/jmg.17.5.329.

130. Aguayo A, Perkins S, Bray G DI. Transplantation of nerves from patients with CharcotMarie-Tooth (CMT) disease into immune-suppressed mice. J Neuropathol Exp Neurol. 1978;37:582.

131. Lupski JR, de Oca-Luna RM, Slaugenhaupt S, et al. DNA duplication associated with Charcot-Marie-Tooth disease type 1A. Cell. 1991;66:219-232. doi:10.1016/00928674(91)90613-4.

132. Raeymaekers P, Timmerman V, Nelis E, et al. Duplication in chromosome 17p11.2 in Charcot-Marie-Tooth neuropathy type 1a (CMT 1a). Neuromuscul Disord. 1991;1:93-97. doi:10.1016/0960-8966(91)90055-W.

133. Hayasaka K, Himoro M, Sawaishi Y, et al. De novo mutation of the myelin P0 gene in Dejerine-Sottas disease (hereditary motor and sensory neuropathy type III). Nat Genet. 1993;5:266-268. doi:10.1038/ng1193-266.

134. Bergoffen J, Scherer SS, Wang S, et al. Connexin mutations in X-linked Charcot-MarieTooth disease. Science (80- ). 1993;262(5142):2039 LP - 2042. http://science.sciencemag.org/content/262/5142/2039.abstract.

135. Warner LE, Mancias P, Butler IJ, et al. Mutations in the early growth response 2 (EGR2) gene are associated with hereditary myelinopathies. Nat Genet. 1998;18:382-384. doi:10.1038/ng0498-382 [doi].

136. Fledrich R, Stassart RM, Sereda MW. Murine therapeutic models for Charcot-MarieTooth (CMT) disease. Br Med Bull. 2012;102:89-113. doi:10.1093/bmb/lds010.

137. Huxley C, Passage E, Robertson AM, et al. Correlation between varying levels of PMP22 expression and the degree of demyelination and reduction in nerve conduction velocity in transgenic mice. Hum Mol Genet. 1998;7:449-458. doi:10.1093/hmg/7.3.449.

138. Fledrich R, Stassart RM, Klink A, et al. Soluble neuregulin-1 modulates disease pathogenesis in rodent models of Charcot-Marie-Tooth disease 1A. Nat Med. 2014;20(9):1055-1061. doi:10.1038/nm.3664. 
139. Meyer zu Horste G, Prukop T, Liebetanz D, Mobius W, Nave K-A, Sereda MW. Antiprogesterone therapy uncouples axonal loss from demyelination in a transgenic rat model of CMT1A neuropathy. Ann Neurol. 2007;61(1):61-72. doi:10.1002/ana.21026.

140. Fledrich R, Schlotter-Weigel B, Schnizer TJ, et al. A rat model of Charcot-Marie-Tooth disease 1A recapitulates disease variability and supplies biomarkers of axonal loss in patients. Brain. 2012;135:72-87. doi:10.1093/brain/awr322.

141. Huxley C, Passage E, Manson a, et al. Construction of a mouse model of Charcot-MarieTooth disease type 1A by pronuclear injection of human YAC DNA. Hum Mol Genet. 1996;5(5):563-569.

142. Kleitman N, Wood P, Bunge R. Tissue culture methods for the study of myelination. In: G B, K G, eds. Cultering Nerve Cells. Cambridge: MIT; 1998:545-594.

143. Larocca JN, Norton WT. Isolation of Myelin. 2006:1-19.

144. Patzig J, Kusch K, Fledrich R, et al. Proteolipid protein modulates preservation of peripheral axons and premature death when myelin protein zero is lacking. Glia. 2016;64(1):155-174. doi:10.1002/glia.22922.

145. Sørensen BK, Højrup P, Østergård E, et al. Silver staining of proteins on electroblotting membranes and intensification of silver staining of proteins separated by polyacrylamide gel electrophoresis. Anal Biochem. 2002;304(1):33-41. doi:10.1006/abio.2001.5604.

146. Gerl MJ, Bittl V, Kirchner S, et al. Sphingosine-1-phosphate lyase deficient cells as a tool to study protein lipid interactions. PLoS One. 2016;11(4):1-25.

doi:10.1371/journal.pone.0153009.

147. Özbalci C, Sachsenheimer T, Brügger B. Quantitative Analysis of Cellular Lipids by NonElectrospry Ionization Mass Spectrometry. In: Rapaport D, Herrmann JM, eds. Membrane Biogenesis: Methods and Protocols, Methods in Molecular Biology. Vol 1033. Springer Science+Business Media; 2013. doi:10.1007/978-1-62703-487-6_1.

148. Paltauf F, Hermetter A. Strategies for the synthesis of Glycerophospholipids. Prog Lipid Res. 1994;33(3):239-328.

149. Özbalci, C., Sachsenheimer, T. \& Brügger B. Membrane Biogenesis: Methods and Protocols,. In: Methods in Molecular Biology. Rapaport, . Rapaport, D. \& Herrmann, J. M; 2013:1033.

150. Ejsing CS, Sampaio JL, Surendranath V, et al. Global analysis of the yeast lipidome by quantitative shotgun mass spectrometry. Proc Natl Acad Sci \{USA\}. 2009;106(7):21362141. doi:10.1073/pnas.0811700106. 


\section{Bibliography}

151. Smyth GK. Limma: linear models for microarray data. 2005;(2005):397-420. doi:10.1007/0-387-29362-0_23.

152. Stassart RM, Fledrich R, Velanac V, et al. A role for Schwann cell-derived neuregulin-1 in remyelination. Nat Neurosci. 2013;16(1):48-54. doi:10.1038/nn.3281.

153. Nobbio L, Mancardi G, Grandis M, et al. PMP22 transgenic dorsal root ganglia cultures show myelin abnormalities similar to those of human CMT1A. Ann Neurol. 2001;50:4755. doi:10.1002/ana.1034.

154. Norrmén C, Figlia G, Lebrun-Julien F, et al. mTORC1 controls PNS myelination along the mTORC1-RXR $\gamma$-SREBP-lipid biosynthesis axis in Schwann cells. Cell Rep. 2014;9(OCTOBER 2014):646-660. doi:10.1016/j.celrep.2014.09.001.

155. Gould RM, Dawson RMC. Incorporation of newly formed lecithin into peripheral nerve myelin. J Cell Biol. 1976;68:480-496. doi:10.1083/jcb.68.3.480.

156. Küllenberg de Gaudry D, Taylor L a, Schneider M, Massing U. Health effects of dietary phospholipids. Lipids Health Dis. 2012;11:3. doi:10.1186/1476-511X-11-3.

157. Cermenati G, Audano M, Giatti S, et al. Lack of sterol regulatory element binding factor1c imposes glial fatty acid utilization leading to peripheral neuropathy. Cell Metab. 2015;21:571-583. doi:10.1016/j.cmet.2015.02.016.

158. Da Silva TF, Eira J, Lopes AT, et al. Peripheral nervous system plasmalogens regulate Schwann cell differentiation and myelination. J Clin Invest. 2014;124(6). doi:10.1172/JCI72063.

159. Norton WT. The myelin sheath. In: Scientific Approaches to Clinical Neurology. E. S. Gold. Philadelphia: Lea \& Febiger; 1977:259-298. 
Appendices

\section{Appendices}




\section{Appendix A: Abbreviation list:}

\begin{tabular}{|c|c|}
\hline Abb. & Meaning \\
\hline AKT & Protein Kinase B \\
\hline AP1 & Activator protein 1 \\
\hline Arf6 & ADP ribosylation factor- 6 \\
\hline CHKA & choline kinase alpha \\
\hline CHPT1 & choline phosphotransferase 1 \\
\hline CMAP & Compound muscle action potential \\
\hline CMT & Charcot-Marie-Tooth \\
\hline CMTA1 & Charcot-Marie-Tooth A1 \\
\hline CNS & Central nervous system \\
\hline СурА) & cyclophilin A \\
\hline DLg1 & Discs large homolog 1 \\
\hline DRG & dorsal root ganglions \\
\hline EAE & experimental autoimmune encephalomyelitis \\
\hline Egr2 & Early growth response protein 2 \\
\hline ER & Endoplasmic Reticulum \\
\hline ErbB2/ErbB3 & Erythroblastic leukemia viral oncogene homolog $2 / 3$ \\
\hline Erk1/2 & extracellular signal-regulated kinases \\
\hline GPC-PDE (GPCPDI) & glycerophosphocholine phosphodiesterase 1 \\
\hline HDAC1 & Histone deacetylase 1 \\
\hline HDAC2 & Histone deacetylase 2 \\
\hline HNPP & hereditary neuropathy with liability to pressure palsies \\
\hline $\mathrm{Id} 2$ & inhibitor of DNA binding-2 \\
\hline $\mathrm{Id} 4$ & inhibitor of DNA binding-4 \\
\hline Krox 20 & ERG2 gene encoding Early growth response protein 2 \\
\hline LDLR & low density lipoprotein receptor \\
\hline Lpin 1 & phosphatidate phosphatase gene \\
\hline MAG & myelin-associated glycoprotein \\
\hline MBP & myelin basic protein \\
\hline MEK & Mitogen activated kinase \\
\hline MPZ & Myelin Protein Zero \\
\hline$m T O R$ & mammalina Target of Rapamycin \\
\hline NAB & NGFI-A/Egr-binding \\
\hline $\mathrm{NCV}$ & nerve conduction velocity \\
\hline NFATc4 & calcineurin-dependent-4 \\
\hline NFATc4 & Nuclear Factor Of Activated T Cells 4 \\
\hline NF-kB & nuclear factor 'kappa-light-chain-enhancer' of activated B-cells \\
\hline NGF & Neuronal growth factor \\
\hline NICD & Notch intracellular domain \\
\hline
\end{tabular}


NRG 1_I

NRG 1_III

Oct 6.

OL

PA

PCYT1a/b

PFA

PI3K

PIP2

PIP3

PLA2(PLA2G4A

PLC

PLP

PMP22

PNS

Ppia

PTEN

QPCR

$\mathrm{SC}$

SCAP

SCP

SHP2

SLIs

Sox 10

SREBPs

Yy1
Neuregulin 1 type I

Neuregulin 1 type III

octamer-binding transcription factor-6

oligodendrocyte

phosphatidic acid

phosphate cytidylyltransferase 1 choline, alpha and beta

Paraformaldehyde

phosphatidylinositol 3-kinase

Phosphatidylinositol 4,5-bisphosphate

Phosphatidylinositol $(3,4,5)$-triphosphate

phospholipase A2 group IVA

Phosopholipase C

proteolipid protein

Peripheral Myelin Protein 22

Peripheral nervous system

Peptidylprolyl isomerase A

Phosphatase and Tensin homolog

Quantitative real-time polymerase chain reaction

Schwann cells

SREBP cleavage-activating protein

Schwann cell precursors

Src homology region 2-containing protein tyrosine phosphatase 2

Schmidt Lantermann incisures

SRY-related HMGbox- 10

sterol regulatory element-binding proteins

YY1 transcription factor 


\section{Appendix B: Publications}

- Fledrich R*, Abdelaal T*, Rasch L, Stenzel J, Prukop T, Stassart RM, Nave KA, Sereda MW: Targeting lipid metabolism as an effective therapeutic strategy in a rodent model of CMT1A neuropathy. Nature communication (under revision, passed the first round of revision). (* shared first authorship).

- Fledrich R., Akkermann D., Abdelaal T., Schütza V., Unternbarnscheid T., Soto-Bernardini C., Kusch K., Mott A., Maack C., Möbius W., Schwab M., Sereda M.W., Brück W., Nave K.-A., Stassart R.M. A. Neuregulin-1 type I signaling axis mediates Schwann cell interactions upstream of disease hallmarks in the most common inherited neuropathy. Nature Neuroscience (under revision, passed the first round of revision).

- Fledrich R, Abdelaal T, Rasch L, Prukop T, Stassart RM, Nave KA, Sereda MW: Lecithin therapy improves disease progression in a rat model of Charcot Marie Tooth disease 1A. Journal of the peripheral nervous system 2016; 21(3); 255-256.

- Ammar NM, El-Hawary SS, El-Anssary AA, El-Desoky AH, Abdelaal TA: Phytochemical study of the bioactive fractions of Chrysanthemum fructescens $L$. cultivated in Egypt. International Journal of Pharmacognosy and Phytochemical Research 2016; 8(8); 1314-1321.

- Fledrich R, Stassart RM, Klink A, Rasch LM, Prukop T, Haag L, Czesnik D, Kungl T, Abdelaal

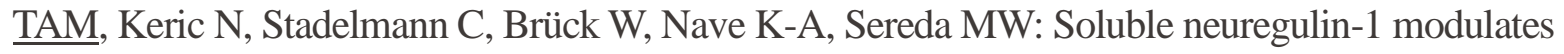
disease pathogenesis in rodent models of Charcot-Marie-Tooth disease 1A. Nature Medicine 2014, 20:1055-1061.

- Abdelaal TAM, Abdelwahed NAM, Awad G, El Diwany : Improvement of anisomycin production through mutation and medium optimization for Streptomyces griseolus. Australian Journal of Basic and Applied Sciences. 2011; 5 (12); 2637-2648. 


\section{Appendix C: Curriculum Vitae}

\section{Tamer Abdelaal}

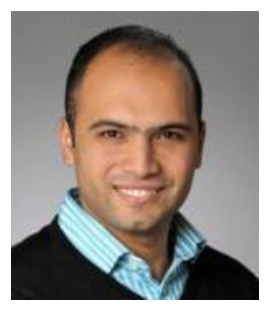

Narzissenweg Str., 24, 37081 Göttingen (Germany)

0049(0)17642004232 U⿴囗十 0049(0)5513899773

Abdelaal@em.mpg.de

http://www.gpneuro.uni-goettingen.de/content/profile/index.php?ID=2054

(0 https://www.gpneuro.uni-goettingen.de/students/stud2012/stud_01.php

\section{WORK EXPERIENCE}

\section{1/10/2014-Present Research Assistant}

Neurogenetics Department, Max Planck Institute of Experimental Medicine, Göttingen (Germany).

\section{0/12/2009-Present Assistant Researcher}

Chemistry of Natural and Microbial Products Department, Pharmaceutical and Drug Industries Division, National Research Center, Cairo (Egypt).

\section{1/10/2011-04/01/2012 Internship}

Laboratoire Universitaire de Biodiversité et d'Ecologie Microbienne, Université de Bretagne Occidentale (UBO), Quimper, Brittany (France).

\section{5/10/2010-14/04/2011 Internship}

Redox Biology Center, Structural Biology Lab, Cellular and Molecular Interaction Department, VIB institute, Vrije Universiteit Brussel, Brussels (Belgium).

- The main goal of this internship was to learn biochemical techniques dealing with Structural Biology.

- During the internship time, I was involved in two projects:

a) Chaperone tuned cell free expression system for the production of disulfide rich cancer related proteins.

b) Nanobody aided crystallization of human protein disulfide isomerase (PDI). 


\section{4/10/2005-07/12/2009 Microbiologist}

Chemistry of Natural and Microbial Products Department, Pharmaceutical and Drug Industries Division, National Research Center, Cairo (Egypt).

EDUCATION AND TRAINING

01/10/2014-Present

20/08/2012-30/08/2014

European Master Degree in Neurophysiology (Grade:B)

Neurasmus (a European Master in Neuroscience):

- In First year:

I have completed an intensive curriculum in Neurophysiology (including ( $3 \times 2$ months each) lab rotations during my first year in different Neurosciences research disciplines including Electrophysiology, Neuroimmunology and Neurogenetics) (90 ECTS in one year) at International Max Planck Research School (IMPRS) for Neurosciences, Faculty of Biology and Physiology, Georg-August-Universität, Göttingen, Germany.

- In second year:

Pursued an external semester entitled " Advanced course in Neurosciences and Neuropharmacology " at Faculty of Biology, Bordeaux University, France.

Master thesis at the Neurogenetics Department, Max Planck Institute for Experimental Medicine entitled with "The impact of Pmp22 over-expression on peripheral nervous system (PNS) myelination in vitro".

\section{1/10/2005-18/04/2009 Master Degree in Microbiology}

Microbiology \& Botany Department, Faculty of Science, Al-Azhar University, Cairo (Egypt).

\section{0/09/2001-30/05/2005 Bachelor's Degree in Science in Microbiology/Chemistry (Excellent with honour)}

Microbiology \& Botany Department, Faculty of Science, Al Azhar University, Cairo (Egypt). 


\section{Appendices}

\section{Job-related skills $\quad$ Mastered experimental techniques:}

Protein biochemistry: Cloning and recombinant proteins expression, purification, crystallization trials setup.

Primary cultures: Schwann cell monocultures, mouse and rat DRG-Schwann cells cocultures establishment and using it as an in vitro model for CMT1A to test treatment approaches.

Experimental therapy trial design and execution: Study plan preparation, motor phenotyping tests, surgery to collect different nervous system tissues for further analysis including transcription analysis (qRt-PCR), myelin fraction preparation from peripheral nerve, protein quantification: western blot (quantitative and qualitative WB \& phospho-WB) and silver gel. Histology: Light and electron microscopy, Immunocytochemistry and Immunohistochemistry,Fluorescence imaging, Images analysis using ImageJ.

Electrophysiology: Two-electrode voltage clamp and Electroneurography (of Sciatic nerve and tail nerve): Nerve conduction velocity and compound muscle action potential.

\section{ADDITIONAL INFORMATION}

\section{Honours and awards}

- Göttingen Graduate School for Neurosciences and Molecular Biosciences (GGNB) Travel Grant for attending the 2017 PNS Annual Meeting, Sitges-Barcelona, Spain (8th-12th July, 2017).

- Registration fees waiver for junior presenting author to participate in the 2017 PNS Annual Meeting- Sitges-Barcelona, Spain (8th-12th July, 2017).

- Poster Prize at "8th Westerberg Herbsttagung, September 2016" which is a scientific meeting organized on the Science Campus of the University of Osnabrück together with the Study Group "Molecular Neurobiology" of the GBM (Gesellschaft für Biochemie und Molekularbiologie).

- Registration fee wavier, for outstanding applicant, by the organizing committee for attending the Göttingen SPIRIT Summer School (Multimodal molecular imaging: from high resolution in vitro towards in vivo imaging), Max Planck Institute for Experimental Medicine, Göttingen (4th -7th April, 2016).

- Doctoral grant from Max Planck Society (January 2015-Februray 2015).

- Göttingen Graduate School for Neurosciences and Molecular Biosciences (GGNB) Bridging Fund to start PhD Studies at International Max Planck Research School For Neurosciences (October2014 - December 2014).

- Erasmus Mundus master Scholarship via Neurasmus Program (August2012 - August 2014).

- Internship at LUBEM institute, Quimper, France funded by Scientific Sector, French Centre for Culture and Cooperation (CFCC), Embassy of France in Egypt (September 2011 - January 2012).

- Internship at VIB Department of Molecular and Cellular Interactions, Brussel, Belgium, funded by Ministry of Higher Education in Egypt (October 2010 - April 2011).

Conferences, Scientific meetings and $\mathrm{PhD}$ retreats
- Oral poster presentation at the 2017 PNS Annual Meeting- Sitges-Barcelona (Spain) entitled with (Lecithin therapy ameliorates disease progression in a rat model of Charcot Marie Tooth Disease 1A(CMT1A) (8th-12th July, 2017).

- Oral presentation at the Myelin Meeting in Kassel (Theme: Current Topics in Myelin Research) entitled with (Lecithin therapy improves disease progression in a rat model of Charcot Marie Tooth Disease 1A(CMT1A) (2nd-4th March, 2017). 


\section{Appendices}

- Poster presentation at "8th Westerberg Herbsttagung" which is a scientific meeting organized on the Science Campus of the University of Osnabrück together with the Study Group "Molecular Neurobiology" of the GBM (Gesellschaft für Biochemie und Molekularbiologie) (22nd-24th September, 2016).

- Oral presentation at the International Max Planck Research School for Neurosciences, Göttingen $\mathrm{PhD}$ retreat, Spiekeroog (4th -7th April, 2016). The oral presentation was entitled "Glial cell differentiation in CMT1A".

- Participation in the Göttingen SPIRIT Summer School (Multimodal molecular imaging: from high resolution in vitro towards in vivo imaging), Max Planck Institute for Experimental Medicine, Göttingen (4th -7th April, 2016).

- Poster presentation at the Max Planck Institute for Experimental Medicine $\mathrm{PhD}$ retreat. The poster was entitled with (Impact of Pmp22 overexpression on peripheral nervous system myelination in vitro ) Berlin (4th - 7th, April, 2015).

- Oral presentation of master thesis work outcomes at the 3rd Neurasmus Annual Meeting at Charité - Universitätsmedizin Berlin and participated in a workshop entitled "Transnational Research" (10th - 15th July, 2014).

- Participation in the 2nd Neurasmus annual meeting which was held at the Center For Neuroscience and Cell Biology in Coimbra, Portugal (1st-5th July,2013).

- Participation in the 3rd international Brussels' Center for Redox Biology (BCRB) fall symposium at Vrije Universiteit Brussel, Belgium (3rd of December, 2010). 